Merci d'utiliser le titre suivant lorsque vous citez ce document :

Engman, M. (2007-07-04), « L'extension des chaines d'approvisionnement internationales : Le rôle des économies émergentes dans la fourniture de services informatiques et de services aux entreprises », Éditions OCDE, Paris.

http://dx.doi.org/10.1787/147137243556

\title{
L'extension des chaines d'approvisionnement internationales
}

\section{LE RÔLE DES ÉCONOMIES ÉMERGENTES DANS LA FOURNITURE DE SERVICES INFORMATIQUES ET DE SERVICES AUX ENTREPRISES}

\section{Michael Engman}

La version originale de ce document a été publiée comme suit :

Engman, M. (2007-05-25), "Expanding International Supply Chains: The Role of Emerging Economies in Providing it and Business Process Services", OECD Trade Policy Papers, No. 52, OECD Publishing, Paris. http://dx.doi.org/10.1787/147465274176 
Organisation de Coopération et de Développement Economiques

DIRECTION DES ECHANGES

Français - Or. Anglais

COMITE DES ECHANGES

Annule \& remplace le même document du 04 juillet 2007

Groupe de travail du Comité des échanges

L'EXTENSION DES CHAINES D'APPROVISIONNEMENT INTERNATIONALES : LE ROLE DES ECONOMIES EMERGENTES DANS LA FOURNITURE DE SERVICES INFORMATIQUES ET DE SERVICES AUX ENTREPRISES

Etudes de cas sur la Chine, la République tchèque, l'Inde et les Philippines

Document de travail de l'OCDE sur la politique commerciale No. 52

par Michael Engman 


\begin{abstract}
AVANT-PROPOS
La délocalisation des services de soutien aux entreprises et des services des technologies de l'information (STI) - qu'il s'agisse d'approvisionnement interne ou d'approvisionnement externe à l'étranger - révolutionne les pratiques des entreprises. Le présent document traite de l'expansion des chaînes d'approvisionnement internationales et de la montée de la Chine, de la République tchèque, de l'Inde et des Philippines en tant qu'exportateurs de services de soutien aux entreprises et de STI. Il présente aussi une analyse de la nature et des facteurs de ces échanges et expose les défis économiques et commerciaux qu'entraînent ces mutations. Dans ce contexte sont présentées certaines des conséquences, pour le marché du travail, du développement des échanges entre les pays de l'OCDE et les pays tiers.
\end{abstract}

L'analyse révèle que, dans les quatre économies émergentes susmentionnées, les secteurs des services de soutien aux entreprises et des STI sont structurés de façons très différentes : les entreprises chinoises et tchèques approvisionnent essentiellement leurs marchés intérieurs tandis que les entreprises indiennes et philippines fournissent principalement les marchés étrangers. Du point de vue des exportations, elles approvisionnent aussi des zones géographiques différentes: la Chine exporte principalement vers le Japon, la République tchèque vers l'Union européenne, les Philippines vers les Etats-Unis et l'Inde vers les Etats-Unis et le Royaume-Uni. Plusieurs des grandes entreprises nationales des quatre pays sont en train d'établir une présence importante sur des marchés étrangers, en particulier dans d'autres pays émergents, afin de développer leurs capacités et d'exploiter l'avantage comparatif local. Cela fait bien ressortir le fait que les pays ont des atouts divers selon leur situation géographique et que l'IDE lié aux services de soutien aux entreprises et aux STI entre économies émergentes se développera sans doute rapidement dans l'avenir.

Les quatre pays sont confrontés à des contraintes du côté de l'offre. La pénurie de personnel chevronné dans ce secteur en Chine, en République tchèque et aux Philippines freine la croissance. De nombreuses entreprises ont du mal à faire face à des taux élevés de rotation du personnel et d'inflation salariale. Les restrictions réglementaires sont relativement peu nombreuses mais n'en affectent pas moins certaines entreprises. Dans le secteur des STI, les mouvements temporaires de personnel peuvent poser de graves difficultés aux exportateurs nationaux. Le problème est particulièrement aigu dans le secteur indien des STI, qui est tributaire de l'envoi de professionnels pour des visites de plus longue durée dans les locaux des clients. La lenteur et l'imprévisibilité des procédures de délivrance de visas d'affaires et de permis de travail, ainsi que les limitations imposées par les systèmes de quotas au nombre de permis de travail accordés, posent des problèmes opérationnels. Dans le secteur des services de soutien aux entreprises et, dans une moindre mesure, dans le secteur des STI, la législation relative à la confidentialité et la sécurité des données peut avoir un effet négatif sur la délocalisation vers l'étranger. Cependant, les nouvelles réglementations ont également créé des débouchés commerciaux entièrement nouveaux, notamment dans le domaine des transcriptions médicales. 


\section{REMERCIEMENTS}

Cette étude a été rédigée par Michael Engmann, de la Direction des échanges et de l'agriculture de l'OCDE, sous la supervision d'Anthony Kleitz.

L'auteur souhaite remercier toutes les personnes avec lesquelles il s'est entretenu et dont les noms sont indiqués à l'Appendice B. Il tient aussi à remercier tout particulièrement Rupa Chanda, Michael Chen, John Chiang, Harry Fozzard, Mitch Locsin, Damian Domingo Mapa, Jan Rancak, Fermin Taruc, Michal Zalesak et Max von Zetdwitz, qui lui ont communiqué de précieuses informations et l'ont aidé à contacter les parties intéressées dans les secteurs des services de soutien aux entreprises et des STI.

Le document a été examiné par le Groupe de travail du Comité des échanges, qui a décidé d'en diffuser plus largement les conclusions en le déclassifiant sous sa responsabilité.

L'étude est disponible en anglais et en français sur le site web de l'OCDE :

http://www.oecd.org/tad 


\section{TABLE OF CONTENTS}

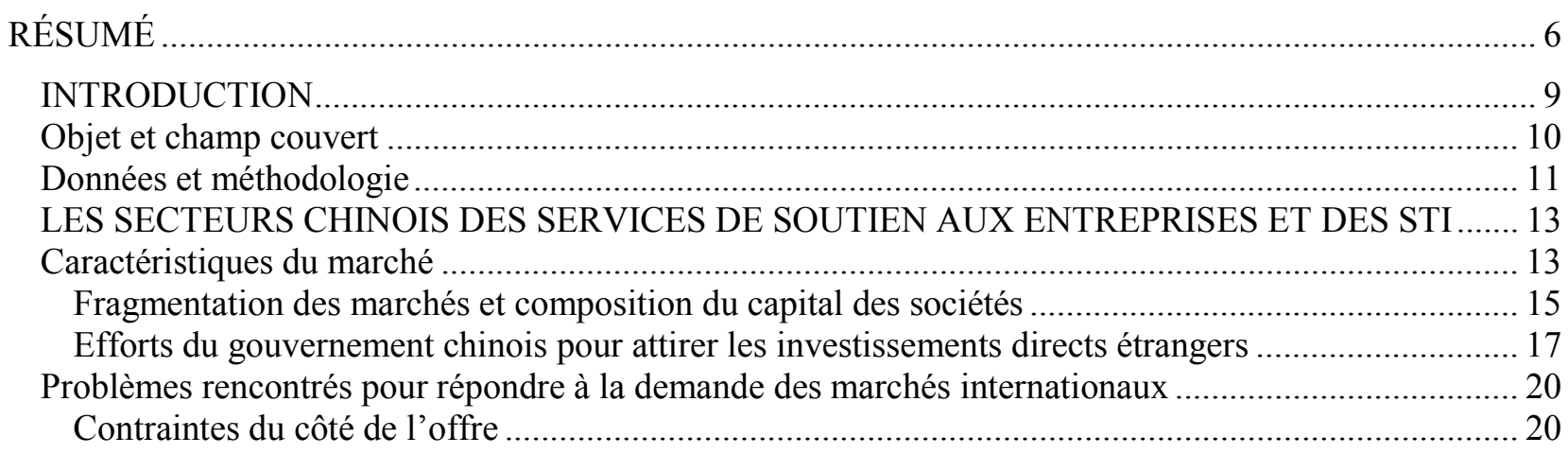

LES SECTEURS TCHÈQUES DES SERVICES DE SOUTIEN AUX ENTREPRISES ET DES STI...... 26

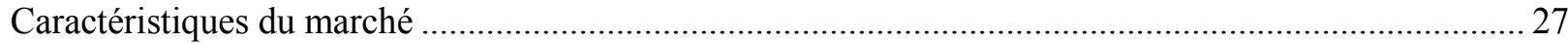

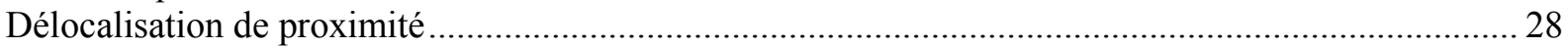

Efforts du gouvernement tchèque pour attirer les investissements directs étrangers ............................ 30

Problèmes rencontrés pour répondre à la demande des marchés internationaux ....................................... 32

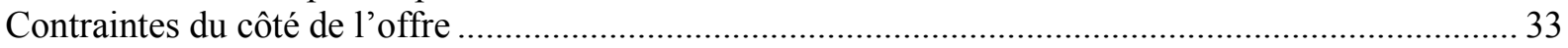

LES SECTEURS INDIENS DES SERVICES DE SOUTIEN AUX ENTREPRISES ET DES STI........... 35

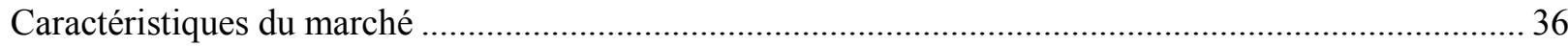

Problèmes rencontrés pour répondre à la demande des marchés internationaux .................................... 39

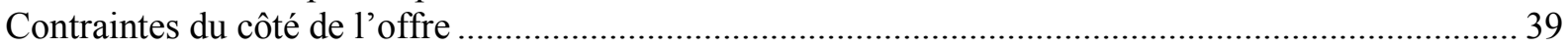

LES SECTEURS PHILIPPINS DES SERVICES DE SOUTIEN AUX ENTREPRISES ET DES STI...... 46

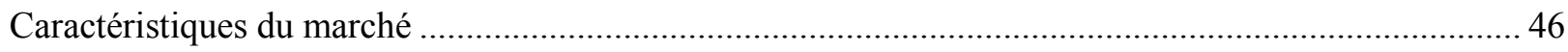

Efforts du gouvernement philippin pour attirer les investissements directs étrangers ........................... 48

Problèmes rencontrés pour répondre à la demande des marchés internationaux .................................... 51

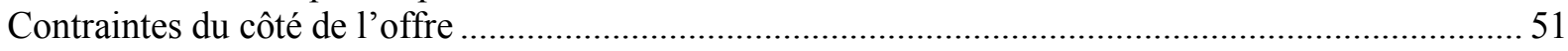

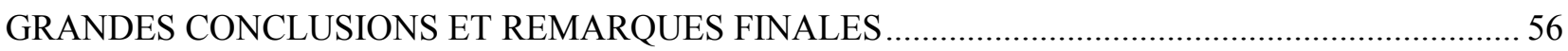

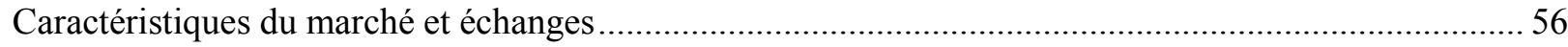

Problèmes relatifs aux échanges et à l'activité économique ….............................................................. 58

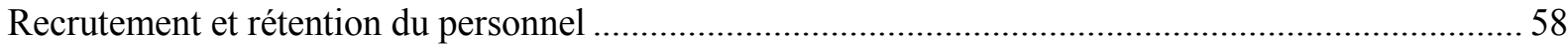

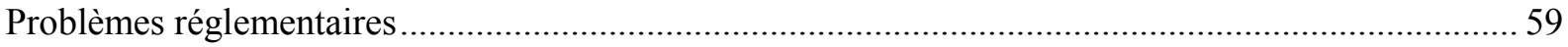

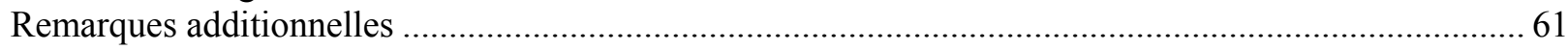


Délocalisation internationale des STI et conséquences potentielles pour les marchés du travail Possibilités d'ajustement du marché du travail dans le secteur des STI................................................ 63 61

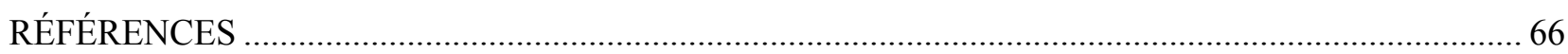

ANNEXE A : LISTE INDICATIVE DES SERVICES DÉLOCALISÉS À L'ÉTRANGER ...................... 72

ANNEXE B : LISTE DES PERSONNES INTERVIEWÉES :................................................................... 73

ANNEXE C. EFFICIENCE RÉGLEMENTAIRE ET INSTITUTIONNELLE: CONDUITE DES

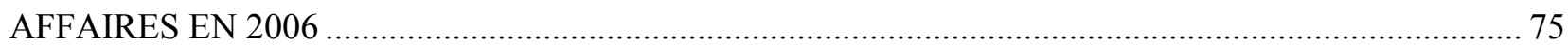

ANNEXE D. INDICATEURS DES SALAIRES DES TRAVAILLEURS DU SAVOIR, 2005................ 76

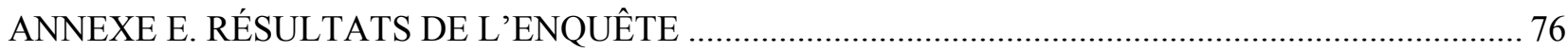

ANNEXE F. INDICE D'ATTRACTIVITÉ DE NEOIT POUR LA DÉLOCALISATION DES STI* ........ 77 ANNEXE G. INDICE D'ATTRACTIVITÉ DE NEOIT POUR LA DÉLOCALISATION DES SERVICES

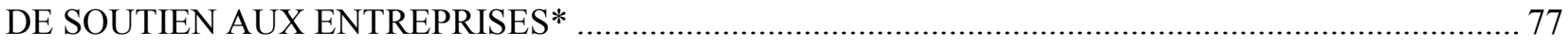

ANNEXE H. INDICE POUR LA LOCALISATION MONDIALE DES SERVICES ÉTABLI PAR A.T.

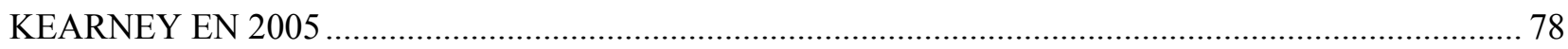

ANNEXE I. INDICATEURS COMPARATIFS ÉCONOMIQUES ET COMMERCIAUX, 2005 ............. 79

ANNEXE J. QUELQUES INDICATEURS DE L'OFFRE DE TRAVAIL ............................................ 80

ANNEXE K. PRINCIPAUX PRESTATAIRES DE SERVICES DE SOUTIEN AUX ENTREPRISES ET

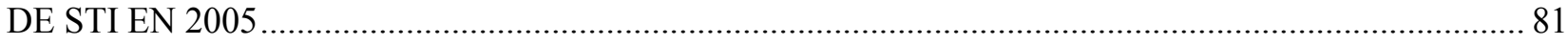

ANNEXE L. EFFECTIFS DE QUELQUES GRANDS PRESTATAIRES DE STI................................... 82 


\section{RÉSUMÉ}

Les services de soutien aux entreprises et les services des technologies de l'information (STI) font l'objet d'échanges croissants entre les économies émergentes et les pays de l'OCDE. Les échanges de ces deux types de services ont certes enregistré une notable expansion ces derniers temps, mais ce n'est que par rapport à des niveaux de départ relativement modestes en volume absolu. Parmi les économies émergentes, la Chine, l'Inde, les Philippines et la République tchèque sont des exportatrices importantes de ces services. Leurs recettes d'exportation ont atteint en 2005 un volume global estimé à 8.7 milliards de dollars pour les services de soutien aux entreprises et à 14.5 milliards de dollars pour les STI. Elles représentaient de 2 à $3 \%$ environ des dépenses mondiales dans le domaine des services de soutien aux entreprises et des STI, dont la plus grande partie a été importée par les pays de l'OCDE.

Rédigé dans le cadre des travaux sur la mondialisation et l'ajustement structurel actuellement menés par l'OCDE, le présent document analyse l'expansion des chaînes internationales d'approvisionnement et la montée en puissance de la Chine, de l'Inde, des Philippines et de la République tchèque en tant qu'exportateurs de services de soutien aux entreprises et de STI. Il vise à donner une image plus précise de la nature des nouvelles chaînes internationales d'approvisionnement au sein de ces secteurs, tout comme des facteurs qui en déterminent l'apparition, ainsi qu'à identifier les principaux problèmes relatifs à l'activité économique et aux échanges qui se profilent à l'horizon. Dans ce contexte, il décrit certaines des conséquences que ces échanges croissants entre les pays de l'OCDE et les économies non membres ont sur le marché du travail.

Les secteurs des services de soutien aux entreprises et des STI ont dans les quatre pays bénéficient d'un accès à des infrastructures stables dans le domaine des TIC ainsi qu'à une main-d'œuvre possédant un niveau d'instruction élevé et une bonne maîtrise des langues, ce qui leur permet de répondre à la demande des marchés extérieurs. Ils bénéficient par ailleurs d'une série d'autres facteurs favorables qui facilitent leur activité. Premièrement, ces pays ont en règle générale créée des zones dotées d'infrastructures spécialisées ainsi que d'une administration rationalisée afin de remédier aux faiblesses locales dont souffre l'environnement des entreprises. Ils ont ainsi pu lever la plupart des contraintes réglementaires excessives qui entravent le développement des entreprises et assurer l'accès aux services intermédiaires nécessaires. Toutefois, une libéralisation plus large des services de support et une réglementation plus efficace des activités des entreprises pourraient rendre ces zones superflues et générer des bénéfices pour l'ensemble de l'économie.

En plus, ces pays ont instauré des réglementations libérales en matière d'investissements directs étrangers (IDE), ce qui a permis aux multinationales étrangères d'établir des unités captives ou des centres de services communs en vue de fournir des prestations aux marchés extérieurs. Cela a donné lieu avec le temps à d'importants transferts de technologies mais aussi de pratiques de gestion. Enfin, l'ouverture des marchés à la fourniture de services à travers les frontières et les restrictions réglementaires relativement peu nombreuses imposées dans les pays clients ont permis aux sociétés des économies émergentes de fournir aussi bien des services de soutien aux entreprises que des STI aux marchés internationaux.

Les études par pays montrent que la structure des secteurs des services de soutien aux entreprises et des STI est très différente dans les quatre pays : seuls 10 à $15 \%$ des services de soutien aux entreprises et des STI de la Chine et de la République tchèque sont exportés, alors que près de $80 \%$ de ceux de l'Inde et des Philippines sont destinés aux marchés extérieurs. Ils fournissent également des zones géographiques 
différentes : la Chine exporte principalement vers le Japon et la région de l'Asie de l'Est, la République tchèque vers les pays de l'UE, les Philippines vers les États-Unis, et l'Inde vers les États-Unis, le Royaume-Uni et dans une moindre mesure vers les autres marchés de la zone de l'OCDE. Cela met en évidence que la proximité linguistique et culturelle constitue un facteur décisif dans le choix des lieux de délocalisation des services de soutien aux entreprises et des STI.

Les échanges de services de soutien aux entreprises et de STI sont dominés par des multinationales de la zone de l'OCDE mais les sociétés nationales des économies non membres y prennent une part croissante. Aux Philippines et en République tchèque, les exportations de services de soutien aux entreprises et de STI sont principalement assurées par des multinationales étrangères. En Chine et en Inde, elles sont bien plus équitablement réparties entre les sociétés nationales et celles sous contrôle étranger.

L'Inde se classe au premier rang des économies émergentes grâce à un secteur des STI parvenu à maturité et compétitif au plan international. Le secteur national des STI de ce pays a réussi à créer un modèle d'entreprise performant fondé sur le principe de la prestation de services dans le monde entier et associant fourniture de services à travers les frontières et migrations temporaires de main-d'œuvre. Plusieurs des grandes sociétés nationales des quatre pays s'attachent actuellement à établir une présence importante sur d'autres marchés, et notamment sur ceux des autres économies émergentes, en vue de renforcer leurs capacités et de tirer parti des avantages comparatifs locaux. Cela met en évidence que chaque zone géographique possède ses propres points forts et que les flux d'IDE entre économies émergentes se développeront sans doute rapidement dans le futur dans le domaine des services de soutien aux entreprises et des STI. Certains éléments paraissent par ailleurs indiquer que les échanges sud-sud sont en passe de prendre davantage d'importance sur certains créneaux spécialisés.

Le marché des services délocalisés de soutien aux entreprises délocalisés est jeune et en rapide développement et la concurrence entre les quatre pays y est plus égale que dans celui des STI. L'Inde est le principal pays exportateur mais les Philippines en sont désormais un important concurrent dans le domaine des services en anglais, en particulier lorsqu'ils sont vocaux. Le secteur des services de soutien aux entreprises axé sur les exportations poursuivra sans doute dans l'avenir son expansion dans les quatre pays examinés. Certaines des multinationales qui donnent le ton ont déjà recours à l'ensemble de ces quatre pays pour fournir des services de soutien aux entreprises dans les zones géographiques de même langue.

Les quatre pays sont confrontés à des contraintes croissantes du côté de l'offre dans leur effort pour fournir des services de soutien aux entreprises et des STI aux marchés internationaux. La forte demande a été à l'origine d'importants taux de rotation des effectifs tout comme d'une inflation salariale élevée que certaines sociétés s'efforcent de maitriser. Dans le secteur des STI, il faut en outre procéder à de lourds investissements de formation pour faire en sorte que les jeunes professionnels deviennent productifs, et il est donc essentiel de parvenir à les retenir. La Chine, les Philippines et la République tchèque ne disposent que de peu de personnel confirmé possédant une expérience réelle dans ce secteur, ce qui constitue un frein à la croissance.

Les restrictions réglementaires sont relativement limitées mais n'en affectent pas moins certaines entreprises. Dans le secteur des STI, les mouvements temporaires de personnel peuvent poser de graves difficultés aux exportateurs nationaux. Le problème est particulièrement aigu dans le secteur indien des STI, qui est tributaire de l'envoi de professionnels pour des visites de plus longue durée dans les locaux des clients. La lenteur et l'imprévisibilité des procédures de délivrance de visas d'affaires et de permis de travail, ainsi que les limitations imposées par les systèmes de quotas au nombre de permis de travail accordés, posent des problèmes opérationnels aux sociétés indiennes. 
Dans le secteur des services de soutien aux entreprises comme dans une moindre mesure dans celui des STI, la législation sur la confidentialité et la sécurité des données peut avoir un effet négatif sur la délocalisation vers l'étranger. Les nouvelles réglementations ont cependant également créé des débouchés commerciaux totalement nouveaux, par exemple dans le secteur des transcriptions médicales. Les réglementations relatives à la confidentialité et à la sécurité des données n'ont pas nécessairement une incidence négative pour autant qu'elles ne soient pas de nature discriminatoire. Des solutions technologiques permettent dans la plupart des cas aux sociétés de se conformer aux exigences réglementaires et les clients exigent généralement que leurs fournisseurs respectent des normes plus strictes que celles imposées par la législation en vigueur.

L'intégration à l'économie mondiale de grands pays tels que la Chine et l'Inde ouvre aux sociétés des pays de l'OCDE de considérables possibilités d'accès à de nouveaux marchés. Elle leur permet également d'accéder à de nouvelles compétences pour la réalisation de certaines tâches dans le cadre de la fragmentation verticale des chaînes de valeur, y compris en ce qui concerne les services de soutien aux entreprises et les STI. La plupart des tâches de travail ne peuvent certes être menées à bien en des lieux éloignés avec un modèle d'entreprise économiquement incontestable et avec une qualité de service satisfaisante, mais la concurrence internationale n'en crée pas moins une insécurité de l'emploi pour certains travailleurs qui étaient auparavant à l'abri de telles pressions. Cela montre que la libéralisation des échanges doit s'accompagner de politiques du marché du travail appropriées destinées à faciliter la réaffectation des travailleurs à des emplois plus productifs et à aider les citoyens à bénéficier des avantages offerts par les échanges.

Le secteur des STI des pays à revenu élevé pourrait être soumis à moins de pressions à l'ajustement que certains ne le craignaient initialement. Les raisons en sont que la concurrence internationale ne concerne que certains types de services - tels que le développement et la maintenance des applications - et la demande mondiale de STI devrait connaître dans l'avenir prévisible une croissance supérieure au rythme de création de nouvelles capacités de fourniture dans les pays à faible revenu. Les niveaux d'emploi dans le secteur des STI ne devraient probablement pas chuter en chiffres absolus, mais les marchés de l'OCDE pourraient bien enregistrer un déplacement de la demande au profit de certains types d'emplois au sein du secteur des STI à mesure que celui-ci recrutera des travailleurs plus qualifiés en vue de fournir des services de plus grande valeur. 


\section{INTRODUCTION}

1. Les services de soutien aux entreprises et les services des technologies de l'information (STI) font l'objet d'échanges croissants entre les économies émergentes et les pays de l'OCDE. Les échanges de ces deux types de services ont certes enregistré une notable expansion ces derniers temps, mais ce n'est que par rapport à des niveaux de départ relativement modestes en volume absolu. Les dépenses mondiales dans les secteurs des services de soutien aux entreprises et des STI ont atteint environ 836 milliards de dollars des États-Unis en 2005 et la plus grande partie des échanges en ce domaine ont lieu entre les pays de l'OCDE $^{1}$. Les exportations des quatre pays examinés dans ce document - Chine, Inde, Philippines et République tchèque - représentaient de 2 à $3 \%$ environ des dépenses mondiales dans les secteurs des services de soutien aux entreprises et des STI. Tous ces pays offrent non seulement des infrastructures stables dans le domaine des TIC mais aussi des réglementations libérales en matière d'investissements directs étrangers (IDE), ainsi qu'une main-d'œuvre possédant un niveau d'instruction élevé et une bonne maîtrise des langues. Ce n'est pourtant qu'en Inde et aux Philippines que les industries des services de soutien aux entreprises et des STI sont devenues d'importantes sources de recettes d'exportation et de créations d'emplois. L'Inde se classe au premier rang et détient environ $60 \%$ du marché extraterritorial dans le domaine des échanges de services de soutien aux entreprises et de STI (Citigroup, 2005).

2. La délocalisation internationale des services de soutien aux entreprises et des STI offre d'importants avantages du point de vue des coûts de main-d'œuvre et permet aux sociétés de fournir à leurs clients de nouveaux services moins chers, plus souples et souvent de meilleure qualité. Elle peut également permettre de réduire les délais de mise sur le marché, faciliter l'accès aux marchés extérieurs et offrir aux entreprises la possibilité de mettre au point des produits nouveaux pour des créneaux spécialisés. Le recours à des prestataires extérieurs permet également aux entreprises de se concentrer sur ce qu'elles font le mieux et de libérer ainsi des capitaux susceptibles d'être réinvestis dans la R-D et des activités plus productives. De nouvelles pratiques commerciales et une faible progression de la productivité ont été des facteurs déterminants dans d'autres cas. La délocalisation internationale des services de soutien aux entreprises et des STI vers des pays lointains ne constitue pas une solution viable pour la plupart des entreprises. Il leur faudrait en effet réaliser de lourds investissements et déployer de considérables efforts pour pouvoir mener à bien une tâche aussi complexe et la plupart des services continuent par ailleurs de ne pouvoir faire l'objet d'échanges. Il n'en reste pas moins que les échanges de services de soutien aux entreprises et de STI prendront une plus grande importance à mesure que les modèles de fourniture internationale arriveront à maturité et que davantage de pays feront leur entrée sur les marchés mondiaux des services de soutien aux entreprises et des STI, que ce soit du côté de la demande ou de l'offre.

3. Le présent document fait partie d'une série d'études de l'OCDE sur la mondialisation et l'ajustement structurel (MAS). Il cherche à mieux comprendre les effets de la mondialisation dans les pays de l'OCDE et dans les économies non membres. Il porte en particulier sur les effets économiques d'ensemble de la mondialisation, sur l'effet de la mondialisation et de l'innovation sur le secteur des

\footnotetext{
${ }^{1}$ Cette estimation a été établie par la société International Data Corporation (IDC) et elle est citée par Nasscom (2006). Elle est mentionnée à titre indicatif et n'a pas l'ambition de révéler quelle est la valeur exacte du marché mondial des services de soutien aux entreprises et des STI.
} 
services de soutien aux entreprises et sur le rapport entre les échanges et l'ajustement des marchés du travail $^{2}$. Dans le cadre du projet MAS, le papier examinera le rôle des principales économies emergeantes dans l'approvisionnement de services de soutien aux entreprises et de STI auprès des marchés de l'OCDE. Il s'addresse plus particulierement aux analystes et decideurs en matière de politiques commerciale, mais il peut aussi interessser toute personne concernée par le débat sur les delocalisations, puisque l'analyse inclut des informations qui ne sont pas facilement accessibles par ailleurs.

\section{Objet et champ couvert}

4. Le présent document a pour objet d'examiner l'expansion des chaines internationales d'approvisionnement ayant recours aux services de soutien aux entreprises et aux STI. En particulier l'analyse portera sur l'integration des marchés emergeants dans les chaines d'approvisionnement des compagnies basées dans les pays de l'OCDE. Les pays qui sont étudiés dans ce document ont développé un secteur exportateur compétitif dans le domaine des services de soutien aux entreprises et des STI ou ont la possibilité de le faire dans le futur. Il vise à donner une image plus précise de la nature des nouvelles chaînes internationales d'approvisionnement au sein de ces secteurs, tout comme des facteurs qui en déterminent l'apparition, ainsi qu'à identifier les principaux problèmes relatifs à l'activité économique et aux échanges qui se profilent à l'horizon. Dans ce contexte, il décrit certaines des conséquences que ces échanges croissants entre les pays de l'OCDE et les économies non membres ont sur le marché du travail.

5. Ce document se limite à étudier la fourniture internationale de services de soutien aux entreprises et de STI, fréquemment appelée "délocalisation" (voir le graphique 1). La délocalisation recouvre aussi bien l'approvisionnement interne à l'étranger que l'approvisionnement externe à l'étranger et elle implique la fourniture de services à travers les frontières (modes $1 / 2$ de l'AGCS, $)^{3}$. Dans le cas des STI, les prestations de services peuvent également être assurées en associant fourniture transfrontières et migrations temporaires de main-d'œuvre (mode 4 de l'AGCS). Le champ couvert par ce document est encore plus réduit puisqu'il ne porte que sur les flux de services des économies émergentes vers les pays de l'OCDE. Il convient cependant de remarquer que les sociétés des pays de l'OCDE comptent parmi les principaux fournisseurs de services de soutien aux entreprises et de STI aux économies émergentes au travers d'une présence commerciale (mode 3 de l'AGCS) et que les fournisseurs de services des marchés emergeants établissent de plus en plus de filiales dans les pays de l'OCDE. ${ }^{4}$

6. Le document couvre un groupe assez etendu de services qu'on designe à travers le document comme services de soutien aux entreprises (SSE) et services des technologies de l'information (STI). Un "processus d'entreprise" est une "suite d'opérations de bout en bout déclenchée par un événement qui débute par la demande d'un client et s'achève par un certain résultat pour le client". "Dans la mesure où ils portent sur des "processus d'entreprise", les services de soutien aux entreprises visent à assurer en tout ou partie une telle suite d'opérations. Les services d'interaction avec la clientèle, les activités de back office et les services professionnels tels que ceux relatifs aux ressources humaines, aux finances et à la comptabilité en sont des exemples. Les "services des TI" recouvrent notamment le conseil en TI, l'intégration de systèmes, le développement d'applications spécifiques, la maintenance des applications, ainsi que les activités traditionnelles d'externalisation des TI et de soutien en matière de matériel. ${ }^{6}$ Le nombre

\footnotetext{
${ }^{2}$ Il il s'inscrit dans le prolongement de l'étude OECD (2005a) Enhancing the Performance of the Service Sector et OCDE (2005b) Les échanges et l'ajustement structurel: les enjeux de la mondialisation.

${ }^{3}$ Les pays membres de l'OMC ne sont toujours pas d'accord pour savoir si l'approvisionnement electronique fait partie du mode 1 ou 2 de l'accord AGCS, d'où l'utilisation du terme mode 1/2.

${ }^{4}$ Voir le tableau 3 et l'annexe $\mathrm{K}$.

${ }^{5}$ Voir le glossaire de la société Gartner : www.gartner.com/6_help/glossary/GlossaryB.jsp

${ }^{6}$ Pour plus de précisions, voir MGI (2005a).
} 
d'activités susceptibles d'être classées parmi les SSE et les STI s'accroît sans cesse du fait du progrès technologique et de l'innovation commerciale. Aussi toute liste exhaustive non fondée sur une méthodologie générique deviendrait-elle rapidement obsolète. ${ }^{7}$

Graphique 1. Illustration des modes d'approvisionnement

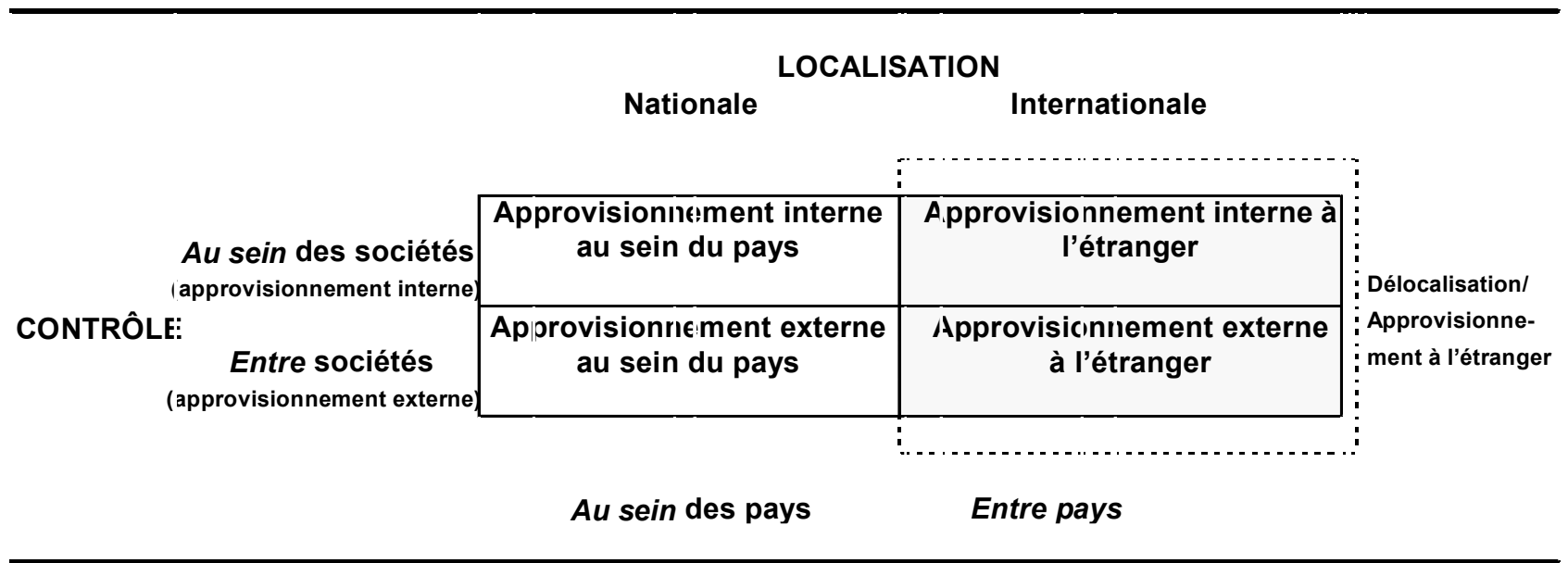

Source : Secrétariat de l'OCDE

\section{Données et méthodologie}

7. Les statistiques du commerce international sont pour une large part dans l'incapacité de mesurer les échanges de services de soutien aux entreprises et de STI. Plusieurs rapports sont parvenus à la conclusion qu'il existe d'importants écarts entre les données relatives aux échanges de services de soutien aux entreprises et de STI dont il est fait état dans le système de la balance des paiements (BDP) du FMI et celles présentées par certains gouvernements et certaines associations professionnelles. Dans le cas de l'Inde, l'écart entre les données fournies par la BDP du FMI et par l'association nationale indienne des sociétés de logiciels et de services (National Association of Software and Service Companies ou Nasscom) est supérieur à $90 \%$ pour les années les plus récentes. ${ }^{8}$

8. Compte tenu des problèmes de définition et faute de disposer de données exhaustives, l'analyse ci-dessous repose sur des données fournies par les gouvernements, les associations professionnelles nationales et les sociétés d'information commerciale. Ces données sont généralement issues des déclarations de revenus auprès de l'administration fiscale ainsi que d'études de marché. Il est essentiel de garder à l'esprit que certaines des données présentées dans ce document correspondent en réalité à la meilleure estimation disponible et pourraient ne pas être tout à fait comparables d'un pays à l'autre. ${ }^{9}$

9. Le document s'appuie également sur des informations obtenues au moyen d'entretiens avec autour de 90 personnes, directeurs d'entreprises, fonctionnaires, experts de l'industrie et associations professionnelles menés en Chine, en Inde, aux Philippines et en République tchèque (l'annèxe B présente

\footnotetext{
${ }^{7}$ C'est là une des principales raisons pour lesquelles les études sur le sujet ne s'appuient sur aucune définition commune tirée de nomenclatures telles que la classification sectorielle des services de l'OMC (1991). L'annexe B1 présente une liste indicative des services délocalisés à l'étranger.

${ }^{8}$ Voir par exemple GAO (2005) et OCDE (2004a).

${ }^{9}$ Afin de faciliter l'analyse du secteur des services de soutien aux entreprises, il convient de préciser que les données dont il est fait état en ce qui concerne ces derniers peuvent couvrir aussi bien les services rendus possibles par les TI que l'externalisation des processus d'entreprise, certaines sources utilisant ces deux termes de façon interchangeable.
} 
une liste des personnes interrogées). Les entretiens ont eu lieu pendant des missions d'une à deux semaines entre septembre 2005 et septembre 2006. Dans la mesure du possible, les données issues de ces entretiens sont étayées par des données de travaux précédemment réalisés sur le même sujet.

10. Le present document s'articule autour d'études de cas par pays portant sur les secteurs des services de soutien aux entreprises et des STI en Chine, en Inde aux Philippines et en République tchèque. Chaque étude par pays décrit les caractéristiques du marché des secteurs locaux des services de soutien aux entreprises et des STI en mettant l'accent sur les aspects relatifs aux échanges. Ils indiquent quelles en sont les spécificités dans chacun des pays afin de montrer comment les secteurs qui fournissent ces services réussissent à s'intégrer dans les chaînes internationales d'approvisionnement et dans quelle mesure ils parviennent se concentrer sur les marchés d'exportation. Les chapitres par pays s'efforcent également d'identifier les principaux problèmes relatifs à l'activité économique et aux échanges auxquels doivent faire face les entreprises et les pouvoirs publics. Les études par pays sont suivies de la présentation des observations et des conclusions principales. Ce document s'achève par un examen de certaines des conséquences auxquelles les travailleurs et les gouvernements pourraient être confrontés du fait de l'intégration des économies émergentes dans les chaînes d'approvisionnement des sociétés de l'OCDE. 
TD/TC/WP(2007)2/FINAL

\section{LES SECTEURS CHINOIS DES SERVICES DE SOUTIEN AUX ENTREPRISES ET DES STI}

11. La Chine a plusieurs atouts dans le domaine des SSE et STI en tant que fournisseur des entreprises basées à l'OCDE. L'économie a connu une croissance rapide pendant des nombreuses années et les marchés locaux des SSE et STI bénéficient également de la présence d'un nombre important et croissant de multinationales étrangères et chinoises operant en Chine. Il existe une offre abondante de diplômés de l'université, et en particulier d'ingénieurs logiciels, dont beaucoup sont extrêmement qualifiés et motivés. Les coûts de main-d'œuvre sont particulièrement peu élevés dans le cas des jeunes professionnels, ce qui fait de la Chine un pays économiquement incontournable pour la fourniture de services de soutien aux entreprises et de STI. La proximité géographique et les aptitudes linguistiques s'avèrent utiles pour répondre à la demande des marchés du Japon, de la Corée, du Taipei chinois, de Singapour et de Hong Kong. En plus l'environnement des entreprises est favorable grâce aux parcs technologiques et logiciels chinois qui offrent une administration rationalisée, une infrastructure de qualité, ainsi qu'un certain nombre de mesures d'incitation aux nouveaux exportateurs potentiels. Cependant, malgré tous ces atouts la Chine reste un acteur mineur sur les marchés internationaux pour tout type de service autre que les services R\&D haut de gamme et les services SSE d'entrée de gamme.

12. L'Index de A.T. Kearney sur la localisation des services mondialisés classe la Chine comme le deuxième pays le plus attractif pour l'approvisionnement des services SSE et STI (voir Annex H). La main d'œuvre est bon marché et les coûts d'infrastructure peu élévés mais les taxes et les coûts liés à la reglementation sont plus élévés en Chine qu'en Inde ou aux Philippines. Tandis que la Chine a une main d'œuvre très large en termes absolus, le profil des travailleurs disposant de l'experience et des aptitudes linguistiques nécessaires la rend moins apte à fournir des services à des marchés autres que ceux de l'Asie de l'Est. Même si on considère que le pays présente des risques relativement faibles pour les investisseurs et possède une infrastructure de qualité acceptable, il obtient un mauvais classement en ce qui concerne l'adaptabilité culturelle et la protection de la propriété intellectuelle. Le classement des marchés emergeants effectué par neoIT considère la Chine comme le troisième pays le plus attractif pour la délocalisation des services STI mais lui attribue seulement la neuvième position en ce qui concerne les services SSE (voir Annexe F-G). La Chine semble légerement mieux placée que l'Inde en termes de coûts, mais n'arrive pas vraiment à concurrencer son voisin pour ce qui est de la maturité des companies SSE et STI locales et la disponibilité de main d'œuvre qualifiée.

\section{Caractéristiques du marché}

13. Les secteurs chinois des services de soutien aux entreprises et des STI s'attachent principalement à répondre à la demande du marché intérieur. En 2000, les exportations ne représentaient que 6\% de l'ensemble des prestations de service (Tschang et Xue, 2003). En 2006 la part des exportations était estimée entre 10 et $15 \% .{ }^{10}$ Les sociétés chinoises et les filiales de multinationales étrangères se partagent à

\footnotetext{
${ }^{10}$ Walter Fang, de Neusoft Group, estime ainsi que 85\% des recettes tirées de ces services sont issues du marché intérieur alors que de Filippo et al. (2005) évaluent cette proportion à $90 \%$.
} 
parts à peu près égales le marché de l'exportation. Les multinationales étrangères obtiennent une plus forte proportion des gros marchés de services privés que leurs concurrentes chinoises (IDC, 2006a) ${ }^{11}$.

14. Un des problèmes auxquels se heurte l'analyse des échanges de services de soutien aux entreprises et de STI tient à la rareté des données commerciales fiables. En Chine, la situation est rendue d'autant plus difficile par le manque relatif de données désagrégées et leur absence de transparence. Très peu de sociétés chinoises de services de soutien aux entreprises ou de STI sont cotées en bourse. Les chiffres ci-dessous sont représentatifs des estimations fréquemment citées :

- Analysys International estime que la valeur du marché chinois de l'externalisation logicielle s'est élevée en 2005 à 8.7 milliards de dollars des États-Unis (OSW, 2005).

- Selon le ministère chinois de l'Industrie de l'information, les exportations de logiciels ont atteint en 2005 un montant total de 3.59 milliards de dollars des États-Unis, contre 2.80 milliards en 2004 (MII, 2006).

- Les fonctionnaires du ministère du Commerce ont estimé à 3.6 milliards de dollars des États-Unis la valeur des exportations de STI et de services rendus possibles par les TI en 2005, dont 960 millions correspondaient à des exportations de programmes informatiques et d'applications logicielles. $^{12}$

- D'après la société IDC (2006a), les exportations de services de mise au point de logiciels ont atteint 933 millions de dollars des États-Unis en 2005, contre 600 millions en 2004 et 400 millions en $2003 .^{13}$

- A.T. Kearney (2004) a estimé que la valeur des services de soutien aux entreprises délocalisés vers la Chine s'élèverait à 320 millions de dollars des États-Unis en 2005, contre 260 millions en 2004.

15. Les exportations de services de soutien aux entreprises et de STI sont principalement destinées à des sociétés opérant dans les pays voisins de la Chine : la région Asie-Pacifique a importé plus des trois quarts de ces services en 2005. Le Japon absorbe les deux tiers environ des exportations, dont une bonne part est destinée aux filiales de sociétés de la zone de l'OCDE opérant dans ce pays. Les marchés européens et nord-américains représentent environ un cinquième des exportations chinoises. Plus spécifiquement, les sociétés japonaises sont grosses consommatrices d'applications logicielles et de services de maintenance alors que les sociétés européennes et nord-américaines sont les principales clientes pour ce qui est des services d'essais (IDC, 2006a).

16. Malgré la rivalité annoncée entre la Chine et l'Inde en tant que fournisseurs de services délocalisés, le premier de ces pays n'a pas encore la stature d'un grand centre de délocalisation internationale des services de soutien aux entreprises et des STI. Certains indices donnent à penser que la

\footnotetext{
${ }^{11}$ D'après Analysys International, les deux principales sociétés de services de soutien aux entreprises sont en Chine les filiales chinoises d'IBM et de Hewlett-Packard.

12 Les fonctionnaires du ministère du Commerce estiment que, si l'on tient compte de la part destinée à la consommation intérieure aussi bien que des exportations, la production totale de l'industrie chinoise des services logiciels et des STI s'est élevée en 2005 à 48.4 milliards de dollars des États-Unis. Ce chiffre doit être manié avec précaution car les dix premières sociétés de logiciels au monde ont enregistré cette même année un chiffre d'affaires total de 84 milliards de dollars des États-Unis (OCDE, 2006b).

${ }^{13}$ Ce chiffre recouvre les sociétés chinoises ou étrangères qui fournissent des "services de mise au point de logiciels" à des sociétés étrangères, que ce soit directement ou au travers de leurs filiales en Chine.
} 
Chine est en passe de devenir la destination la plus prisée pour la fourniture de certains types de services de soutien aux entreprises et de STI aux sociétés opérant au Japon et en Corée. Il n'en est cependant pas de même pour ce qui est de la prestation de services aux sociétés établies en Europe ou en Amérique du Nord, et de nombreux analystes jugent qu'il est peu probable que la situation évolue dans un futur prévisible.

17. La Chine pourrait néanmoins parvenir à exceller sur les marchés extérieurs dans certains créneaux spécialisés, dont quelques-uns pourraient générer des recettes d'exportation assez importantes. Elle dispose à l'heure actuelle de capacités aux deux extrémités de la chaîne de valeur dans le secteur des services : les activités de traitement et d'essai des données, dont la valeur est faible, et celles de R-D, dont la valeur est élevée. La Chine est déjà un des principaux centres de R-D au monde, mais les investissements en ce domaine demeurent assez limités dans les secteurs chinois des services de soutien aux entreprises et des STI. Entre les deux extrémités de la chaine de valeur, la Chine doit encore concrétiser son potentiel en tant que fournisseur des marchés extérieurs, malgré les ambitions de ce secteur d'activité naissant et l'objectif explicite du gouvernement chinois de mettre sur pied une industrie logicielle nationale compétitive.

18. Les relations commerciales sino-japonaises pourraient être largement renforcées dans le domaine des services de soutien aux entreprises et des STI. Par exemple, les activités des cinq grandes sociétés chinoises de services de soutien aux entreprises et de STI présentées à l'annexe $K$ s'attachent principalement à répondre à la demande du marché japonais. La proximité géographique, la bonne connaissance de la langue japonaise et les facteurs démographiques et économiques exercent une influence incontestable et donnent à penser que ces relations continueront probablement de se développer si le climat politique et l'environnement des entreprises demeurent stables. Une augmentation des investissements visant à améliorer les aptitudes en japonais aurait en particulier pour effet d'accroître les débouchés commerciaux des sociétés chinoises de services de soutien aux entreprises.

\section{Fragmentation des marchés et composition du capital des sociétés}

19. Il est certes fort possible que la Chine devienne dans le futur un centre de choix pour la délocalisation des activités, mais elle n'en est pas encore là et les capacités actuelles de l'industrie nationale et la structure du marché pourraient être largement renforcées. Le marché des services de soutien aux entreprises et celui des STI sont extrêmement fragmentés puisque plus de 13000 PME employant au total environ 900000 personnes s'y affrontent. ${ }^{14}$ Aucune société chinoise ne possède une part de marché supérieure à $3 \%$ et rares sont celles tournées vers l'exportation : la concurrence est acharnée. Bien des raisons contribuent à expliquer la fragmentation du marché des services de soutien aux entreprises et de celui des STI.

20. En premier lieu, ces marchés en sont encore aux premiers stades de développement et il a fallu attendre ces toutes dernières années pour que la participation étrangère prenne de l'ampleur. Deuxièmement, en raison de faibles obstacles à l'entrée, ils comptent d'innombrables petites entreprises non encore parvenues à maturité qui tendent à se faire concurrence sur les prix plutôt que sur la qualité, adoptent des comportements opportunistes sans se soucier de développer une expertise du domaine considéré et n'investissent ni dans la formation ni dans le contrôle des processus. Aussi les marges d'exploitation sont-elles faibles par rapport aux normes internationales : 7\% d'après de Filippo (2005). Par ailleurs, la Chine exporte principalement des services de saisie de données, de programmation et d'essai de logiciels modulaires, ainsi que de maintenances qui n'ont qu'une très faible valeur.

\footnotetext{
${ }^{14}$ D'après le ministère chinois de l'Industrie de l'information, 13194 sociétés de logiciels étaient immatriculées en Chine fin 2005 (AI, 2006a). Le nombre de professionnels au sein de l'industrie nous a été communiqué par le ministère du Commerce.
} 
21. Troisièmement, la Chine est un grand pays dont les différentes provinces et régions possèdent leurs propres champions dans le domaine des TI. Les collectivités territoriales détiennent d'importantes participations au capital des sociétés locales de services de soutien aux entreprises et de STI et elles tendent à les favoriser au détriment de leurs concurrentes venues d'ailleurs. La réticence des collectivités territoriales à perdre le contrôle de ces compagnies empêche aussi les marchés de se consolider. L'apparition de sociétés présentes sur l'ensemble du territoire national s'en est trouvé freinée. Les estimations de la participation publique dans le secteur des services de soutien aux entreprises et des STI varient: Tschang et Xue (2003) ont évalué à 30\% environ le pourcentage des sociétés entièrement contrôlées par le secteur public, et à $10 \%$ celui des sociétés d'économie mixte, qui conjuguent capitaux publics et privés, alors que Gartner est d'avis que la participation publique atteint $70 \%$ (Ilett, 2006). Saxenian (2003) affirme que 30\% des sociétés de logiciels chinoises appartiennent au secteur public, 27\% sont des coentreprises sino-étrangères, $20 \%$ sont propriété collective (les entreprises issues de la recherche universitaire), $17 \%$ sont privées et $6 \%$ sont contrôlées par des capitaux étrangers.

22. Bon nombre des sociétés de STI fondées dans les années 80 et 90 l'ont été par des facultés universitaires, et une part de leur capital social a souvent été attribuée aux universités. D'autres sociétés chinoises n'ont pu être créées et gérées que sous la forme de sociétés d'économie mixte faisant appel à des capitaux publics et privés : il est souvent indespensable en Chine de s'assurer une aide publique (au travers du guanxi) ${ }^{15}$ pour pouvoir obtenir les autorisations, les permis, les ressources financières et l'accès aux installations. Opérer sous capitaux publics permet aussi de bénéficier d'une protection, d'une interprétation favorable des réglementations, ainsi que des moyens d'imposer le respect des contrats. Un autre avantage essentiel des liens avec le secteur public concerne l'attribution de marchés par des institutions ou des entreprises publiques que l'on pense plus favorable à ces enterprises (Saxenian, 2003). La fourniture de services de programmation logicielle et des technologies de l'information à des industries sensibles telles que celle de la défense ou l'aérospatiale est essentiellement assurée par des sociétés contrôlées par le secteur public.

23. La fragmentation du marché des services de soutien aux entreprises et de celui des STI présente plusieurs inconvénients : à moins d'atteindre une échelle suffisante, il est difficile d'attirer les clients multinationaux, qui composent une grande partie des marchés des services de soutien aux entreprises et des technologies de l'information délocalisés à l'étranger. Les principales raisons en sont que les petits prestataires de services sont moins fiables du fait qu'ils sont tributaires de compétences clés et de ressources financières limitées. Des capacités ou une taille insuffisantes pour leur permettre de prendre en charge de grands projets et d'offrir une expertise du domaine considéré ont également des effets négatifs sur leurs possibilités techniques et leur flexibilité. Elles ont également une incidence négative sur leur aptitude à mettre au point des procédures efficientes et parvenues à maturité pour assurer le contrôle des processus et de la qualité.

24. Plusieurs des sociétés chinoises qui exportent des services de soutien aux entreprises et de STI sont des "jeunes pousses" créées par d'anciens employés de multinationales de la zone de l'OCDE. L'industrie nationale a par ailleurs recruté à l'étranger bon nombre des cadres supérieurs chinois. Cette situation est similaire à celle observée en Inde, où beaucoup de grandes sociétés de services ont été créées par d'anciens employés de multinationales américaines et britanniques. La principale différence tient cependant au fait que la plupart des sociétés de services indiennes aujourd'hui florissantes ont été fondées à la fin des années 80 et au début des années 90, alors que bien des sociétés de services chinoises en rapide

\footnotetext{
${ }^{15}$ Le terme guanxi renvoie à un concept essentiel au sein de la société chinoise. Il désigne entre autres la relation personnelle qui lie deux individus dont l'un peut convaincre l'autre de lui faire une faveur ou de lui rendre un service, et vice versa. Les deux individus doivent avoir le même statut social. Le terme peut également désigner un réseau de relations auxquelles un individu peut avoir recours lorsqu'il lui faut faire quelque chose et grâce auquel il peut exercer une influence pour le compte de quelqu'un d'autre (www.wikipedia.org).
} 
expansion l'ont été à la fin des années 90 et au début des années 2000. L'industrie indienne bénéficie donc d'une bonne longueur d'avance alors que la chinoise s'efforce de son mieux de la rattraper. ${ }^{16}$

25. Certaines des sociétés de STI chinoises tournées vers l'exportation qui enregistrent la croissance la plus rapide appartiennent aujourd'hui au secteur privé. Compte tenu des pressions concurrentielles et des faibles marges bénéficiaires sur le marché chinois, de plus en plus de sociétés s'efforcent de créer des modèles d'entreprise répondant efficacement à la demande des marchés extérieurs. Les obstacles à l'entrée sont nettement plus élevés sur les marchés de la zone OCDE que sur les marchés intérieurs, mais les sociétés qui réussissent à y prendre pied opèrent sur des marchés où la concurrence est moindre et les débouchés commerciaux plus rentables : un petit nombre de sociétés chinoises de services de soutien aux entreprises et de STI réalisent un chiffre d'affaires à l'exportation supérieur à 10 millions de dollars des États-Unis sur les marchés de l'OCDE (voir l'annexe K).

\section{Efforts du gouvernement chinois pour attirer les investissements directs étrangers}

26. Le gouvernement chinois soutient les secteurs locaux des services de soutien aux entreprises et des STI et s'efforce d'attirer les sociétés étrangères au moyen d'incitations fiscales et tarifaires, de subventions, ainsi que de facilités administratives dans ses parcs de haute technologie. Il encourage par ailleurs activement les partenariats et les coentreprises avec des sociétés étrangères en vue de favoriser le développement des sociétés de STI chinoises. Le gouvernement chinois ne se contente pas de jouer le rôle d'organe de réglementation des secteurs des services de soutien aux entreprises et des STI mais en est en outre également le principal client en Chine, tout comme il détient la plus grande partie du capital des sociétés locales. Les secteurs chinois des services de soutien aux entreprises et des STI se distinguent donc de ceux de l'Inde, des Philippines et de la République tchèque, où la participation publique au capital des entreprises est quasiment inexistante et où les marchés publics ne représentent qu'une part relativement faible de la demande totale.

27. Le gouvernement chinois considère que l'industrie des logiciels revêt une importance essentielle pour le progrès économique et la sécurité nationale. La principale politique publique en ce domaine a été annoncée en juin 2000 et publiée dans le document $n^{\circ} 18$ du Conseil des affaires de l'État, intitulé "Notification de certaines mesures destinées à promouvoir le développement de l'industrie des logiciels et des circuits intégrés", auquel a fait suite en 2002 le document n ${ }^{\circ} 47$ du Conseil des affaires de l’État. Ce document d'orientation prenait des mesures préférentielles en vue de promouvoir le développement des deux secteurs en question, parmi lesquelles figuraient notamment les dispositions suivantes en faveur des sociétés de logiciels : ${ }^{17}$

- des remboursements de taxe sur la valeur ajoutée au titre des activités de R-D et de l'expansion de la production ;

- des privilèges fiscaux pour les sociétés de création récente ;

- une procédure d'agrément rapide pour les sociétés de logiciels désireuses de mobiliser des capitaux sur les marchés boursiers étrangers ;

- une exonération de droits de douane et de TVA pour toutes les importations de technologies et d'équipements ;

\footnotetext{
${ }^{16}$ La revue Computerworld a affirmé en 2003 que le secteur chinois des STI avait 12 ans de retard sur celui de l'Inde.

${ }^{17}$ Voir la page web www.csia.org.cn/chinese_en/index/No18Document.html pour le texte, ainsi que Saxenian (2003).
} 
- le droit de procéder à des exportations directes pour toutes les sociétés de logiciels réalisant un chiffre d'affaires supérieur à 1 million de dollars des États-Unis ;

- le pouvoir de fixer les niveaux de salaire et de verser des dividendes exceptionnels aux investisseurs.

28. Outre les incitations précédemment mentionnées, le document $\mathrm{n}^{\circ} 18 \mathrm{du}$ Conseil des affaires de l'État prévoyait également une restructuration du secteur des logiciels, dont l'adoption d'un plan visant à financer et à promouvoir certaines sociétés afin de les transformer en champions nationaux (le gouvernement chinois a ensuite sélectionné environ 160 sociétés nationales à cet effet). Il a également créé un comité formé de représentants de 15 ministères en vue d'instaurer et de mettre en œuvre un cadre juridique assurant une protection effective des brevets, des marques déposées et des droits d'auteur. Un autre volet fondamental de ce document stratégique avait trait aux mesures d'incitation publiques destinées à favoriser le développement des ressources humaines (voir ci-dessous pour plus de précisions).

29. Les documents $n^{\circ} 18$ et $n^{\circ} 47$ du Conseil des affaires de l'État ont été suivis en novembre 2003 par une initiative du Torch Centre - une subdivision du ministère de la Science et de la Technologie baptisée "projet chinois pour la délocalisation des activités de génie logiciel" (China Offshore Software Engineering Project ou COSEP). Il s'agissait de fournir depuis la Chine des services à des sociétés clientes établies à l'étranger. Le Torch Center procède tous les ans à la sélection de sociétés de logiciels qualifiées au sein des parcs logiciels régionaux afin qu'elles participent à ce projet et ces sociétés bénéficient d'une formation dispensée sous la supervision d'ExperExchange - une société américaine de services de soutien aux entreprises et de STI - ce qui leur permet d'obtenir une certification de qualité (ChinaTechNews, 2003). Ce projet lancé avec le concours d'ExperExchange a contribué à donner l'impulsion initiale à l'expansion de la délocalisation des activités de services vers la Chine, et plus particulièrement de celles destinées à répondre à la demande européenne et nord-américaine (Simon, 2005).

30. L'administration centrale et les collectivités locales fournissent il est vrai un appui non négligeable à l'industrie des services de soutien aux entreprises et des STI, mais l'industrie n'en souhaiterait pas moins assister à de nouveaux progrès dans deux domaines afin d'améliorer l'environnement dans lequel opèrent les entreprises comme pour renforcer sa visibilité internationale. Tout d'abord, les secteurs chinois des services de soutien aux entreprises et des STI ne disposent pas d'une association professionnelle efficace qui soit à même de leur fournir, à des fins de comparaison, des indicateurs sur les meilleurs pratiques, ou des données exhaustives sur l'industrie, mais aussi d'assurer leur promotion auprès des investisseurs potentiels à l'étranger. C'est là un handicap par rapport à leurs concurrents des autres économies émergentes. À l'instar de ce qu'ont pu faire Nasscom en Inde, BPA/P aux Philippines ou Czech ICT Alliance en République tchèque, une telle association professionnelle pourrait également aider le gouvernement chinois à formuler des priorités communes concernant l'environnement que devraient mettre en place les pouvoirs publics. L'association chinoise de l'industrie des logiciels (China Software Industry Association ou CSIA) couvre actuellement l'ensemble du territoire national, mais elle est principalement tournée vers le marché intérieur des logiciels et des services connexes. Son champ d'activité est limité par le mandat restreint qui lui a été donné par le gouvernement chinois. La CSIA est réputée être surtout et avant tout responsable devant le gouvernement plutôt qu'à l'égard de l'industrie proprement dite.

31. Deuxièmement, au sein du gouvernement, dix ministères sont actuellement habilités à s'occuper à différents titres des enjeux et des problèmes spécifiques auxquels sont confrontés les secteurs des services de soutien aux entreprises et des STI. La Commission nationale du développement et de la réforme fixe les grandes orientations que devront suivre les divers ministères, le ministère de l'Industrie de l'information (MII) s'attache essentiellement à définir la politique sectorielle à mettre en œuvre, le ministère du Commerce encourage les échanges, le ministère de la Science et de la Technologie établit les 
grands axes de la stratégie de R-D, etc. De nombreux observateurs locaux estiment que le gouvernement chinois pourrait encore mieux faire et faciliter les choses en mettant en place une politique à long terme plus cohérente et exempte de conflits de compétences entre les différents ministères gouvernementaux.

\section{Encadré 1. Parc logiciel de Dalian}

Créé en 1999, le Parc logiciel de Dalian (Dalian Software Park ou DLSP) est l'un de ceux qui enregistrent l'expansion la plus rapide en Asie orientale et il constitue l'un des principaux points de transit des exportations chinoises de STI et de services rendus possibles par les TI à destination du Japon et de la Corée. C'est également l'une des six "bases nationales d'exportation de logiciels" autorisées par le gouvernement chinois à exporter des services. Du fait de sa proximité géographique et de se liens historiques avec les pays voisins, à savoir le Japon et la Corée, la région de Dalian possède une importante population de langue japonaise et coréenne sur laquelle elle peut s'appuyer pour fournir des services vocaux et non vocaux de soutien aux entreprises. Elle accueille de nombreuses universités et instituts de recherche qui forment en grands nombres les diplômés qui constituent l'épine dorsale du secteur de la délocalisation des activités de services.

Les exportations se sont rapidement développées : après les premières implantations de sociétés, principalement nationales, Panasonic a été la première multinationale japonaise à y engager des activités en 2001, puis GE Capital International Services s'y est installée l'année suivante. En septembre 2006, 340 sociétés, dont environ $40 \%$ étaient contrôlées par des capitaux étrangers, employaient aux alentours de 30000 personnes dans le DLSP. La moitié de ces sociétés fournissent des services de soutien aux entreprises et des STI à des clients étrangers, principalement en Asie orientale, et le Japon absorbe quelque $80 \%$ des exportations. Les recettes sont dans une large mesure générées par le développement d'applications logicielles (40\%) et les services de soutien aux entreprises (30\%). Une bonne partie du reste provient des services d'ingénierie, des logiciels incorporés et des activités de R-D. Une coentreprise entre le DLSP et une société de Singapour procède actuellement à des investissements en vue d'étendre le parc en ajoutant $9 \mathrm{~km}^{2}$ aux $3 \mathrm{~km}^{2}$ déjà existants, afin d'en faire le plus grand parc logiciel de Chine. Ce projet doit aboutir à la création d'un complexe industriel composé de différentes zones respectivement consacrées au développement de logiciels, à la R-D, aux services d'information, à l'éducation et à la formation, ainsi que d'un campus d'entreprises, auxquels viennent s'ajouter des services publics et des logements situés à proximité.

Le DLSP offre aux sociétés toute une série de mesures préférentielles. Les sociétés étrangères qui opèrent dans le DLSP peuvent bénéficier d'un régime fiscal privilégié durant les cinq années postérieures à celle où elles commencent à dégager des bénéfices : elles jouissent d'une exonération d'impôts les deux premières années et d'une réduction de $50 \%$ les 3 années suivantes. Si en outre la valeur de leurs exportations représente au moins $70 \%$ de celle de leur production totale, le taux de l'impôt sur le bénéfice est ramené de $33 \%$ à $10 \%$ et le taux maximal de TVA de $17 \%$ à $0-3 \%$. Les produits logiciels bénéficient d'une exonération de la TVA et des taxes à l'exportation. Les exportations technologiques sont quant à elles exonérées de l'impôt sur les ventes et de l'impôt sur le bénéfice. Les sociétés dont les exportations de produits logiciels dépassent une valeur de 1 million de dollars des États-Unis peuvent réaliser des opérations de commerce international sans avoir à passer par un agent importexport indépendant. Les équipements importés utilisés par les sociétés de logiciels, ainsi que les technologies, et notamment les logiciels, ou encore les éléments et pièces détachées incorporés dans ces équipements jouissent en outre (à certaines exceptions près) d'une exonération des taxes à l'importation et de la TVA.

Les sociétés qui comptent parmi leurs salariés des titulaires d'une licence ou d'un diplôme de niveau plus élevé peuvent en outre leur conférer le statut de résidents permanents, ce qui leur permet d'être exonérés du paiement de la redevance d'environnement perçue par la ville. Il en est de même des Chinois de l'étranger qui viennent travailler dans le DLSP. Ils bénéficient d'une carte de résidence temporaire de longue durée et leur progéniture jouit de droits similaires à ceux des enfants de la population locale en matière d'accès aux jardins d'enfants et aux établissements scolaires. Des "concours financiers spéciaux" sont versés chaque année aux sociétés établies dans le DLSP par les services de l'État, les autorités de la province et de la ville, outre le soutien qui leur est fourni par les sociétés de capital-risque. Les sociétés et leurs salariés jouissent également de conditions préférentielles pour l'achat ou la location d'espaces de bureaux dans le parc.

Source : OCDE (2006), site web www.dlsp.com.cn, et entretiens avec des représentants du DLSP. 


\section{Problèmes rencontrés pour répondre à la demande des marchés internationaux}

32. Les sociétés chinoises et étrangères qui fournissent des services de soutien aux entreprises et des STI depuis la Chine se heurtent à un certain nombre de difficultés. La plupart des problèmes que rencontrent les secteurs des services de soutien aux entreprises et des STI et résultent des contraintes qui s'exercent du côté de l'offre. La principale difficulté consiste à recruter un personnel compétent et à parvenir à le retenir, surtout dans le cas des cadres moyens et supérieurs ayant une envergure suffisante pour répondre aux exigences des marchés extérieurs. Un autre problème a trait à la sauvegarde de l'efficience opérationnelle - et notamment aux systèmes de contrôle formel des procédures, des processus et de la qualité - et ce document ne fait qu'évoquer certaines des difficultés propres à la Chine auxquelles sont confrontées les sociétés. Les contraintes réglementaires auxquelles sont soumis les échanges sont relativement peu nombreuses et les entreprises de ces secteurs bénéficient d'un environnement assez ouvert. Cela est en partie dû à des modèles d'entreprise fondés sur la fourniture transfrontières de services et sur l'ouverture aux investissements directs étrangers. La section suivante se penche sur les problèmes fréquemment signalés par les cadres des sociétés en Chine.

\section{Contraintes du côté de l'offre}

\section{Recrutement et rétention du personnel}

33. Les secteurs des services de soutien aux entreprises et des STI ne pas sont pas très intensives en capital mais en main-d'œuvre, et les ressources humaines constituent dès lors un actif essentiel pour chacune des sociétés intéressées. Bien que la Chine forme chaque année un grand nombre de diplômés, le recrutement est aujourd'hui le principal problème pour la plupart des sociétés de service qui opèrent dans ce pays. La taille même du réservoir de compétences dont elle dispose est souvent considérée comme un atout majeur mais les sociétés éprouvent de réelles difficultés à sélectionner, recruter, former, recycler et retenir les membres de leur personnel. La plupart des ingénieurs et des diplômés de l'université ne sont pas en mesure de travailler pour un secteur tourné vers l'exportation où une communication efficace et une bonne interaction avec les clients s'avèrent bien souvent essentielles. La lutte pour s'attacher les services des meilleurs ingénieurs logiciels (dans le secteur des STI) ou des meilleurs diplômés de l'université possédant une formation technique et commerciale (dans le secteur des services de soutien aux entreprises) est acharnée. Les multinationales étrangères sont avantagées car elles peuvent se permettre de verser des primes de salaire aux plus compétents, être propriétaires d'une marque prestigieuse, ou encore offrir la possibilité de travailler à l'étranger avec de nouvelles technologies et sur des projets stimulants. Les sociétés nationales versent généralement des salaires moins élevés mais offrent d'autres avantages à leurs employés.

34. Le recrutement de personnel débutant ne pose pas encore de problème majeur en Chine, même si de considérables investissements devront être consentis dans le domaine de la formation avant que les nouveaux employés ne deviennent productifs. Il n'en va pas de même en ce qui concerne les responsables de projets et les cadres moyens. Les secteurs des services de soutien aux entreprises et des STI en sont encore en Chine à un stade de développement relativement peu avancé, aussi est-il naturel qu'ils éprouvent des difficultés à trouver des personnes possédant des compétences en matière de gestion et ayant une expérience et une expertise suffisantes des missions à mener à bien. Le déficit structurel légué par la Révolution culturelle, qui a radicalement réduit le niveau d'instruction de toute une génération de Chinois, ne contribue guère à améliorer la situation.

35. La pénurie de cadres moyens et supérieurs a de fait freiné la croissance et abouti à une rapide inflation salariale pour ces catégories de personnel (les hausses salariales sont bien plus modestes pour les jeunes professionnels). Certaines sociétés chinoises s'efforcent de remédier à la situation en recrutant des cadres à l'étranger, en particulier au sein de la diaspora chinoise, dont la taille est loin d'être négligeable. 
D'après DeWoskin (2005), environ 60 millions de Chinois vivent hors de Chine et sont non seulement à l'origine de considérables transferts de capitaux et de technologies mais permettent en outre d'entrer en relation avec des réseaux d'affaires d'une importance cruciale.

36. Plusieurs programmes d'action ont été mis en œuvre par le gouvernement chinois en vue d'inciter les universitaires chinois installés à l'étranger à rentrer en Chine. Le document $\mathrm{n}^{\circ} 18 \mathrm{du}$ Conseil des affaires de l'État a ainsi créé un fonds cogéré par le Bureau d'État des experts étrangers et le ministère de l'Éducation en vue d'envoyer des développeurs de logiciels à l'étranger à des fins de formation. A.T. Kearney (2004) fait état des résultats de l'enquête réalisée par la firme Hewitt et associés, qui montrent que les deux tiers des sociétés emploient de nombreux Chinois expatriés et qu'environ la moitié des postes de direction sont occupés par ces derniers. Le manque de cadres moyens et supérieurs contraint également de nombreuses sociétés à former elles-mêmes leurs jeunes professionnels de talent en vue de les promouvoir rapidement à des postes d'encadrement.

37. Un autre problème tient aux taux de rotation des effectifs. ${ }^{18}$ Compte tenu que le pays ne compte que six centres de services tournés vers l'exportation, la concurrence est particulièrement vive à mesure que de plus en plus de sociétés s'installent aux mêmes endroits et sont en concurrence pour recruter du personnel compétent. Dans le secteur des services de soutien aux entreprises, les taux de rotation des effectifs sont élevés - notamment dans le cas des services vocaux - mais même s'ils atteignent $30 \%$, leur niveau demeure moins élevé qu'en Inde et aux Philippines, et sensiblement plus faible que dans bien des pays de l'OCDE. Le secteur des STI souffre également de la rotation des effectifs, mais elle est généralement moindre que dans celui des services de soutien aux entreprises. Pour remédier à cette situation, les sociétés s'attachent de plus en plus à améliorer leurs politiques de gestion des ressources humaines essentielles, par exemple en offrant de claires possibilités d'évolution de carrière, en investissant dans l'éducation et la formation, et en mettant de travail un cadre de travail plus agréable. De nombreuses sociétés transfèrent par ailleurs leurs sites de prestations de services vers des villes plus petites situées en dehors des centres logiciels et technologiques traditionnels, où les salaires sont moins élevés et où leur personnel a moins de risques d'être débauché par des concurrents installés dans leur voisinage immédiat. De plus en plus de sociétés versent en outre des primes liées aux résultats et l'assouplissement des règles de participation au capital des entreprises permettra à un plus grand nombre d'entre elles d'offrir des actions aux membres de leur personnel qui occupent des postes clés.

\section{Encadré 2. Offre de travail en Chine et en Inde}

Les principaux indicateurs éducatifs montrent que la Chine est assez bien placée pour fournir en abondance des personnes compétentes à son industrie des services. D'après Deloitte Research (2006), les taux d'inscription dans l'enseignement supérieur pour la tranche d'âge de 18 à 23 ans est plus de deux fois plus élevé en Chine (15\%) qu'en Inde (7\%). Dans le secondaire, les effectifs par enseignant sont près de moitié moins importants en Chine (18 élèves/enseignant) qu'ils ne le sont en Inde (34 élèves/enseignant). La Chine consacre de même davantage de ressources à la R-D et les taux d'informatisation et de connexion à l'Internet y sont bien plus élevés (voir l'annexe J).

Pour ce qui est de la fourniture de services de soutien aux entreprises et de STI en langue anglaise, l'Inde jouit d'un gros avantage sur la Chine : beaucoup d'Indiens sont bilingues (ou trilingues) et ont l'anglais pour langue maternelle alors que la grande majorité des Chinois sont peu exposés à la langue anglaise. Il suffira cependant d'une seule génération pour que cet écart s'estompe puisque le gouvernement chinois a décrété que tous les enfants chinois devront dorénavant apprendre l'anglais dès l'âge de cinq ans.

\footnotetext{
${ }^{18}$ Associés à de considérables besoins d'investissement dans le domaine de la formation, les taux élevés de rotation des effectifs créent un cercle vicieux dans lequel les incitations à investir dans la formation sont d'autant plus faibles qu'il est moins probable que les salariés restent durablement dans la société.
} 


\section{Maîtrise des langues et sens des affaires internationales}

38. La fourniture de services de soutien aux entreprises et de STI exige souvent une interaction et une communication intensives avec les sociétés clientes. La prestation de services de soutien aux entreprises implique fréquemment une situation de communication en temps réel. La capacité des professionnels des services à bien identifier la tâche à accomplir, résoudre le problème et indiquer quelle est la solution est par conséquent fonction de leurs compétences en matière de communication, de leurs aptitudes techniques et de leur sens des affaires. Les professionnels chinois sont naturellement avantagés par rapport aux étrangers lorsqu'il s'agit de répondre à la demande de leur marché intérieur. Ils se heurtent toutefois à de sérieuses difficultés dès lors qu'ils visent à répondre à la demande de clients étrangers. Ils ont, pour la plupart d'entre eux, des contacts limités avec les étrangers comme avec l'environnement dans lequel opèrent les entreprises étrangères. Les sociétés de services de soutien aux entreprises et de STI s'efforcent de remédier à ce problème en investissant en vue de développer les compétences immatérielles telles que les aptitudes linguistiques ou dans le domaine de la communication, ou encore la sensibilisation culturelle.

39. La Chine a une population relativement importante de langue japonaise et coréenne dans ses provinces du nord-est. Un nombre croissant de multinationales étrangères fournissent des services vocaux de soutien aux entreprises en japonais et en coréen à des clients établis chez les voisins orientaux de la Chine (voir l'encadré 3). La maîtrise des langues de ces pays et une affinité culturelle avec eux permettent de leur fournir plus aisément des services non vocaux de soutien aux entreprises et des technologies de l'information. Bien que le phénomène n'en soit encore qu'aux tous premiers stades de développement, la Chine est dès à présent la principale destination pour la délocalisation des activités en vue de la fourniture transfrontières de services de soutien aux entreprises et de STI au Japon et à la Corée.

40. L'obstacle de la langue est sans doute la raison principale pour laquelle la Chine n'est pas encore devenue un lieu de choix pour la délocalisation des services de soutien aux entreprises et des STI destinés aux sociétés européennes et nord-américaines. Font figure d'exception certaines activités de haut niveau liées à la programmation de logiciels et à la R-D auxquelles les grands nombres de scientifiques et de travailleurs du savoir dont dispose la Chine conviennent particulièrement bien. Il n'en est pas de même en ce qui concerne les langues indo-européennes. Les enfants chinois de la génération actuelle apprennent certes l'anglais dès l'école élémentaire, mais les étudiants qui obtiennent aujourd'hui un diplôme universitaire ont au mieux une connaissance limitée de l'anglais parlé. Ceux qui apprennent l'anglais ont peu d'occasions de le pratiquer. Même lorsqu'ils possèdent le niveau des programmes internationaux de maîtrise de certaines des meilleures universités chinoises, les étudiants savent certes lire l'anglais mais leurs compétences en matière de communication écrite et orale demeurent réduites.

41. Cela commence toutefois à changer, et l'évolution dans ce sens ne pourra que se poursuivre, à mesure que davantage d'étudiants parlant l'anglais seront diplômés dans le futur et qu'un nombre croissant d'étudiants chinois reviendront au pays après avoir obtenu des diplômes et acquis des aptitudes linguistiques à l'étranger. Pour pouvoir répondre à la demande des marchés extérieurs, les sociétés ne devront pas seulement recruter des personnes compétentes et possédant des aptitudes linguistiques : elles devront en outre réaliser de considérables investissements dans le domaine de la formation en vue de permettre à leurs salariés de mieux saisir les nuances linguistiques et de mieux prendre conscience du rôle crucial que joue l'intonation dans l'interaction avec les clients. Ces facteurs sont particulièrement importants pour les activités de vente et de commercialisation à l'étranger.

\section{Problèmes réglementaires}

42. Les problèmes réglementaires sont à la fois liés à l'environnement dans lequel opèrent les entreprises nationales et au cadre réglementaire en place dans les pays clients. Dans les principaux pays clients : Japon, Corée et États-Unis, les sociétés de services de soutien aux entreprises et de STI établies en 
Chine ne se heurtent actuellement qu'à de rares problèmes réglementaires. Les sociétés chinoises qui fournissent des services de soutien aux entreprises en s'appuyant sur le modèle de la prestation de services dans le monde entier, qui repose pour partie sur les mouvements temporaires de personnel entre leur siège et les locaux des clients se heurtent aux mêmes types d'obstacles que ceux que rencontrent les sociétés indiennes en Europe et en Amérique du Nord (voir le chapitre sur l'Inde pour une discussion plus approfondie).${ }^{19}$ Ces obstacles tiennent à la relative imprévisibilité des procédures de délivrance des visas d'affaires et des permis de travail et aux délais nécessaires à leur obtention, qui compliquent la tâche des entreprises et les exposent à un risque accru.

43. Jusqu'à présent, rares sont les sociétés chinoises qui envoient du personnel dans les pays clients. Aussi, quoique bien réel, le problème se limite-t-il aux sociétés qui s'appuient sur un modèle de fourniture dans le monde entier comportant une part importante de prestations sur place. D'autant plus que les professionnels chinois ne se heurtent pas à ce type de problèmes dans leurs relations avec le Japon et la Corée, pays qui absorbent par ailleurs la plus grande partie des exportations de services de la Chine. Les multinationales étrangères qui opèrent en Chine peuvent détacher leurs salariés en recourant à des permis de travail intra-entreprise qu'il est plus aisé d'obtenir et dont la délivrance est moins tributaire du bon vouloir des autorités compétentes.

44. Les sociétés de la zone de l'OCDE jugent par ailleurs que la situation est assez positive en Chine pour ce qui est des problèmes réglementaires, d'autant plus que les parcs logiciels et technologiques qui accueillent la quasi totalité des sociétés sous contrôle étranger offrent aux entreprises un environnement d'exception caractérisé par une administration rationalisée, des équipements de grande qualité, ainsi que par l'octroi d'incitations financières. Ces parcs logiciels et technologiques sont pour elles un soulagement, étant donné que la procédure de création d'une filiale en Chine est assez longue et fastidieuse et que certains autres problèmes se posent par ailleurs (voir l'annexe C).

\section{Encadré 3. Les sociétés indiennes investissent de plus en plus en Chine}

Au terme d'une longue période de réflexion et d'évaluation, les secteurs indiens des services de soutien aux entreprises et des STI ont décidé de ne plus considérer la Chine comme un dangereux concurrent mais comme un débouché potentiel. Les principales sociétés indiennes Satyam Computer Systems, TCS et Infosys Technologies ont toutes créé des succursales en Chine en 2002-03. À l'automne 2006, ces sociétés employaient quelque 400 à 600 professionnels chinois dans leurs centres de développement en Chine. Elles prévoient cependant de multiplier par dix d'ici la fin de la décennie leurs effectifs présents en Chine. Une grande partie de ces effectifs auront pour mission de répondre à la demande de clients établis au Japon et en Corée, pays voisins de la Chine.

Les sociétés étrangères/indiennes peuvent tirer parti de la Chine de trois grandes façons. Premièrement, certaines sociétés prennent actuellement pour cible son marché intérieur en rapide expansion, sur lequel sont présentes des multinationales locales et étrangères. Quelque $80 \%$ des sociétés figurant parmi les 500 d'entre elles qui réalisent d'après le magazine Fortune le plus gros chiffre d'affaires mènent à bien des activités en Chine. La concurrence est acharnée mais les nouveaux créneaux spécialisés tels que celui des services d'ingénierie offrent actuellement de nouvelles perspectives de croissance. L'accession de la Chine à l'OMC et la libéralisation du secteur bancaire soumettront les banques nationales à des pressions pour qu'elles accroissent leur productivité et il devrait en résulter un développement du marché intérieur des services de soutien aux entreprises et des STI. Deuxièmement, la Chine s'impose tout naturellement comme le lieu privilégié de délocalisation des activités des sociétés désireuses de se rapprocher du Japon, de la Corée et des pays de la région Asie-Pacifique en vue de répondre à la demande de leurs marchés. Troisièmement, ces sociétés développeront à termes leurs capacités à se servir également de leurs succursales chinoises pour répondre à la demande de leurs clients établis dans d'autres pays que ceux du nord-est asiatique.

Source : OutsourcingWorld et Vandrevala (2006)

${ }^{19}$ Les sociétés ont souvent besoin d'envoyer leurs salariés dans les locaux de leurs clients aux fins de négociation, de familiarisation, de transfert d'informations, de supervision, de mise en œuvre et de maintenance des solutions informatiques et des logiciels. 
45. Le système judiciaire chinois est réputé imprévisible et le recours aux voies de droit est jugé coûteux. La plupart des contrats sont directement signés dans le pays client, de sorte que les litiges potentiels puissent être réglés conformément à la jurisprudence en vigueur dans celui-ci. Les sociétés étrangères font généralement appel aux services de grands cabinets de conseillers pour la création de leurs filiales en Chine, car la procédure peut être particulièrement longue et exiger des négociations avec de nombreux organismes publics.

46. En vertu de la liste d'engagements spécifiques auxquels elle a souscrit dans le cadre de l'AGCS en ce qui concerne les "services informatiques et services connexes", la Chine n'impose aucune restriction à l'accès aux marchés ou au traitement national pour les modes de fourniture 1 à 3 de "services de consultation en matière d'installation des matériels informatiques", de "services de traitement de données", de "services de préparation des données d'entrée", de "services de traitement et de tabulation des données", de "services de traitement en temps partagé" et de "services de conseil en gestion". Les restrictions au mode 4 sont liées aux niveaux d'instruction et d'expérience professionnelle. Pour les "services de réalisation de logiciels", les "services de consultation en matière de systèmes et de logiciels", les "services d'analyse de systèmes", les "services de conception de systèmes", les "services de programmation" et les "services de maintenance de systèmes", l'accès aux marchés n'est autorisé que sous la forme de coentreprises, au capital desquelles les partenaires étrangers peuvent toutefois détenir une participation majoritaire (OMC, 2002). L'industrie étrangère avait précédemment demandé que ces restrictions soient levées (USITO, 2003).

47. Cependant, contrairement à ce qui se produit dans bien d'autres secteurs de services (tels que celui des télécommunications) en Chine, les sociétés de services de soutien aux entreprises et de STI consultées en vue de la réalisation de la présente étude n'ont pas le sentiment que les réglementations relatives à la composition du capital des sociétés aient pour effet de restreindre leurs activités. La composition du capital a des conséquences bien plus importantes dans le cas des marchés publics : les sociétés étrangères se trouvent désavantagées par les procédures d'appel d'offres lancées par les organismes et les entreprises du secteur public. Il faut toutefois bien reconnaître que la situation est similaire dans les autres pays étudiés dans le présent rapport et que les sociétés chinoises se trouvent ellesmêmes désavantagées lorsqu'elles soumissionnent aux appels d'offres à l'étranger.

48. Les violations des droits de propriété intellectuelle (DPI) en Chine, et notamment celles des brevets, des marques déposées et des droits d'auteur, sont une importante source de préoccupation. Il est facile d'acheter au marché noir des versions piratées des logiciels d'entreprise ou de ceux destinés au grand public. Ces violations de la propriété intellectuelle n'affectent toutefois pas nécessairement les secteurs des services de soutien aux entreprises et des STI, et les sociétés confrontées à ce problème adoptent une approche relativement pragmatique pour y faire face en Chine. La plupart des applications et même des solutions logicielles sont difficiles à pirater lorsqu'elles sont conçues sur mesure pour les sociétés clientes. Les DPI n'ont dans la plupart des cas aucune incidence sur la fourniture de services dans les secteurs qui nous intéressent ici. Les experts de l'industrie estiment qu'en Chine le cadre juridique approprié est dans une large mesure en place mais que son application n'est pas nécessairement aussi stricte qu'elle pourrait l'être.

49. Les investisseurs étrangers sont un peu moins inquiets depuis l'accession de la Chine à l'OMC, qui les protège en vertu de l'Accord sur les aspects des droits de propriété intellectuelle qui touchent au commerce (ADPIC). ${ }^{20}$ Le document $\mathrm{n}^{\circ} 18$ du Conseil des affaires de l'État prévoit également une

\footnotetext{
${ }^{20}$ L'accession à l'OMC a également eu pour effet d'ouvrir aux investisseurs étrangers le marché chinois des services de télécommunications, d'abaisser les droits de douane en vertu de l'Accord sur les technologies de l'information (ATI), de bannir les exigences en matière de transfert de technologies ou de contenu local, et de garantir le traitement national pour ce qui est de la fiscalité interne (Rohlmeier et al., 2003).
} 
répression sévère du piratage. Le gouvernement chinois a redoublé d'efforts pour combattre les violations de la propriété intellectuelle parallèlement à la campagne qu'il a lancée en vue d'encourager l'innovation nationale - laquelle est elle-même très largement tributaire du respect effectif des DPI. Les efforts pour résoudre les problèmes de propriété intellectuelle sont dans une certaine mesure fonction du modèle d'entreprise adopté en Chine par les sociétés étrangères. L'unité captive, la coentreprise et le recours à des prestataires externes présentent chacun leurs propres avantages tant du point de vue du contrôle que de la sécurité (pour plus de précisions, voir A.T. Kearney, 2004).

50. Les réglementations relatives à la confidentialité et à la sécurité des données revêtent une importance particulière dans le secteur des services de soutien aux entreprises. Rares sont celles qui font obstacle aux échanges, et les clients exigent qui externalisent certaines parties de leurs chaînes de valeur ou certaines de leurs activités exigent le respect des normes les plus strictes en matière de sécurité et de confidentialité des données. Les sociétés rivalisent d'efforts pour mettre en place l'infrastructure et les processus d'entreprise qui leur permettront de travailler dans le respect de ces normes, afin de gagner ce faisant de nouvelles parts de marché. Certaines réglementations risquent certes d'accroître les obstacles à l'entrée auxquels se heurtent les fournisseurs mais elles ne sont généralement pas appliquées de façon discriminatoire (voir le chapitre sur l'Inde pour plus de précisions sur cette question). 


\section{LES SECTEURS TCHÈQUES DES SERVICES DE SOUTIEN AUX ENTREPRISES ET DES STI}

51. La République tchèque est considérée comme un des lieux les plus attractifs d'Europe centrale et orientale pour la fourniture internationale de services de soutien aux entreprises et de STI. C'est également l'un des plus attractifs au monde. Le pays présente plusieurs avantages du point de vue de la fourniture de services de soutien aux entreprises et de STI en Europe. Parmi ses principaux atouts figurent sa proximité géographique et culturelle à l'égard des vastes marchés d'Europe occidentale, sa main-d'œuvre bien formée qui possède une bonne maîtrise des langues et dont la productivité est relativement élevée par rapport à son coût, la puissance traditionnelle de son secteur de l'ingénierie, ainsi que son infrastructure bien développée. Les sociétés de services étrangères s'attachent également à répondre à la demande croissante du marché intérieur et les expatriés étrangers aiment Prague pour sa grande qualité de vie. Depuis mai 2004, la République tchèque est membre de 1'UE, ce qui facilite la circulation du personnel du secteur des services au sein du marché intérieur, garantit l'harmonisation des lois et réglementations nationales avec celles des autres pays de l'UE - notamment en matière de confidentialité et de sécurité des données - et assure un accès illimité au marché européen.

52. A.T. Kearney (2006) classe la République tchèque au $7^{\text {ème }}$ rang des zones géographiques les plus attractives pour la fourniture de services de soutien aux entreprises et de STI (voir l'annexe H). Le pays obtient une note particulièrement élevée pour l'environnement qu'il offre aux entreprises, qui se caractérise par un faible risque pays, une infrastructure bien développée et une grande adaptabilité culturelle. Il figure également en bonne place dans les comparaisons internationales sous l'angle de la qualité de l'éducation, de la maîtrise des langues et des taux de rotation des effectifs. Ses principales faiblesses tiennent au nombre limité de jeunes actifs ayant reçu une formation technique et au manque d'expérience de l'industrie nationale en matière de fourniture de services de soutien aux entreprises et de STI à l'extérieur des frontières nationales. De surcroît, les coûts de main-d'œuvre sont sensiblement plus importants que dans beaucoup d'autres économies émergentes dotés de capacités comparables. Les salaires versés dans les secteurs des services de soutien aux entreprises et des STI sont de 100 à $150 \%$ plus élevés en République tchèque qu'en Chine et en Inde, et de 60 à 100\% plus élevés qu'aux Philippines (voir l'annexe D). Les coûts de main-d'œuvre ne constituent pas le facteur décisif pour les investisseurs étrangers en République tchèque.

53. D'après l'EIU (2005), la République tchèque est la destination la plus attractive d'Europe pour la délocalisation des activités et se classe au troisième rang des économies émergentes de ce point de vue, derrière l'Inde et la Chine. ${ }^{21}$ Son attractivité tient à ses coûts de main-d'œuvre relativement faibles, à un cadre réglementaire favorable et à sa proximité - culturelle et historique - des marchés d'Europe occidentale. Le degré d'instruction de sa population active distingue la République tchèque de la Pologne et de la Slovaquie, dont la place dans le classement est très proche de la sienne. L'indice d'attractivité pour la délocalisation des STI établi par le cabinet de conseil neoIT classe la République tchèque au $6^{\text {ème }}$ rang, derrière des pays tels l'Inde ou la Chine qui sont mieux placés du fait de la plus grande maturité de leur

${ }^{21}$ Le modèle d'évaluation appliqué par l'EIU montre également que les pays à revenu élevé tels que le Canada, Singapour et Hong Kong figurent parmi les sept destinations les plus attractives pour la délocalisation des activités du fait de leur main-d'œuvre qualifiée, de leur infrastructure de qualité, ainsi que du cadre réglementaire qu'ils ont mis en place. 
industrie, mais devant les Philippines (voir les annexes F-G). Pour ce qui est de la fourniture internationale de services de soutien aux entreprises, la République tchèque se classe au $7^{\text {ème }}$ rang derrière l'Inde et les Philippines mais devant la Chine. Dans l'un et l'autre cas, la Pologne et l'Irlande sont un peu mieux classées que la République tchèque, ce qui met en évidence que les avantages comparatifs des différents pays varient selon les services de soutien aux entreprises et des technologies de l'information considérés.

\section{Caractéristiques du marché}

54. D'après la société IDC (2006b), le chiffre d'affaires total du secteur tchèque des STI s'est élevé en 2005 à 1.15 milliard de dollars des États-Unis et le marché a enregistré une croissance d'environ 10\% par an. L'augmentation des dépenses de services extérieurs est imputable à une externalisation des activités au sein même du pays qui est en progression quoique par rapport à un niveau de départ assez faible, tout comme aux marchés publics et aux nouvelles créations de centres de services partagés par les multinationales étrangères. Le marché intérieur s'avère de plus en plus attractif pour les fournisseurs nationaux aussi bien que pour les étrangers. En 2005, les services d'installation et d'assistance matérielle et logicielle composaient $28 \%$ du marché, l'intégration de systèmes $22 \%$, l'adaptation aux besoins des clients $23 \%$ et l'externalisation des activités $15 \%$. Les principaux secteurs d'activité des clients étaient celui des finances ( $26 \%$ du marché), celui des industries manufacturières considérées dans leur ensemble $(16 \%)$ et celui des administrations publiques $(14 \%)$.

55. Les dix principales sociétés de STI s'adjugent 38\% du marché et sept d'entre elles - dont les six premières - sont des filiales de multinationales étrangères (voir l'annexe K). Quelques grandes sociétés étrangères sont en situation dominante dans le secteur des marchés publics. Les sociétés nationales sont en position de force dans certains créneaux spécialisés du marché des STI : Unicorn est ainsi le numéro un du développement d'applications douanières, alors que AutoCont $\mathrm{CZ}$ et ČEZData sont les leaders du marché dans le domaine des réseaux et de l'informatique de bureau. Les recettes ne proviennent ont toutefois pas tant des exportations que des ventes aux clients établis au sein même du pays.

56. À ce jour, les secteurs nationaux des services de soutien aux entreprises et des STI n'ont pas encore atteint la taille critique en République tchèque, pas plus qu'ils n'ont établi une présence significative dans les pays clients. McKinsey (2006) affirme que cet état de fait est dû aux débouchés commerciaux de plus en plus importants qui s'offrent au sein même du pays, aux réglementations en vigueur et aux incohérences dont souffre le droit du travail et qui compliquent l'expansion de la présence étrangère, ainsi qu'à la relative lenteur avec laquelle les sociétés d'Europe centrale et orientale ont commencé à avoir recours à la délocalisation internationale. La prestation internationale de services de soutien aux entreprises et de STI en provenance de la République tchèque est principalement assurée par un nombre limité de multinationales étrangères qui opèrent pour l'essentiel dans le secteur des TI et fournissent des services à leurs clients européens depuis des centres de services partagés. La République tchèque n'est traditionnellement pas tant une destination pour la délocalisation internationale des activités dans laquelle des services faisant l'objet d'une sous-traitance interne ou externe à l'étranger seraient fournis à des clients établis dans des pays éloignés qu'une destination pour la délocalisation de proximité dans laquelle les services font l'objet d'une sous-traitance interne à l'étranger en vue d'être exportés vers d'autres pays européens.

57. McKinsey (2006) estime que la valeur totale du marché mondial des services de soutien aux entreprises et des technologies de l'information délocalisés à l'étranger s'élève à environ 30 milliards de dollars des États-Unis et que l'Europe orientale en fournit moins de un pour cent. En 2004, la République tchèque a exporté pour environ 60 millions de dollars des États-Unis de STI, contre 26 millions ${ }^{22}$ 1'année

\footnotetext{
${ }^{22}$ Cette estimation tient compte des sociétés nationales de STI et des multinationales qui mènent à bien des activités de prestation de services en République tchèque.
} 
précédente, et pour 40 millions de dollars des États-Unis de services de soutien au entreprises, contre 15 millions en 2003 (Vashistha et al. 2005; neoIT, 2004). Ces chiffres montrent que l'industrie a tendance à se développer, quoique par rapport à un niveau de départ relativement modeste, et demeure soucieuse de répondre à la demande du marché intérieur. Comme en Chine, les secteurs des services de soutien aux entreprises et des STI de la République tchèque n'ont encore qu'un degré de maturité relativement faible et s'efforcent de développer leurs capacités pour se tourner à l'avenir vers une clientèle plus internationale.

58. D'après les résultats d'une enquête réalisée en 2005 auprès de 52 des 150 sociétés qui fournissent des services délocalisés des technologies de l'information en République tchèque, la plupart de ces sociétés sont établies à Prague mais les villes de second rang telles qu'Ostrava, Plzen et Brno gagnent en importance du fait qu'elles permettent d'avoir accès aux diplômés issus de leurs universités techniques respectives et que les coûts de main-d'œuvre y sont moins élevés et ne représentent que de 70 à $80 \%$ des salaires versés à Prague (IT Outsourcing Center, 2005). L'Allemagne, l'Autriche et la Slovaquie voisines étaient les principaux marchés d'exportation des sociétés couvertes par cette enquête. Le Royaume-Uni, l'Allemagne et l'Autriche étaient quant à eux les principaux marchés pour les services de soutien aux entreprises. Parmi les autres pays clients figurent le Canada, les États-Unis et les pays nordiques.

\section{Délocalisation de proximité}

59. La délocalisation de proximité est un processus dans lequel un pays particulier est choisi pour répondre à la demande des pays situés à grande proximité d'un point de vue géographique du fait qu'il combine avantageusement un certain nombre de conditions favorables sur le plan des coûts de maind'œuvre, de l'accès à un personnel compétent, de la proximité culturelle, etc. ${ }^{23}$ La République tchèque est en passe de s'imposer comme une destination de choix pour la délocalisation de proximité auprès des multinationales désireuses de regrouper leurs activités de back office et d'assistance dans le domaine des TI dans des centres de services partagés en vue de répondre à la demande des pays d'Europe continentale. ${ }^{24}$ Les pays d'Europe centrale et orientale sont en train de se hisser tout en haut de la liste des destinations potentielles pour les multinationales qui cherchent à réduire leurs coûts de fourniture de services de soutien aux entreprises et de STI aux marchés d'Europe mais ne veulent pas pour autant supporter les risques liés à une délocalisation vers l'Asie.

60. DHL est l'un des principaux investisseurs dans les secteurs des services de soutien aux entreprises et des STI en République tchèque. Cette société gère en effet à Prague un grand centre de services partagés en vue de suivre les transactions et de traiter la facturation de sa clientèle européenne (voir l'encadré 5). IBM possède un effectif fort de 1200 personnes dans son Centre de services intégrés (Integrated Delivery Centre) de Brno, conformément à sa stratégie de fourniture dans le monde entier. Accenture dispose pour sa part de 1250 professionnels des services dans son centre de services partagés de Prague, qui a pour rôle de fournir des solutions d'entreprise à ses clients européens, par exemple dans le domaine des finances et de la comptabilité (IDC, 2006). Parmi les autres exemples de centres partagés - ou de délocalisation de proximité - figurent ceux d'ExxonMobil (centre de services financiers et comptables partagés), de Hewlett-Packard (siège régional pour l'Europe, le Moyen-Orient et l'Afrique), d'Icon Communication Centers (centre de contact avec la clientèle), de la Lufthansa (centre de traitement de données), de Siemens (centre de services financiers et comptables partagés), de Symbol Technologies

\footnotetext{
${ }^{23}$ La main-d'œuvre tchèque est trop coûteuse et trop peu nombreuse pour que le pays puisse accueillir des activités délocalisées destinées à répondre à la demande des marchés non européens.

${ }^{24}$ Parmi les autres pays où sont fréquemment établis les centres de services partagés figurent notamment l'Irlande, la Hongrie, la Slovaquie et la Roumanie.
} 
(centre de services partagés et de services financiers) et de Tesco Stores (centre de services partagés dans le domaine des TI, des finances et de la comptabilité). ${ }^{25}$

61. Les principales sociétés indiennes de services de soutien aux entreprises et de STI ont également commencé à investir dans des centres de développement en Europe, et plus particulièrement en Europe orientale. Le modèle de fourniture dans le monde entier que l'industrie indienne de la délocalisation des activités de services a été la première à mettre en pratique n'est pas le mieux adapté aux besoins de bon nombre de clients étrangers et il est souvent plus facile et plus efficace de répondre à la demande de la clientèle européenne depuis la République tchèque. Progeon, une filiale d'Infosys Technologies, a été le premier investissement réalisé en République tchèque par l'industrie indienne dans le domaine des TI. La société dispose de 100 professionnels qui assurent des services d'assistance dans le domaine des TI depuis son bureau de Prague et de 100 autres professionnels qui fournissent des services de soutien aux entreprises depuis son bureau de Brno. La société prévoit de porter dans un proche avenir à 1000 personnes ses effectifs en République tchèque. ${ }^{26}$

\section{Encadré 4. Répondre depuis la République tchèque à la demande des clients européens}

À la suite de la fusion de DHL, de Danzas et de Deutsche Port Euro Express en avril 2003, le nouveau DHL, dont le siège social est à Bonn, a décidé d'établir trois centres mondiaux de services dans le domaine des TI afin de répondre $24 \mathrm{~h} / 24 \mathrm{~h}$, sept jours sur sept et 365 jours par an aux besoins en la matière de ses 120000 clients, qui expédient plus d'un milliard de colis par an. Prague a été choisie pour accueillir le centre européen, qui devait se substituer aux unités plus petites établies en Suisse et au Royaume-Uni, les deux autres centres mondiaux de services dans le domaine des TI étant implantés à Scottsdale et à Kuala Lumpur. Ces centres situés en République tchèque, aux États-Unis et en Malaisie sont reliés entre eux par un réseau de télécommunications interne à l'entreprise et ils apportent un appui aux activités de courrier, de livraison express et de logistique de DHL dans le monde.

Le centre de Prague était pleinement opérationnel dès janvier 2005 et DHL prévoit d'investir 500 millions d'euros sur une période de cinq ans dans ses activités dans la capitale tchèque. Dès 2008, le centre de Prague devrait compter environ 2000 salariés. D’après le responsable du service informatique de DHL, la République tchèque a été choisie pour sa main-d'œuvre qualifiée et flexible, ses réseaux de télécommunications fiables et éprouvés, ses bonnes liaisons aériennes, ainsi que pour les mesures d'incitation optimales offertes par le gouvernement tchèque. DHL espère que ce projet lui permettra de réduire de $60 \%$ le budget de 1 milliard de dollars des États-Unis consacré par la société aux TI, et le regroupement des services de soutien dans ces centres a déjà accru la productivité de $20 \%$.

Sources : Czech Focus (2005), EIU (2006) et McCue (2004).

62. Le recours croissant à la délocalisation de proximité pour les activités de prestation de services s'explique par le fait qu'il est plus aisé de répondre à la demande des clients étrangers depuis une zone géographique située à plus grande proximité. D'après DiamondCluster (2005), le degré de satisfaction des clients pour ce qui est de la délocalisation vers des pays lointains est tombé recemment. La complexité de gestion a un effet de dissuasion non négligeable. La proximité culturelle a une grande incidence sur la communication et des décalages horaires importants constituent un handicap pour certains types de services. Pour les PME, la délocalisation de proximité est souvent la seule alternative viable au maintien des activités dans le pays d'origine, en raison des frais généraux de gestion et des risques opérationnels liés à la délocalisation vers des destinations plus éloignées. À l'instar de la République tchèque, les destinations retenues pour la délocalisation de proximité offrent un avantage supplémentaire dans la mesure où elles

\footnotetext{
${ }^{25}$ D'après le site web www.czechinvest.org.

${ }^{26}$ D’après CzechInvest.
} 
permettent que les données sensibles demeurent soumises à un cadre réglementaire similaire à celui en vigueur dans le pays d'origine du client.

63. La République tchèque s'attache à attirer les mêmes entreprises étrangères que les autres pays d'Europe orientale avec lesquels elle est en concurrence, tels que la Hongrie, la Slovaquie, la Pologne et la Roumanie. Tous ces pays sont jusqu'à présent parvenus à drainer une bonne partie des investissements internationaux. Ils n'ont par contre pas encore clairement différencié leurs capacités dans le domaine des services. Ces différents pays ont des atouts et des faiblesses similaires et tant les responsables publics que les entreprises mettent tout en œuvre pour obtenir une aussi grande part que possible des investissements dans l'espoir que les multinationales étrangères établiront des centres de services susceptibles d'entraîner des retombées technologiques et des transferts de savoir-faire en matière de gestion dont l'industrie nationale pourra à terme tirer parti.

\section{Efforts du gouvernement tchèque pour attirer les investissements directs étrangers}

64. Le gouvernement tchèque fournit des incitations à l'investissement par l'intermédiaire de l'agence CzechInvest et l'agence a fait du secteur des services de soutien aux entreprises une de ses principales priorités. En vertu du décret gouvernemental n ${ }^{\circ} 1238$ du 10 décembre 2003, qui met en place le Programme-cadre d'appui aux centres de technologie et aux centres de services de soutien aux entreprises, peuvent bénéficier d'une aide les investisseurs étrangers qui établissent leurs sièges sociaux, leurs centres de développement de logiciels ou leurs centres de solutions expertes dans le pays et qui investissent au moins 0.5 million d'euros, créent au moins 15 emplois nouveaux d'une durée minimale d'existence égale à cinq ans et exportent au moins $50 \%$ des services qu'ils fournissent. Dans le cas des centres d'appel, des centres de réparation high-tech et des centres de services partagés, ils doivent investir au moins 1 million d'euros et créer au moins 50 emplois nouveaux. Les sociétés sont également tenues de financer sur leurs fonds propres au moins 0.25 à 0.5 million d'euros (CzechInvest, 2006). Les incitations prennent la forme de subventions pour :

- les activités commerciales : jusqu'à 50\% des dépenses éligibles des entreprises (dépenses salariales ou d'investissement dans les actifs corporels et incorporels) sont financées pendant une durée maximale de dix ans, dans les limites du montant maximal des aides publiques ; et

- la formation et le recyclage : jusqu'à $35 \%$ (30\% à Prague) du coût des formations spécifiques et $60 \%$ (55\% à Prague) de celui des formations générales sont financés pendant une période de 3 à 5 ans, en fonction du nombre d'emplois créés. ${ }^{27}$ Le montant maximal des subventions au titre de la formation est de 100000 à 150000 CZK par salarié.

65. Les plafonds maximaux applicables aux aides d'État au cours de la période 2007-2013 n'avaient pas encore été négociés au moment de la rédaction du présent rapport, mais il est probable qu'ils soient ramenés de $20-50 \%$ à $10-40 \%$, selon la région où est effectué l'investissement. Entre juin 2001 et le 16 novembre 2006, pas moins de 90 sociétés ont obtenu que CzechInvest approuve le versement d'un soutien financier en leur faveur. Ces sociétés se sont en contrepartie engagées à investir 492 millions d'euros et à créer 14872 emplois. La majorité des emplois s'adressent à des diplômés de l'université. Les graphiques 2 et 3 indiquent le pays d'origine des sociétés qui ont établi des centres de services en République tchèque, ainsi que le pourcentage des créations d'emplois imputables à ces différents investissements. Abstraction faite des $10 \%$ de créations d'emplois attribuables aux sociétés tchèques, les investissements les plus

\footnotetext{
${ }^{27}$ Par "formations spécifiques" il faut entendre celles qui permettent aux salariés d'acquérir des connaissances et des compétences spécifiques à un projet et qui ne sont pas aisément transférables à d'autres entreprises. Par "formations générales" il faut par contre entendre celles qui permettent aux salariés d'acquérir des connaissances et des compétences d'ordre général non spécifiques à un projet.
} 
intensifs en main-d'œuvre ont été effectués par les sociétés des autres pays membres de l'UE (57\%), par les sociétés américaines $(22 \%)$ et par les sociétés indiennes $(7 \%)$.

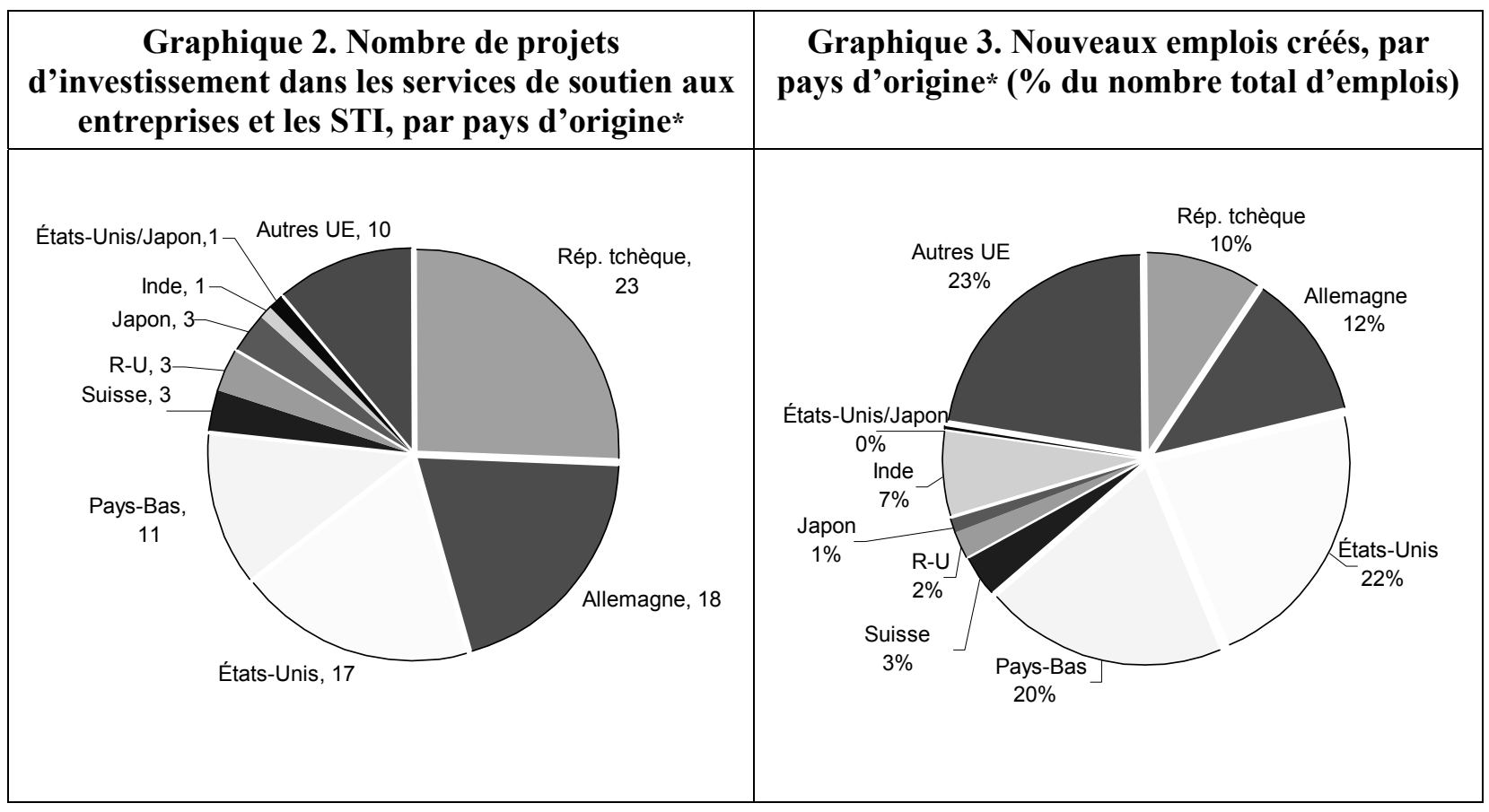

* Pays d'origine : siège social de l'actionnaire majoritaire

Source : CzechInvest

66. L'"Alliance tchèque des technologies de l'information et de la communication" (Czech ICT Alliance) a été fondée en décembre 2005 avec le soutien de l'agence CzechInvest en vue d'aider à améliorer l'image internationale de l'industrie des TIC tchèque. Face à un environnement commercial international de plus en plus concurrentiel, il est essentiel de renforcer la notoriété des secteurs tchèques des services de soutien aux entreprises et des STI, et la République tchèque doit encore se différencier des pays voisins. La principale raison pour laquelle les mesures d'incitation mises en œuvre par les pouvoirs publics sont jugées importantes en Europe centrale et orientale tient au fait que les différents pays présentent des profils assez similaires. Le financement par le gouvernement de programmes plus généreux peut faire la différence au moment où les investisseurs étrangers décident du lieu d'implantation des centres de services partagés dans la région. La situation n'est pas la même en Chine, en Inde ou aux Philippines, car leurs profils sont sensiblement différents et leurs coûts structurellement plus faibles.

67. Le gouvernement tchèque accorde son appui aux secteurs des services de soutien aux entreprises et des STI, mais sa politique d'achats publics pourrait être largement améliorée. Les marchés publics sont dominés par quelques grandes sociétés et divers observateurs estiment que la procédure de passation des marchés pourrait être nettement plus ouverte et transparente. ${ }^{28}$ Les résultats d'enquête publiés par la Banque mondiale (2006) montrent que le pourcentage de sociétés qui déclarent que la corruption est un problème qui entrave aussi bien leurs activités que la croissance économique de la République tchèque a spectaculairement augmenté. Entre 2002 et 2005, ce pourcentage est passé de $28 \%$ à $49 \%$. Cette situation est bien pire qu'en Slovaquie, en Pologne et en Bulgarie, qui enregistrent une évolution en sens inverse.

${ }^{28}$ Les problèmes de corruption et de transparence ont été évoqués au cours de plusieurs des entretiens et la société IDC (2006b) estime qu'ils n'auront à moyen terme qu'une incidence négative modérée sur le marché. 


\section{Problèmes rencontrés pour répondre à la demande des marchés internationaux}

68. Les problèmes auxquels se heurtent les secteurs des services de soutien aux entreprises et des STI dans leur effort pour répondre à la demande des marchés internationaux sont dans une large mesure liés aux difficultés opérationnelles que rencontrent toutes les industries naissantes qui commencent à se tourner vers les marchés étrangers. Du côté de l'offre, ces problèmes ont trait au recrutement de professionnels techniquement compétents et de cadres expérimentés maîtrisant les langues étrangères, au renforcement de l'expertise du domaine considéré, à l'accroissement de la productivité et à la gestion de la complexité sur un marché de plus en plus international. Du côté de la demande, les principaux problèmes consistent à développer les circuits de vente et de commercialisation à l'étranger et à faire de façon générale mieux connaître les avantages qu'offre la République tchèque pour la fourniture de services de soutien aux entreprises et de STI. Bien que les exportations tchèques demeurent relativement modestes dans l'un et l'autre domaines, le pays a potentiellement les moyens d'attirer d'importants volumes d'activités délocalisées par des sociétés étrangères et le gouvernement tchèque espère que les secteurs des services de soutien aux entreprises et des STI contribueront à réduire la forte dépendance de l'économie à l'égard des exportations de biens manufacturés (voir l'annexe I).

69. Une enquête réalisée par le "Centre pour l'externalisation des technologies de l'information" (IT Outsourcing Center) en 2005 a mis en évidence deux problèmes qui affectent le secteur des services de la République tchèque. Il s'agit en premier lieu de la pénurie de personnel technique : le nombre de diplômés de l'université est relativement faible et certains ingénieurs logiciels partent à l'étranger. En second lieu, l'efficacité par rapport aux coûts des secteurs tchèques des services de soutien aux entreprises et des STI est réduite par l'inflation salariale, par la fiscalité ainsi que par les pesanteurs administratives. D'après CzechInvest (2004) et le ministère de l'Informatique de la République tchèque (2006), les sociétés tchèques de services de soutien aux entreprises et de STI souffrent de leur incapacité à se vendre efficacement à l'étranger et tendent à être extrêmement tributaires de leurs compétences techniques. L'industrie aurait tout intérêt à ce que sa main-d'œuvre maîtrise mieux l'allemand et l'anglais, à développer une plus grande culture de service et à assurer une meilleure protection des DPI. Les PME éprouvent par ailleurs des difficultés à faire appel au marché des capitaux : Cermak et al. (2006) affirment ainsi que l'accès au crédit s'est amélioré à la suite de la privatisation de l'industrie bancaire tchèque mais que les possibilités d'emprunt des PME demeurent néanmoins limitées. Ces faiblesses mettent la République tchèque dans une situation délicate dans laquelle les services de valeur élevée sont principalement fournis par des sociétés occidentales alors que celles d'Europe orientale renforcent actuellement leurs capacités et se montrent de plus en plus compétitives au niveau des coûts sur les mêmes marchés extérieurs que l'industrie tchèque.

70. Les avantages dont jouit le pays sur le plan des coûts de main-d'œuvre ne devraient pas s'avérer durables à long terme et les futurs pays adhérents à l'UE, à savoir la Bulgarie et la Roumanie, ne feront sans doute qu'intensifier la concurrence, en particulier à l'extrémité inférieure de la chaine de valeur du secteur des services. L'Ukraine pourrait elle aussi s'imposer comme une destination à bas coût pour les services de soutien aux entreprises et les STI et finir par faire de l'ombre à la République tchèque. Les sociétés chinoises, indiennes et philippines étudiées dans ce rapport ne concurrencent pas directement l'industrie tchèque car elles ne s'adressent pas au même secteur d'activité.

71. Certains des services de soutien aux entreprises et des STI actuellement fournis en République tchèque migreront probablement vers l'est au cours de la prochaine décennie du fait des écarts de coûts de main-d'œuvre. Face à la concurrence de plus en plus vive que lui livrent ses voisins orientaux, à savoir la Hongrie, la Slovaquie, la Pologne et la Roumanie, mais aussi l'Ukraine et la Russie, qui ne sont pas membres de l'UE, la République tchèque devra tenter de se rapprocher de l'extrémité supérieure de la chaîne de valeur et de trouver des créneaux spécialisés qui lui permettent de s'imposer parmi les meilleurs dans certains domaines ou secteurs d'expertise technique particuliers. L'industrie tchèque pourrait avoir 
intérêt à ce que les sociétés implantées plus à l'est développent leurs activités si elle se montre à même de développer un modèle d'entreprise qui lui permette de tirer parti des capacités de ces pays. Les sociétés tchèques pourraient par exemple avoir recours à une délocalisation interne ou externe d'une partie de leurs activités vers ces pays. Pour devenir un partenaire plus attractif pour la clientèle internationale, l'industrie tchèque devra de plus en plus se focaliser sur le contrôle de la maturité et de la qualité des processus (ainsi que sur l'obtention de certifications ISO ou SEI CMMi, par exemple) et mettre en place des circuits efficaces de vente et de commercialisation à l'étranger.

\section{Contraintes du côté de l'offre}

\section{Recrutement et rétention du personnel}

72. Le système éducatif tchèque - et plus particulièrement ses universités technologiques - est un des atouts intrinsèques du pays et constitue un facteur décisif pour l'implantation de nouvelles sociétés de STI. Le pourcentage de la population tchèque âgée de vingt à trente ans ayant achevé le deuxième cycle de l'enseignement secondaire s'élève à $92 \%$ (contre une moyenne de $69 \%$ pour l'ensemble de l'UE) et environ $30 \%$ des étudiants de l'enseignement supérieur poursuivent des études dans le domaine des sciences, de l'ingénierie, des industries manufacturières ou de la construction (voir l'annexe J). Ce pourcentage est plus élevé que dans bien d'autres économies émergentes et la République tchèque est d'après l'étude PISA de l'OCDE le pays d'Europe centrale et orientale où l'enseignement en mathématiques et en sciences est de plus grande qualité (CzechInvest, 2005). La République tchèque forme 14000 diplômés de l'université par an dans les matières techniques et scientifiques (neoIT, 2004) et environ 26700 étudiants y sont actuellement inscrits dans des disciplines en rapport avec les TI (CzechInvest, 2005). Les estimations du nombre annuel de diplômés dans le domaine des TI varient : ils seraient de 2000 à 3000 si l'on retient une définition restrictive mais leur effectif atteindrait les 4000 si l'on adopte une définition plus large.

73. D'après les chiffres établis par Universitas ${ }^{29}, 60 \%$ des $18-29$ ans parlent peu ou prou l'anglais et $52 \%$ ont étudié l'allemand. Le pourcentage de tchèques sachant parler anglais devrait augmenter dans la mesure où $95 \%$ des élèves de l'enseignement secondaire apprennent désormais cette langue (neoIT, 2004). Le russe est une langue courante parmi les générations plus âgées. Les dépenses totales par élève ont certes augmenté de $15 \%$ en termes réels depuis 1989 mais il n'en est pas moins préoccupant pour le secteur des services de soutien aux entreprises et celui des STI que les dépenses par étudiant de l'université aient diminué de plus de $40 \%$ en termes réels et que le taux d'inscription dans l'enseignement supérieur des jeunes en âge d'aller à l'université soit le troisième plus bas de la zone de l'OCDE (EIU, 2006). La taille de la population active tchèque devrait par ailleurs diminuer dans le futur, compte tenu des taux de natalité extrêmement faibles enregistrés dans les années 90 . Du fait de ce choc démographique, les universités tchèques devront accepter de réduire leurs exigences à l'entrée ou se résoudre à former moins de diplômés à l'avenir. Des nouvelles politiques pour encourager l'immigration de travailleurs étrangers, pourrait être indispensable pour remédier aux pénuries de main-d'œuvre auxquelles il faut s'attendre.

74. En 2006, les sociétés tchèques de services de soutien aux entreprises et de STI ont encore pu recruter sans grand problème - du moins en dehors de Prague. La plupart des établissements étrangers sont implantés à Prague et tendent à verser des salaires nettement plus élevés que les sociétés tchèques. La rotation des effectifs pose en République tchèque moins de problèmes que dans les pays asiatiques étudiés dans le présent rapport, dont l'Inde en particulier. Il n'en demeure pas moins que des multinationales s'établissent dans le pays et promettent de recruter à brève échéance des centaines de travailleurs, ce qui risque non seulement de provoquer des fluctuations à court terme au niveau de la rotation des effectifs mais aussi d'exercer une pression à la hausse des salaires.

\footnotetext{
${ }^{29}$ Cités par Czech Invest (2006).
} 
75. Comme en Chine, les secteurs des services de soutien aux entreprises et des STI souffrent en République tchèque d'une pénurie de cadres expérimentés qui soient tout à la fois soucieux de satisfaire la clientèle et attentifs à la qualité (Economist, 2005). Le pays manque également de cadres possédant une solide expérience du marché intérieur comme des marchés extérieurs, un sens aigu des affaires, ainsi que des compétences en matière de communication conformes aux exigences des clients étrangers. La réticence générale des Tchèques à déménager pour aller travailler dans d'autres villes ne contribue guère à améliorer la situation. Le secteur des STI éprouve également des difficultés à trouver des programmeurs confirmés possédant de 5 à 7 ans d'expérience professionnelle, car ceux qui présentent ce type de profil tendent à occuper des postes d'encadrement.

\section{Problèmes réglementaires}

76. L'environnement des entreprises tchèques s'est à bien des égards amélioré ces dernières années et la fiscalité des sociétés est en cours de révision en vue de pouvoir faire face à la concurrence des autres nouveaux États membres adhérents de l'UE. L'annexe C montre que l'efficience du cadre réglementaire et institutionnel auquel sont confrontées les entreprises en République tchèque est à peu près équivalente à la moyenne des pays de l'OCDE pour ce qui est de la protection des investisseurs, de l'accès au crédit, du paiement de l'impôt et de l'embauche de salariés. La facilité avec laquelle un entrepreneur peut créer ou fermer une entreprise, ou encore imposer le respect effectif des contrats, pourrait toutefois être encore largement accrue. Le système judiciaire est particulièrement lent par rapport à la moyenne des pays de l'OCDE et il l'est même davantage qu'en Chine et aux Philippines.

77. Les sociétés de STI tchèques n'ont que rarement recours à un modèle de fourniture dans lequel la prestation de services est dans une large mesure tributaire des mouvements temporaires de professionnels des services. Les conditions économiques qui sous-tendent le modèle de fourniture dans le monde entier, qui est basé sur l'envoi temporaire de personnel du fournisseaurs aurpès du client, ne peuvent tout simplement pas être réunies dans l'environnement dans lequel opèrent les entreprises tchèques. Certains membres clés du personnel n'en doivent pas moins se rendre occasionnellement à l'étranger, chose qui leur est rendue plus difficile par la décision de certains États de l'UE d'étaler sur un certain nombre d'années la mise en place de la libre-circulation au sein du marché interne européen. Cette restriction temporaire exerce une incidence négative uniquement sur un nombre limité de projets STI auprès de clients étrangers. La plupart des professionnels tchèques s'attachent à répondre à la demande du marché intérieur et ceux qui sont tournés vers les marchés extérieurs travaillent essentiellement pour des sociétés étrangères dont le personnel qualifié peut se déplacer sans aucune difficulté. Pour ce qui est de la circulation de la maind'œuvre entre la République tchèque et les pays d'Europe orientale non membres de l'UE, les mouvements de personnel hautement qualifié se heurtent à moins de difficultés que ceux de travailleurs peu qualifiés. 
TD/TC/WP(2007)2/FINAL

\section{LES SECTEURS INDIENS DES SERVICES DE SOUTIEN AUX ENTREPRISES ET DES STI}

78. L'Inde est celle des économies émergentes qui exporte le plus de services de soutien aux entreprises et de STI aux pays de l'OCDE. Le secteur indien des STI tourné vers l'exportation a déjà commencé à monter en puissance au milieu des années 90 et il a depuis enregistré une croissance rapide. La réussite du secteur des STI est démontrée par le fait que trois sociétés de STI indiennes figuraient en 2006 parmi les six premières compagnies STI ${ }^{30}$ au monde. Chacune d'entre-elles exporte davantage de STI que l'ensemble des secteurs des STI de la Chine, des Philippines et de la République tchèque réunies (voir le tableau 3 et l'annexe K).

79. Le secteur indien des services de soutien aux entreprises n'a pas encore le même degré de maturité que le secteur STI et il n'a commencé à prendre davantage d'envergure que depuis environ 3 ou 4 ans. Il est confronté à une forte concurrence d'autres économies émergentes telles que les Philippines en ce qui concerne les services en anglais. Les sociétés indiennes investissent de plus en plus dans les économies émergentes qui possèdent des aptitudes linguistiques complémentaires aux siennes, et plus particulièrement en Chine pour fournir des services aux pays d'Asie orientale, en République tchèque, en Slovaquie et en Hongrie pour approvisionner les marchés de l'UE, ou encore aux Philippines pour répondre à la demande des clients américains. Certaines des principales sociétés indiennes s'attachent de plus en plus à investir dans le développement de capacités de prestation de services dans d'autres pays de l'OCDE.

80. Les atouts de l'Inde tiennent à son vaste réservoir de personnel compétent et maîtrisant l'anglais et à ses grandes compagnies sophistiqueés des services de soutien aux entreprises et des STI. Les secteurs des services de soutien aux entreprises et des STI sont plus intensifs en main-d'œuvre qu'en capital et pour pouvoir répondre à la demande des marchés extérieurs il leur est essentiel de disposer d'une population active hautement qualifiée et possédant des aptitudes linguistiques, ainsi que des compétences en matière de communication. L'Inde se distingue des autres économies émergentes qui exportent des services de soutien aux entreprises et des STI par son industrie nationale plus expérimentée et parvenue à plus grande maturité, de même que par la taille et la qualité de sa population active dans ces secteurs. La main d'œuvre peu onereuse contribue à attirer les entreprises étrangères mais les coûts de main-d'œuvre indiens ne sont pas sensiblement différents de ceux de certaines autres grandes économies émergentes telles que la Chine (voir les annexes $\mathrm{D}$ et $\mathrm{H}$ ).

81. L'environnement dans lequel opèrent les entreprises indiennes constitue la principale faiblesse de cette industrie. L'infrastructure surchargée ne bénéficie pas d'investissements suffisants et le risque pays est considéré comme plus élevé que dans des pays tels que la République tchèque ou la Chine (neoIT, 2006). Une concurrence acharnee pour attirer les meilleurs talents du pays a provoqué une rapide inflation salariale et des taux de départs élevés. La culture indienne est par ailleurs moins propice à la fourniture de services à des marchés très éloignés que ne peuvent par exemple l'être celles des Philippines ou de la République tchèque du fait de leur proximité culturelle par rapport aux grands marchés d'exportation des États-Unis et de l'Europe, respectivement.

\footnotetext{
${ }^{30}$ Sur la base de leur valeur en bourse, TCS, Infosys Technologies et Wipro Technologies étaient classeés en quatrième, cinquième et sixième position parmi les sociétés STI mondialisées (JP Morgan 2006).
} 


\section{Caractéristiques du marché}

82. Au cours des années 90, le taux de croissance annuel composé (TCAC) de l'Inde pour les exportations de services était de $17 \%$ - le plus fort taux de croissance parmi les 15 principaux exportateurs de services au monde (Banque mondiale, 2004). D'après Nasscom (2006), au cours de l'exercice financier qui s'est achevé en mars 2006, l'Inde a exporté des services de soutien aux entreprises d'une valeur de 6.3 milliards de dollars des États-Unis et des STI d'une valeur de 13.2 milliards de dollars des États-Unis. Le développement d'applications douanières et la gestion des applications ont été les deux principales catégories de services exportés (voir le tableau 1). MGI (2005a) estime que l'Inde compte pour 72\% des STI provenant de pays à bas salaires et pour pas moins de $88 \%$ des importations de même origine effectuées par le Royaume-Uni. L'industrie est fortement dependente des marchés extérieurs : la valeur du marché intérieur des services de soutien aux entreprises et des STI s'élève à environ 5.2 milliards de dollars des États-Unis, soit $21 \%$ de l'ensemble. ${ }^{31}$

83. Pour ce qui est des marchés d'exportation, les États-Unis constituent la principale destination pour les services indiens de soutien aux entreprises et des technologies de l'information : ils achètent les deux tiers des exportations, part demeurée stable dans le temps. Le Royaume-Uni, qui en absorbe $14 \%$, se classe quant à lui au second rang (graphique 4). Le secteur privé du Royaume-Uni acquiert toutes proportions gardées légèrement plus de services de soutien aux entreprises et de STI en provenance d'Inde que ne le fait celui des Etats-Unis si on tient compte de la taille relative de leurs économies. Les sociétés indiennes cherchent depuis des années à prendre pied sur d'autres marchés extérieurs, mais les efforts pour ce faire n'ont eu qu'un succès limité. Le Japon et l'Allemagne sont respectivement les troisième et quatrième marchés d'exportation par ordre d'importance mais leurs chiffres d'affaires ne dépassent dans aucun des deux cas une valeur de 500 millions de dollars des États-Unis. Au total, 84.3\% des exportations indiennes de services de soutien aux entreprises et de STI ont été absorbées par des pays anglophones au cours de l'exercice financier qui s'est achevé en mars $2005 .^{32}$ Ce pourcentage aurait probablement été plus élevé s'il avait été tenu compte des sociétés américaines et britanniques qui opèrent à partir de pays non anglophones.

\footnotetext{
${ }^{31}$ Outre les services de soutien aux entreprises et les STI, les sociétés indiennes ont exporté des services d'ingénierie, des services de R-D et des produits logiciels d'une valeur estimée à 3.9 milliards de dollars des États-Unis.

32 À savoir l'Australie, le Canada, les États-Unis, le Royaume-Uni et Singapour.
} 


\begin{tabular}{|c|c|c|}
\hline \multicolumn{2}{|c|}{$\begin{array}{l}\text { Tableau 1. Exportations indiennes de } \\
\text { STI (milliards d'USD) }\end{array}$} & $\begin{array}{l}\text { Graphique 4. Exportations de services de soutien aux } \\
\text { entreprises et de STI par pays de destination, exercice } \\
\text { financier qui s'est achevé en mars } 2005\end{array}$ \\
\hline CATÉGORIES DE SERVICES & EF 2005-06 & \multirow{12}{*}{$\begin{array}{l}\text { Australie, } 0.8 \\
\text { Canada, } 0.9 \\
\text { Pays-Bas, } 1.4 \\
\text { Singapour, 1.7. } \\
\text { Allemagne, 2.3/ } \\
\text { Japon, 2.8/ } \\
\text { R-U, } 14\end{array}$} \\
\hline Engagements axés sur des projets & 7.39 & \\
\hline Dév. d'applications douanières & 6.60 & \\
\hline Conseil en TI & 0.33 & \\
\hline Intégration de systèmes & 0.26 & \\
\hline Conseil et intégration de réseaux & 0.20 & \\
\hline Engagements de sous-traitance & 4.36 & \\
\hline Gestion des applications & 3.56 & \\
\hline Systèmes informatiques & 0.79 & \\
\hline Assistance et formation & 1.45 & \\
\hline \multirow[t]{2}{*}{ TOTAL } & 13.20 & \\
\hline & & \\
\hline
\end{tabular}

84. Les quatre principales sociétés de STI indiennes - TCS, Infosys, Wipro et Satyam - ont réalisé un chiffre d'affaires à l'exportation supérieur à 1 milliard de dollars des États-Unis au cours de l'exercice financier qui s'est achevé en mars 2006. Les cinq plus grandes sociétés ont généré $46 \%$ des exportations indiennes de STI et de 4 à $5 \%$ de celles de services de soutien aux entreprises. ${ }^{33}$ Dix autres sociétés nationales assurent un quart des exportations de STI et de 4 à $5 \%$ de celles de services de soutien aux entreprises. Les trente plus grandes unités captives de multinationales étrangères assurent $15 \%$ des exportations de STI et les 150 plus grandes unités captives comptent pour $50 \%$ du marché indien des services de soutien aux entreprises. Il en résulte que l'Inde joue essentiellement le rôle de centre international de sous-traitance externe dans le cas des STI et de centre international de sous-traitance interne et externe dans celui des services de soutien aux entreprises.

85. Les sociétés indiennes de services de soutien aux entreprises et de STI s'attachent actuellement à créer des capacités de prestation de services à l'extérieur de l'Inde, en procédant par exemple à des acquisitions transfrontières, au rachat des départements des TI de leurs clients, ou encore à des investissements totalement nouveaux. Bien que les sociétés indiennes soient en cours de mondialisation et s'implantent tant sur les marchés émergents que sur ceux de l'OCDE, de plus en plus de multinationales des pays de l'OCDE spécialisées dans les TIC développent actuellement leur présence en Inde. L'annexe L présente des estimations des effectifs des principales multinationales spécialisées dans les STI. En 2005, environ $11 \%$ de l'ensemble des effectifs des multinationales étrangères mentionnées dans l'annexe étaient basés en Inde. D'après Nasscom (2006), ce pourcentage a tendance à s'accroître et devrait atteindre 14\% dès 2007. Un cinquième environ des effectifs de certaines sociétés, telles qu'Accenture et IBM Services, sont basés en Inde. D'autres sociétés telles que Cap Gemini et EDS comptent par contre relativement peu de salariés indiens.

86. D'après les estimations, les secteurs indiens des services de soutien aux entreprises et des STI tournés vers l'exportation comptaient au total 0.8 million de salariés au cours de l'exercice financier qui s'est achevé en mars 2006. Ces effectifs étaient répartis à parts égales entre le secteur des services de

\footnotetext{
${ }^{33}$ www.nasscom.in/upload/5216/Indian_IT_Industry_Factsheet_2006.pdf.
} 
soutien aux entreprises et celui des STI. Au total, 1.3 million de salariés sont employés dans les secteurs indiens des services de soutien aux entreprises et des STI (qu'ils répondent à la demande intérieure ou extérieure) et dans ceux qui fournissent des produits logiciels, des activités de R-D et des services d'ingénierie aux marchés extérieurs. D'après les estimations, ces secteurs génèrent au total 3 millions d'emplois indirects et induits (Nasscom, 2006). Le nombre d'emplois de la première de ces deux catégories a été estimé à partir du volume des dépenses dans les télécommunications, l'énergie électrique, le bâtiment et les travaux publics, la gestion des installations, les technologies de l'information, les transports, la restauration, ainsi que dans les autres types de services. Les emplois de la seconde catégorie sont fonction des dépenses de consommation consacrées par les salariés à l'alimentation, à l'habillement, aux services d'utilité publique, aux loisirs, aux soins de santé, etc.

\section{Encadré 5. Le modèle de fourniture dans le monde entier appliqué aux STI}

Le modèle de fourniture dans le monde entier appliqué aux STI associe fourniture transfrontières et migrations temporaires de main-d'œuvre, et les sociétés indiennes ont été les premières à y avoir recours dans les années 80 et 90. Dans les premiers temps, avant que les réseaux internationaux de fibres optiques et l'Internet ne se généralisent, les documents et les bandes audio étaient expédiés en Inde par avion en vue de leur numérisation et de leur transcription. Des activités de programmation de base étaient également réalisées pour le compte de multinationales étrangères. Avec le temps, les sociétés indiennes ont commencé à envoyer des spécialistes des TI dans les locaux de leurs clients pour mener à bien des travaux de programmation de logiciels. Cette pratique a atteint son niveau maximal immédiatement avant le passage à l'an 2000, époque où la demande de professionnels des TI était supérieure à l'offre dans bien des pays de l'OCDE.

L'expansion rapide des réseaux des TIC, la baisse des coûts de communication, ainsi que le progrès technologique ont permis de maintenir en Inde l'emploi d'un nombre croissant de professionnels des TI ("délocalisés") travaillant en collaboration avec l'équipe indienne envoyée dans les locaux du client (sur place). Les professionnels indiens présents dans les locaux du client définissaient le cahier des charges du projet, coordonnaient les travaux, installaient les logiciels, formaient les effectifs du client et fournissaient des services de maintenance d'urgence, alors que les effectifs restés en Inde menaient à bien les activités technologiques telles que la conception technique ou celle des bases de données, ou encore les services de programmation, d'essais, de documentation et de maintenance à long terme. Ce modèle d'entreprise était économiquement incontournable compte tenu des écarts de coûts de main-d'œuvre entre les professionnels des TI présents dans le pays client et ceux travaillant en Inde. Il s'agissait par ailleurs d'un processus extrêmement délicat à gérer et l'Inde était la seule des économies émergentes à pouvoir pleinement le maîtriser.

Avec le temps, il est devenu moins nécessaire de maintenir une importante équipe indienne dans les locaux du client. Entre 2000 et 2005, la part moyenne des travaux effectués sur place est tombée de $67 \%$ à $42 \%$ à l'échelle de toute l'industrie. Le rapport entre les travaux délocalisés et ceux réalisés sur place est fonction directe de l'écart entre les coûts de main-d'œuvre mais on peut en dire autant de la complexité de gestion des projets. Ce rapport est en outre variable selon les projets.

Le modèle de fourniture dans le monde entier est devenu de plus en plus complexe et sophistiqué au fil des ans. Aujourd'hui, les grandes sociétés indiennes subdivisent les tâches à accomplir en leurs composantes logiques en vue de les répartir entre les lieux où elles peuvent être réalisées le plus efficacement par rapport aux coûts. Un client ayant recours à une société indienne à Londres peut ainsi dialoguer avec l'équipe des ventes de cette dernière, laquelle reste en permanence à Londres et accueillera pendant le cycle de vie du projet une équipe de spécialistes confirmés des technologies de l'information venus d'Inde pour coordonner et mettre en œuvre les différentes composantes des TI fournies depuis Bangalore, Jaipur et Budapest. La société indienne pourrait donc fournir des services de maintenance depuis ses centres de développement de Belfast et Budapest et assurer l'assistance technique téléphonique depuis Bangalore.

Source : OCDE (2006), Kumra et Sinha (2003), Nasscom (2006) et site web www.infosys.com. 


\section{Problèmes rencontrés pour répondre à la demande des marchés internationaux}

87. Les secteurs indiens des services de soutien aux entreprises et des STI bénéficient de l'appui d'une puissante association professionnelle : Nasscom. Elle a contribué à accroître la transparence et à encourager la normalisation, les meilleures pratiques et les investissements directs étrangers au sein de l'industrie, ainsi qu'à promouvoir cette dernière avec une toute particulière efficacité. Nasscom (2006) a identifié trois domaines fondamentaux dans lesquels l'industrie est confrontée à d'importants problèmes : la cybersécurité (piratage, confidentialité, protection des données et DPI), les ressources humaines, et l'infrastructure (aéroports, systèmes de transport en commun, routes et électricité, notamment).

88. Les entreprises opérant en Inde doivent aussi faire face à une bureaucratie et des réglementations excessives. Le pays n'est pas très bien classé d'après plusieurs des indicateurs retenus par l'étude comparative de la Banque mondiale concernant la conduite des affaires (Doing business - voir l'annexe C). Il s'agit en particulier des indicateurs relatifs à la création d'entreprise (qui est longue et fastidieuse), à la fermeture d'entreprise (qui exige de longs délais et se caractérise par de faibles taux de recouvrement), à la fiscalité (les taux d'imposition sont extrêmement élevés), ainsi qu'à la rigidité du marché du travail. Imposer le respect des clauses d'un contrat tient du cauchemar : il faut en moyenne quelque 1420 jours, soit l'un des délais les plus longs au monde. Les contrats sont donc en règle générale signés dans les pays clients et couverts par la jurisprudence en vigueur dans ceux-ci.

89. Pour le plus grand profit des secteurs des services de soutien aux entreprises et des STI, l'environnement des entreprises a été sensiblement amélioré au sein des parcs de technologie logicielle indiens (Indian Software Technology Parks ou STP) créés au début des années 90, dans lesquels opèrent les sociétés tournées vers l'exportation. Ces parcs jouent le même rôle que les zones franches pour l'industrie d'exportation. Ils permettent de bénéficier d'exonérations fiscales, comblent les lacunes dont souffrent les infrastructures, et offrent un environnement plus propice aux entreprises. Pour les multinationales étrangères, les pesanteurs administratives y sont pour la plupart spectaculairement allégées et bon nombre des problèmes qui subsistent peuvent être résolus en faisant appel à des compagnies de consultants externes.

90. La Banque mondiale (2004) affirme que l'Inde doit s'attaquer à deux problèmes essentiels en vue de soutenir le dynamisme de son secteur des services : à l'extérieur, elle doit faire face aux risques de protectionnisme effectifs et potentiels, et à l'intérieur à la persistance des obstacles au commerce et à l'investissement tout comme aux faiblesses de son cadre réglementaire. Pour remédier au premier de ces problèmes, l'Inde devra s'assurer l'accès aux marchés extérieurs. Toutefois, les problèmes les plus pressants auxquels se heurtent aujourd'hui les sociétés des secteurs des services de soutien aux entreprises et des STI tiennent aux contraintes du côté de l'offre. La section suivante examine les problèmes auxquels sont confrontées les sociétés indiennes et les multinationales étrangères qui ont un volume non négligeable d'activités en Inde.

\section{Contraintes du côté de l'offre}

\section{Recrutement et rétention du personnel}

91. La plupart des sociétés de services de soutien aux entreprises et de STI en Inde sont aux prises avec des difficultés de recrutement et de rétention de leurs effectifs. Le problème ne tient pas tant au nombre de diplômés formés chaque année qu'à leur qualité. Le pourcentage de diplômés suffisamment bien formés pour travailler dans les secteurs des services de soutien aux entreprises et des STI tournés vers l'exportation est certes plus élevé qu'il ne l'est dans des pays tels que la Chine, mais la taille relative des effectifs cumulés des secteurs des services de soutien aux entreprises et des STI (soit environ 0.8 million de personnes en mars 2006) et la forte croissance de l'industrie ont entraîné une expansion des activités de 
gestion des ressources humaines. Bien que les jeunes professionnels à la recherche d'un emploi ne manquent pas, les investissements nécessaires à leur sélection et à leur formation ne sont pas négligeables et continuent de progresser à mesure qu'augmentent les grands nombres de diplômés recrutés. Les multinationales étrangères ont tendance à gerer ces problèmes en versant généralement des salaires plus élevés que les sociétés indiennes.

92. La rétention du personnel constitue une autre source de préoccupation du fait que la plupart des personnes compétentes dans le domaine des STI se trouvent concentrées dans des centres tels que Bangalore, Chennai, Delhi, Hyderabad et Mumbai. Les taux de rotation des effectifs dans le secteur des services de soutien aux entreprises sont peut-être plus faibles que dans la plupart des pays de l'OCDE, notamment pour ce qui est des services vocaux. Il n'en reste pas moins que les fréquents changements d'emplois réduisent la productivité des sociétés de services de soutien aux entreprises et tendent à alimenter l'inflation salariale. Dange et al. (2005) estime que toute augmentation du taux de départ de 5\% reduit la marge bénéficiaire brute de $1,5 \%$. L'Inde a cependant un avantage par rapport aux autres pays examinés dans la présente étude dans la mesure où ses secteurs des services de soutien aux entreprises et des STI ont été les premiers à se lancer dans la sous-traitance d'activités délocalisées et possèdent le plus vaste et abondant réservoir de cadres supérieurs et de directeurs de projets.

Restrictions aux mouvements temporaires de professionnels des $\mathrm{STI}^{34}$

93. Le modèle de fourniture dans le monde entier auquel la plupart des sociétés indiennes font appel pour exporter des STI est tributaire des transferts internationaux de personnel expérimenté entre le siège de la société et les locaux des clients étrangers (voir l'encadré 5). En moyenne, un tiers environ du personnel opérationnel d'une société indienne représentative du secteur des STI travaille sur place chez le client pendant toute la durée du cycle de vie d'un projet. La répartition du personnel n'en est pas moins variable d'une société à l'autre, d'un projet à l'autre, et tout au long du cycle de vie du projet. Beaucoup de grandes et moyennes sociétés indiennes disposent d'effectifs affectés en permanence dans des filiales établies dans les pays clients. Ces professionnels assurent généralement l'interaction avec les clients, en particulier dans le cadre des activités de vente et de commercialisation, mais certaines des plus grandes sociétés, telles qu'Infosys Technologies et TCS, maintiennent également sur place des effectifs opérationnels en nombre croissant. La plupart des activités telles que le développement de logiciels continuent toutefois d'être menées à bien par des professionnels basés en Inde ou dans d'autres économies émergentes, dont la Chine, les pays d'Europe orientale et les Philippines.

94. La part des effectifs présents dans les locaux du client est progressivement tombée de plus des deux tiers au milieu des années 90 à un tiers aujourd'hui. Cette part poursuivra sans doute sa tendance à la baisse du fait des progrès technologiques et de l'arrivée à maturité du modèle de fourniture dans le monde entier. Il n'en existe pas moins une limite au volume de travail susceptible d'être mené à bien à l'étranger : la logique économique qui sous-tend la délocalisation internationale consiste à maximiser la part des activités effectuées dans des lieux offrant un bon rapport qualité-prix, or la relation face-à-face avec le client demeure essentielle pour assurer l'efficience opérationnelle. Le modèle de fourniture dans le monde entier appliqué par les sociétés indiennes continuera d'être, dans un avenir prévisible, tributaire de transferts internationaux de cadres et de professionnels des TI.

95. Les procédures administratives de délivrance des papiers nécessaires pour effectuer des voyages d'affaires dans les pays clients peuvent créer des problèmes aux sociétés de STI indiennes. Certaines des difficultés d'ordre administratif liées à l'obtention de ces documents finissent par s'aplanir avec le temps, à mesure que ces sociétés gagnent la confiance des nouveaux pays clients et que les autorités prennent

\footnotetext{
${ }^{34}$ L'OCDE a publié un certain nombre d'études sur les mouvements temporaires des prestataires de services. Voir par exemple OCDE (2003a; 2003b;2004b).
} 
conscience de la valeur ajoutée conférée par les professionnels venus de l'étranger. Les autorités américaines et britanniques ont une longue expérience du traitement des demandes de visas et de permis de travail pour des citoyens indiens mais tel n'est par contre pas le cas de beaucoup d'autres pays de l'OCDE. Certains progrès ont été accomplis dans la gestion des visas et des permis de travail mais elle pourrait être encore améliorée.

96. Les règles de délivrance de visas d'affaires et de permis de travail relèvent de la souveraineté nationale. Chaque pays définit en fonction de ses objectifs nationaux les conditions requises et la procédure administrative à suivre pour la délivrance de visas d'affaires et de permis de travail aux ressortissants étrangers. La section suivante expose certains des problèmes dont il est fréquemment fait état en la matière au sein du secteur indien des STI. En règle générale, bien que la procédure de demande et d'obtention des papiers nécessaires aux mouvements de personnels imposent des coûts directs, les soucis évoqués sont plus souvent liés aux délais et à l'incertitude qu'elle suscite. Ces coûts directs imposent en effet des frais généraux supplémentaires, tandis que les délais et l'incertitude sont à l'origine de lourds coûts indirects et peuvent même aboutir à la rupture des contrats.

\section{Exigences en matière de visas d'affaires et de permis de travail}

97. La procédure d'obtention d'un visa d'affaires est relativement simple dans la plupart des marchés d'exportation de l'Inde. Les écarts d'un pays à l'autre peuvent toutefois être importants : la procédure d'obtention d'un visa d'affaires peut prendre de un à dix jours ouvrables en Inde. Certaines sociétés signalent qu'elles obtiennent souvent des visas d'affaires dont la durée de validité est inférieure à celle demandée par elles. Cela ne fait qu'ajouter à la complexité et à l'incertitude car les sociétés peuvent se trouver contraintes d'acquitter des frais d'annulation des billets d'avion et des réservations d'hôtels et de consentir à de nouvelles dépenses du fait qu'elles devront en relouer d'autres, tout comme elles peuvent avoir à revoir le calendrier de mise en œuvre des projets ou celui des réunions avec les clients, etc. Le titulaire du visa peut également devoir retourner en Inde dans l'unique but de renouveler sa demande avant de pouvoir mener à son terme l'affaire avec le client.

98. La procédure administrative est plus stricte pour les permis de travail que pour les visas d'affaires. Certains pays appliquent des systèmes de quotas pour limiter et contrôler le nombre de permis de travail qui peuvent être délivrés chaque année. Les permis de travail sont d'ordinaire délivrés aux visiteurs qui effectuent des travaux facturables ou restent pendant plus de trois mois dans le pays. Par rapport à celle appliquée dans le cas des visas d'affaires, la procédure administrative de demande de permis de travail a entre autres avantages celui de laisser une moindre marge d'appréciation aux autorités et de ne susciter que rarement des problèmes de durée du séjour.

99. Dans la procédure actuelle de délivrance des permis de travail, la décision est laissée à l'appréciation du fonctionnaire qui assure le traitement de la demande. Dans beaucoup de pays, les demandeurs doivent remettre des copies certifiées conformes des documents, prévoir un entretien pour lequel le délai d'attente peut atteindre de 45 à 120 jours et convaincre ensuite le fonctionnaire au cours de l'entretien qu'il n'a pas l'intention d'immigrer de façon définitive ni de rester dans le pays plus longtemps qu'il n'y sera autorisé. Ce problème récurrent tient au fait que beaucoup de pays appliquent aux mouvements temporaires de personnes physiques le même traitement qu'aux demandes effectuées en vue d'une immigration permanente. Les demandeurs qui parviennent à réunir toutes les pièces requises peuvent ensuite être invités à présenter des documents complémentaires aux fins de vérification de ceux qui doivent être obligatoirement fournis. Ce processus peut nécessiter plusieurs séries de traduction et de légalisation des documents.

100. Par exemple, certains documents tels que les certificats de naissance et les diplômes d'enseignement doivent d'abord être légalisés par l'administration de l'État indien considéré. Les 
documents légalisés sont alors traduits dans la langue du pays pour lequel la demande est faite, puis la traduction du document légalisé peut elle-même devoir être légalisée. Pour certains documents, la procédure peut nécessiter jusqu'à trois séries de légalisation et de visites à la ville de naissance du demandeur, aux autorités de l'État indien concerné et au ministère du gouvernement à New Delhi. Dans certains pays, les professionnels indiens des STI doivent engager une procédure qui peut prendre plus de six mois pour obtenir un permis de travail. Dans certains cas, les délais d'attente peuvent être de 8 à 10 mois. Le délai de traitement est tel qu'il est impossible d'entreprendre certains projets et il risque non seulement d'entrainer la perte de débouchés commerciaux mais aussi de compromettre les relations avec les clients.

101. La procédure administrative de délivrance de permis de travail pose moins de problèmes pour les professionnels indiens qui travaillent pour des filiales étrangères que pour ceux au service de sociétés nationales. Beaucoup de filiales étrangères sont des centres de mise au point de produits dont les salariés n'ont que rarement à entrer en relation directe avec les clients ou à travailler à l'étranger. Ceux des salariés qui ont encore besoin d'un permis de travail peuvent d'ordinaire effectuer leurs déplacements dans le cadre de transferts intra-entreprise. La procédure administrative applicable à ces déplacements est relativement efficiente et n'est assortie que de rares restrictions. Il n'en est pas de même pour les salariés des sociétés indiennes. Certaines des plus grandes parmi ces dernières possèdent des filiales qui emploient du personnel local dans leurs principaux pays clients, ce qui facilite généralement la procédure d'obtention de permis de travail étant donné que les salariés peuvent alors effectuer leurs déplacements dans le cadre de transferts intra-entreprise. Cependant, la grande majorité des sociétés indiennes n'ont pas la puissance financière ou le modèle d'entreprise nécessaires pour établir des unités opérationnelles dans les pays clients et elles sont dès lors tributaires de l'efficacité des ambassades et des consulats de ces derniers.

102. Les permis de travail peuvent être assortis de contraintes réglementaires en matière de salaire minimum ou de parité salariale. Cela a parfois pour effet de gonfler la facture que devra acquitter le client final, mais les réglementations salariales n'exercent que rarement une incidence réelle car la plupart des professionnels envoyés travailler à l'étranger ont atteint un niveau d'expérience et de salaire supérieur à celui qu'elles exigent. Le surcroît de travail administratif nécessaire pour démontrer que la société se conforme à l'ensemble de ces contraintes impose de fait une charge bien plus lourde. Une procédure équitable, transparente et allégée pour les demandes de visas d'affaires et de permis de travail serait tout aussi bénéfique pour le client que pour le fournisseur.

103. Les sociétés indiennes du secteur des TI ont développé des mécanismes complexes en vue de réduire au minimum les perturbations potentielles dont pourraient souffrir leurs activités : les grandes sociétés possèdent des services spécialisés chargés d'organiser les déplacements et de gérer les demandes de visas d'affaires et de permis de travail. Chaque chef de projet peut être responsable de l'obtention de visas pour les professionnels qui prennent part à son projet. La plupart des sociétés ont recours à des cabinets de conseil pour qu'ils les aident à résoudre les problèmes de traduction, de légalisation des documents et de migration temporaire. Les relations à long terme avec les clients facilitent ce processus de planification et ont pour effet d'accroître la prévisibilité.

104. Les sociétés indiennes pourraient diminuer à l'avenir leur dépendance à l'égard des permis de travail par trois grands moyens. Le premier consiste à établir des centres de développement dans les pays clients (voir OCDE, 2006b). Cette approche réduit la nécessité des mouvements internationaux de personnel et les effectifs qui ont à se déplacer peuvent demander à bénéficier de permis de travail intraentreprise. Le second est de maximiser le volume de travail réalisé en Inde, par exemple en passant des accords de partenariat avec des sociétés des pays clients ou en faisant venir le client en Inde à des fins de transferts de connaissances. 
105. Une autre approche de plus en plus fréquente parmi les grandes sociétés indiennes de STI consiste à établir des centres de développement dans des pays situés à très grande proximité des pays clients. Les coûts y sont plus élevés qu'en Inde mais plus faibles que dans les pays clients. L'Europe centrale, et notamment la Hongrie et la République tchèque, sont en passe de se transformer en centres de prestation de services destinés à l'Europe continentale, les sociétés mexicaines et canadiennes répondent à la demande du marché des États-Unis, les pays d'Afrique francophone servent de base pour la prestation de services au marché français, alors que les centres de développement établis en Chine fournissent des services au Japon. Ces centres spécialisés dans la délocalisation de proximité aident à surmonter les obstacles linguistiques et culturels, ainsi que certaines des restrictions aux mouvements internationaux de professionnels, en particulier en Europe. Le respect des réglementations relatives à la confidentialité et à la sécurité des données est en outre plus aisé à assurer à l'intérieur de l'UE.

106. La "délocalisation de proximité" peut faciliter les déplacements de professionnels à destination des pays clients, mais les mouvements entre l'Inde et les pays voisins où les sociétés indiennes effectuent des investissements se heurtent souvent à de graves restrictions. Les sociétés indiennes du secteur des TI sont généralement bien accueillies et bénéficient d'un bon soutien dans les nouvelles économies émergentes dans lesquelles elles investissent mais il faut du temps pour lever les restrictions sud-sud, qui sont en place depuis bien longtemps et s'avèrent très souvent beaucoup plus strictes que celles imposées aux échanges nord-sud. Ces obstacles sont souvent plus difficiles à surmonter que ceux que rencontre l'Inde sur les marchés de l'OCDE.

\section{Restrictions à la circulation des informations ${ }^{35}$}

107. Les problèmes de confidentialité et de sécurité des données sont liés aux risques: a) que les données soient perdues, et b) que des tiers aient accès aux données ou que celles-ci soient utilisées à mauvais escient par la société qui en assure le traitement. La sécurité des TI peut dans une certaine mesure être garantie par des moyens technologiques, mais la confidentialité des données est l'affaire des individus, aussi les procédures mises en place et l'éthique des sociétés sont-elles de la plus haute importance. Les sociétés indiennes investissent dans des systèmes de sécurité des données et des équipements de sauvegarde en vue de réduire le premier type de risques.

108. La confidentialité des données pose principalement un problème aux sociétés de services de soutien aux entreprises qui transfèrent et/ou traitent de grandes quantités d'informations personnelles relatives aux clients ou aux salariés d'autres sociétés. Ces transferts peuvent notamment porter sur des données sensibles telles que les dossiers financiers, médicaux et de sécurité sociale ou encore les historiques des achats. Les sociétés des pays de l'OCDE sont tenues de se conformer à des réglementations qui visent à protéger la confidentialité des données et elles exigent à leur tour que leurs sous-traitants respectent des normes généralement plus strictes que celles imposées par la législation en vigueur. La mauvaise gestion des informations s'est soldée par le passé par des scandales publics pour les sociétés dont les clients ou les salariés en ont été victimes. Tant les clients qui sous-traitent leurs activités que les sociétés prestataires de services ont beaucoup à perdre à la violation de la confidentialité des données.

109. Les restrictions à la circulation des informations sont un domaine où de nombreuses sociétés craignent qu'une législation puisse à l'avenir ériger des obstacles aux échanges selon les modes de fourniture 1 et $2 .^{36}$ Afin de lutter contre une utilisation à mauvais escient des données, Nasscom collabore

\footnotetext{
35 Voir OCDE (2006b) pour une vue d'ensemble plus complète des problèmes relatifs à la sécurité et à la confidentialité des données.

${ }^{36}$ Afin de se protéger des risques de protectionnisme, plus de 300 sociétés indiennes de services de soutien aux entreprises et de STI ont établi des filiales à Singapour, cité vers laquelle elles pourraient diriger les données si l'Inde devait être la cible d'une législation imposant des restrictions aux échanges (Aron, 2005).
} 
actuellement avec le gouvernement indien à la rédaction d'une loi sur les technologies de l'information qui définira les normes minimales en matière de confidentialité des données auxquelles devra se conformer l'industrie et qui instaurera un code pénal pour les sociétés ou les particuliers qui enfreindraient les règles établies. Jusqu'à présent, rares ont été les cas de vols de données signalés en Inde et l'industrie espère qu'il suffira d'adopter des normes strictes de confidentialité des données et d'en imposer le respect effectif pour réduire au minimum les problèmes futurs.

110. Les sociétés indiennes de services de soutien aux entreprises et de STI signent des accords de non divulgation avec leurs clients et un certain nombre de mécanismes sont en place pour assurer la protection des données. Il s'agit notamment de centres extraterritoriaux spécialement mis en place à cet effet et où par exemple :

- $\quad$ seul peut accéder le personnel chargé des projets ;

- l'infrastructure et le système de TI du client sont reproduits ;

- tous les types de transferts de données sont cryptés ;

- $\quad$ il est interdit au personnel chargé des projets d'être en possession de quelque dispositif de stockage des données que ce soit ;

- $\quad$ il est interdit au personnel chargé d'un projet d'entrer en relation avec le personnel chargé de projets menés pour des clients concurrents ;

- le personnel chargé des projets est placé sous vidéosurveillance.

111. Une multitude de solutions techniques permettent en outre d'éviter tout transfert physique des données. Il s'agit notamment de systèmes de TI qui offrent au personnel chargé de projets à l'étranger la possibilité d'avoir directement accès en ligne aux données dans le pays client. Les activités peuvent également être menées à bien sur des données fictives puis appliquées aux données réelles dans les locaux du client. Pour autant qu'elles s'appliquent à toutes les sociétés quel que soit le pays où se trouve situé leur siège social, les réglementations relatives à la confidentialité et à la sécurité des données ne paraissent pas soulever de problème.

112. Les sociétés indiennes ont mis en place un certain nombre de procédures en vue d'assurer la confidentialité et la sécurité des données car cela a souvent été une condition sine qua non pour attirer les clients étrangers. Le problème de la confidentialité et de la sécurité des données demeure un sujet de préoccupation pour les clients. Booz Allen Hamilton (2006) a récemment publié une enquête qui montre que la sécurité des informations est un des trois principaux critères pris en compte par les sociétés des Etats-Unis pour choisir les partenaires auxquels elles sous-traiteront leurs activités. L'enquête indique également que les problèmes de sécurité des informations sont liés au manque de confiance dans les cadres juridique et réglementaire en vigueur dans les pays en développement.

113. Plusieurs lois des États-Unis exigent que les sociétés prennent des précautions techniques, physiques et administratives raisonnables mais elles n'abordent pas directement le problème des transferts internationaux de données. ${ }^{37}$ Elles imposent plutôt "l'obligation de prendre les mesures raisonnables de sécurité et de contrôle des accès, etc., qui doivent être envisagées dans toute relation de prestation de services, que ce soit sur le territoire national ou à l'étranger..." Il en résulte que “...pour autant que le

\footnotetext{
${ }^{37}$ Il s'agit par exemple de la loi Gramm-Leach-Bliley sur les règles de sauvegarde et de confidentialité des données (Gramm-Leach-Bliley Privacy and Safeguards Rules Act), de la loi sur la portabilité et la responsabilité des assurances-santé (Health Insurance Portability and Accountability Act ou HIPAA), ou encore du projet de loi n ${ }^{\circ} 1386$ du Sénat de Californie.
} 
prestataire de services assure une sécurité et une confidentialité appropriées, les lois des États-Unis ne limitent aucunement à l'heure actuelle les possibilités pour une société d'avoir recours à des prestataires de services établis dans d'autres zones géographiques" (Eisenhauer, 2005). Les sociétés américaines sont tenues de se conformer à la réglementation des États-Unis en matière de confidentialité et de sécurité des données quel que soit le lieu où se trouve le prestataire de services engagé.

114. La directive 95/46/CE de l'UE, relative à la protection des personnes physiques à l'égard du traitement des données à caractère personnel et à la libre circulation de ces données, est entrée en vigueur en 1998 et constitue un texte législatif de portée générale sur la protection et la confidentialité des données. Elle s'applique à la plupart des secteurs d'activité et permet les transferts de données si un ensemble de conditions se trouvent réunies. Certaines réglementations interdisent par ailleurs, par exemple dans le secteur bancaire de divers pays européens, le transfert international des données, tout comme l'accès international en ligne à ces mêmes données. Dans de tels cas, le modèle de fourniture dans le monde entier auquel ont recours les sociétés indiennes de services de soutien aux entreprises ne peut être appliqué, à moins d'établir des unités opérationnelles dans le pays.

115. Outre la législation en vigueur, il existe plusieurs types de normes et de lignes directrices telles que les normes ISO 17799 (relative aux meilleures pratiques en matière de sécurité des informations), ISO 27001 (relative aux systèmes de gestion de la sécurité des informations) et COBIT (Control Objectives for Information \& Related Technology). Le respect de la législation et des lignes directrices relatives à la sécurité et à la confidentialité des données est certes indispensable mais il impose un coût : Pai et Basu (2005) font ainsi état d'une étude de la société de conseil TowerGroup selon laquelle l'obligation de due diligence alourdirait les coûts d'une "sous-traitance internationale efficace" dans une proportion de 3 à $5 \%$ dans le cas des services de soutien aux entreprises et de 7 à $9 \%$ dans celui des STI. La gestion des risques accroît encore les coûts de 3 à $5 \%$ dans le secteur des STI et de 8 à $10 \%$ dans celui des services de soutien aux entreprises. 


\section{LES SECTEURS PHILIPPINS DES SERVICES DE SOUTIEN AUX ENTREPRISES ET DES STI}

116. Les Philippines jouissent de plusieurs atouts pour la fourniture internationale de services et se classent à la seconde place des pays exportateurs de services de soutien aux entreprises et de STI sur lesquels porte ce rapport. Les écarts de coûts de main-d'œuvre sont en effet importants, la zone métropolitaine de Manille, où se trouvent concentrées la plupart des sociétés dispose d'une infrastructure bien développée, et l'infrastructure de télécommunications est fiable et efficace par rapport aux coûts. Les secteurs des services vocaux et non vocaux de soutien aux entreprises attirent des diplômés plus qualifiés que leurs pairs de la plupart des pays à revenu élevé. Les Philippines ont autrefois été un protectorat des États-Unis, d'où d'étroits liens culturels avec ceux-ci et la présence d'une assez importante diaspora philippine sur le territoire américain. Les compétences en matière de communication, la maîtrise de l'anglais et la neutralité de l'accent philippin, qui est influencé par celui des États-Unis sont des atouts essentiels pour répondre à la demande des clients américains. En outre, les taux de rotation des effectifs sont faibles dans l'industrie de la délocalisation des services et certains facteurs culturels sont particulièrement propices à la prestation de services vocaux. Il est ainsi généralement admis que les travailleurs philippins du secteur des services sont à l'écoute du client et ont une capacité naturelle à exprimer de l'empathie.

117. Les comparaisons internationales montrent que les Philippines sont un des lieux les plus attractifs pour la délocalisation des services (voir les annexes F et H). A.T. Kearney (2006) classe ainsi les Philippines au quatrième rang des pays les plus attractifs, grâce à sa main-d'œuvre et à son infrastructure bon marché, à sa grande adaptabilité culturelle et à une faible rotation des effectifs. Le pays est par contre moins bien placé du point de vue de la maturité de l'industrie nationale des services, de la qualité de l'enseignement, ainsi que de la protection des DPI. Le risque pays y est en outre plus important que dans beaucoup d'économies émergentes comparables. Des niveaux élevés de corruption, des problèmes de sécurité dans le sud du pays et l'instabilité politique ont une incidence négative sur l'environnement général dans lequel opèrent les entreprises. Le cabinet de conseil neoIT classe toutefois les Philippines en seconde place juste derrière l'Inde du point de vue de l'“attractivité pour la délocalisation des activités" dans le secteur des services de soutien aux entreprises et le pays est particulièrement bien noté sous l'angle de la maturité du secteur local des services de soutien aux entreprises comme de l'abondance et de la qualité des compétences disponibles (voir l'annexe G). Le pays est moins bien classé dans le secteur des STI ( $11^{\text {ème }}$ sur 40 pays) et sa relative faiblesse en ce domaine est due aux mêmes facteurs qui lui permettent de bénéficier d'une position de force dans celui des services de soutien aux entreprises : la maturité de l'industrie et l'abondance des compétences disponibles ne sont pas aussi grandes que dans bien d'autres pays comparables.

\section{Caractéristiques du marché}

118. L'industrie philippine des services de soutien aux entreprises a enregistré une croissance rapide au cours des cinq dernières années et s'est imposée parmi les principales économies émergentes prestataires de services de soutien aux entreprises. En 2005, l'industrie philippine des relations avec la clientèle, qui existait à peine ne serait-ce que cinq ans auparavant, employait 112000 travailleurs et générait un chiffre d'affaires de 1.6 milliard de dollars des États-Unis (voir le tableau 2). Le chiffre d'affaires du secteur des centres de contact avec la clientèle a été multiplié par deux tous les ans entre 2000 et 2004 (Locsin, 2006). Outre les services de contact avec la clientèle, les Philippines exportent des services de back-office, des services logiciels et des services de transcription médicale. En 2005, environ 150000 travailleurs fournissaient des services de soutien aux entreprises d'une valeur de 2 milliards de 
dollars des États-Unis, principalement aux marchés extérieurs. Il faut ajouter à ce chiffre les 12000 travailleurs qui ont assuré des exportations de STI d'une valeur de 0.2 milliard de dollars des ÉtatsUnis. Au total, les quatre cinquièmes des services de soutien aux entreprises et des STI ont été exportés en 2004 et la grande majorité de ces services ont été fournis par des filiales de multinationales étrangères. ${ }^{38}$ Tableau 2. Chiffre d'affaires et effectifs des secteurs des services de soutien aux entreprises et des
STI, 2004-fin 2006

\begin{tabular}{l|rrrrrrc} 
& \multicolumn{3}{c}{ Chiffre d'affaires (millions d'USD) } & \multicolumn{2}{c}{ Effectifs } \\
\cline { 2 - 8 } & 2004 & 2005 & fin 2006 & 2004 & 2005 & fin 2006 \\
\hline Contacts avec la clientèle & 920 & 1,610 & 2,580 & 64,000 & 112,000 & 179,200 \\
Back office & 120 & 180 & 320 & 15,000 & 22,500 & 40,500 \\
Dév. de logiciels (exportations) & 170 & 204 & 265 & 10,000 & 12,000 & 15,600 \\
Transcription médicale & 42 & 70 & 150 & 4,000 & 5,500 & 13,800 \\
Animation & 39 & 54 & 71 & 3,000 & 4,500 & 6,800 \\
Conception ingénierie & 17 & 26 & 39 & 2,000 & 2,800 & 4,200 \\
Autres transcriptions de données & 20 & 31 & 43 & 2,000 & 3,000 & 4,200 \\
Contenu numérique & 2 & 6 & 11 & 200 & 500 & 1000 \\
Transcription juridique & 2 & 3 & 5 & 300 & 450 & 700 \\
\hline \hline
\end{tabular}

Source : Mapa (2006)

119. Les clients américains ont absorbé environ 90\% des exportations philippines de services de soutien aux entreprises. La dispersion géographique des pays clients est plus grande dans le cas des STI, les États-Unis, le Japon et l'UE étant les principaux marchés d'exportation des Philippines. ${ }^{39}$ Pour ce qui est des services de centres d'appel, $87 \%$ des recettes d'exportation étaient générées par les clients américains au troisième trimestre de 2005 (Aquino, 2006). L'industrie philippine des relations avec la clientèle est dans une large mesure constituée de multinationales américaines qui fournissent des services de centres d'appel depuis des unités captives. Mais un nombre croissant de sociétés philippines, asiatiques et européennes ont également recours aux Philippines pour fournir des services de centres d'appel. Le pays est très dépendant de la zone métropolitaine de Manille, qui assure environ $80 \%$ des exportations. Le gouvernement philippin collabore avec les associations professionnelles nationales en vue d'élaborer des stratégies permettant une diversification géographique des capacités de prestation de services (voir cidessous pour plus de précisions).

120. Outre l'écart de coûts de main-d'œuvre, une des grandes raisons pour lesquelles un pays tel que les Philippines parvient à être un lieu aussi attractif pour l'établissement des centres de contact avec la clientèle tient au fait que le secteur des services de soutien aux entreprises peut faire appel à des diplômés hautement qualifiés pour effectuer des travaux qui dans les pays de l'OCDE seraient assurés par des travailleurs peu qualifiés et se caractérisent par de bas salaires, une faible productivité et une forte rotation du personnel. Aux États-Unis, par exemple, les salariés des centres d'appel restent en moyenne moins de

\footnotetext{
${ }^{38}$ Cette estimation est fondée sur les calculs effectués par le Secrétariat de l'OCDE sur la base des données fournies par Mapa (2006) et Aquino (2006).

${ }^{39}$ Ces informations ont été obtenues lors de réunions avec les associations professionnelles.
} 
six mois chez leur employeur, contre plus de deux ans aux Philippines. Les sociétés telles que eTelecare Global Solutions investissent en permanence dans la formation et la rétention de personnel et elles conservent bien plus longtemps leurs effectifs au sein de leurs centres d'appel aux Philippines. De faibles taux de rotation des effectifs et une main-d'œuvre de grande qualité constituent des atouts incontestables qui ont amené les sociétés multinationales du monde entier qui fournissent des services de centres d'appel à procéder à de gros investissements aux Philippines. ${ }^{40}$

121. Les Philippines sont par ailleurs en passe de devenir un centre de choix pour la délocalisation des activités financières et comptables caractérisées par un haut degré de standardisation. ${ }^{41}$ Les normes et les pratiques nationales en vigueur aux philippines se sont conformées aux principes comptables généralement admis aux États-Unis (Generally Accepted Accounting Principles ou GAAP) jusqu'au $1^{\text {er }}$ janvier 2005, puis après cette date aux normes comptables internationales (Locsin, 2006). Chaque année, environ 100000 étudiants obtiennent un diplôme en comptabilité, en finances, en gestion ou dans d'autres matières connexes, et le pays forme de 2500 à 3000 nouveaux comptables agréés par an.

\section{Encadré 6. La délocalisation internationale ouvre de nouveaux débouchés commerciaux}

La délocalisation internationale ouvre de plus en plus de débouchés commerciaux potentiels du fait des écarts de coûts de main-d'œuvre. Ces nouveaux débouchés commerciaux sont rarement pris en considération et ils sont difficiles à quantifier mais ils n'en sont pas moins un des déterminants de la délocalisation des activités. Un grand constructeur automobile a ainsi récemment commencé à proposer un système de localisation par GPS en contrepartie d'un abonnement mensuel. Il a été demandé à un centre d'appel philippin de lancer une campagne de télémarketing et de prendre contact avec les nouveaux propriétaires de voitures pour leur proposer ce système de GPS. Les anciens clients ont également été contactés et de nouveaux services leur ont été proposés, ou des informations leur ont été fournies s'ils n'avaient pas eu recours à ce service de GPS dans les trois premiers mois suivant leur abonnement. De nombreuses sociétés considèrent que les campagnes de télémarketing constituent un outil efficace pour accroître la valeur d'un client tout au long de sa vie. Mais il n'est souvent pas financièrement viable de les entreprendre depuis des pays à revenu élevé. La délocalisation internationale permet d'envisager de nouveaux modèles d'entreprise du fait des importants avantages qu'elle offre sur le plan des coûts.

\section{Efforts du gouvernement philippin pour attirer les investissements directs étrangers}

122. Le gouvernement philippin et le Bureau des investissements des Philippines (Philippine Board of Investment ou BOI) sont généralement jugés d'un grand secours pour les secteurs des services de soutien aux entreprises et des STI du pays. Le gouvernement a lancé par le passé divers projets afin de réduire les obstacles aux investissements et il coopère actuellement avec les associations professionnelles, dont celle $\mathrm{du}$ secteur des services de soutien aux entreprises des Philippines (Business Processing Association Philippines ou BPA/P) et celle de l'industrie des logiciels des Philippines (Philippine Software Industry Association ou PSIA), en vue d'améliorer l'enseignement dans les disciplines qui s'avèrent essentielles pour l'industrie et de renforcer les normes en matière de confidentialité et de sécurité des données en vigueur au sein de celle-ci.

123. Quelques initiatives ont été rapidement prises en vue d'attirer les investissements directs étrangers. L'adoption d'une loi autorisant les sociétés étrangères à établir aux Philippines des filiales à

\footnotetext{
${ }^{40}$ Le secteur philippin des services de soutien aux entreprises a pénétré jusqu'à l'OMC à Genève : les modules de formation en ligne de cette organisation sont vérifiés par des enseignants et des assistants philippins (Mapa, 2006).

${ }^{41}$ Il s'agit notamment des services de comptabilité générale, de tenue des comptes, de recouvrement des effets à recevoir, de gestion des factures et des effets à payer, de traitement des réclamations, de déclaration des dépenses et des recettes, d'audit des ventes, de tenue des états de paie, de gestion/comptabilité de patrimoine, d'analyse et d'audit financiers, de gestion des stocks et des achats, et d'établissement des déclarations fiscales.
} 
$100 \%$ en vue de fournir des services de soutien aux entreprises et des STI a été la principale d'entre elles. Une autre de ces initiatives a consisté à réduire la superficie minimale d'espaces de bureaux requise par l'Autorité des zones économiques spéciales philippines (Philippine Economic Zone Authority ou PEZA). Créée en 1995, celle-ci exigeait initialement qu'une superficie de 25 hectares soit consacrée aux espaces de bureau pour créer une zone économique spéciale/un parc industriel. En 1999, la superficie minimale a été ramenée de 25 à 15 hectares pour les parcs des TI. En 2000, pour bénéficier de la politique mise en œuvre par la PEZA, les immeubles dédiés aux TI devaient disposer d'espaces de bureaux d'une superficie minimale de $20000 \mathrm{~m}^{2}$. D'après Locsin (2006), la superficie minimale requise par la PEZA est à présent de $5000 \mathrm{~m}^{2}$.

124. Les sociétés dont les locaux sont situés dans les immeubles administrés par la PEZA jouissent d'un certain nombre d'incitations fiscales et de facilités administratives. Elles bénéficient notamment, entre autres avantages, de formalités simplifiées d'inscription au registre des sociétés qui peuvent désormais être effectuées en trois jours ouvrables (le délai moyen pour la constitution d'une société aux Philippines était de 48 jours en 2005 - voir l'annexe C). Les sociétés peuvent également bénéficier d'une exonération temporaire de l'impôt sur les bénéfices durant une période de 4 à 8 ans, de la possibilité d'utiliser sans aucune restriction les équipements mis à leur disposition, de déductions fiscales au titre des dépenses de personnel et de celles de formation (jusqu'à 50\% dans l'un et l'autre cas), ainsi que d'exemptions de droits de quai. Les promoteurs qui créent des parcs des TI sont également exonérés d'impôts et de droits sur les biens d'équipement importés ainsi que du paiement de la TVA sur les intrants de $10 \%$ pour les achats de biens et services déductibles effectués dans le pays (Locsin, 2006).

125. La principale priorité est à présent d'améliorer la qualité de l'enseignement. L'administration actuelle de la Présidente Gloria Macapagal-Arroyo est revenue sur la décision de son prédécesseur de ne promouvoir que l'usage du philippin au sein des écoles. Cette décision allait à l'encontre des intérêts de l'industrie des services de soutien aux entreprises et des STI tournée vers l'exportation, pour laquelle la maîtrise de l'anglais constitue le principal avantage comparatif. Au nombre des nouvelles initiatives figurent des programmes destinés à renforcer la maîtrise de l'anglais et les compétences en communication dont font preuve les enseignants, ainsi que l'élaboration d'enseignements facultatifs adaptés aux étudiants intéressés par une carrière dans les secteurs des services de soutien aux entreprises et des STI. Il s'agit également d'améliorer les capacités d'analyse des étudiants et plusieurs programmes conjoints associant l'industrie et les universités s'attachent à accroître la qualité des professionnels des TI.

126. Le Bureau des investissements a mandaté deux conseils pour qu'ils définissent en concertation avec le secteur privé des lignes directrices sur la protection de la confidentialité et de la sécurité des données. Il s'agissait d'instaurer des normes minimales en matière de protection des données, de prévenir les accidents et de faire échec au protectionnisme. Ces conseils coopèrent avec l'Association des technologies de l'information d'Amérique (Information Technology Association of America ou ITAA) en vue de parer aux problèmes potentiels. Le premier de ces conseils s'attache actuellement à mettre au point des lignes directrices volontaires auxquelles l'industrie puisse se conformer en attendant que le second ait rédigé et fait adopter un projet de loi sur la protection des données, ce qui devrait se produire courant 2007 (voir Lipana et Cooper, 2005).

127. Une autre initiative de grande ampleur a consisté à investir dans la création d'un "corridor des télécommunications" de $600 \mathrm{~km}$ de long. Les villes peuvent se raccorder à cette dorsale des TIC si elles satisfont à un certain nombre de conditions destinées à créer un environnement viable et favorable aux entreprises. Le projet s'est fixé pour objectif de créer un million d'emplois d'ici 2010. Pour y parvenir, le gouvernement estime qu'il faudra investir de 6 à 7 milliards de dollars des États-Unis pour améliorer l'infrastructure. Cette diversification géographique répond à plusieurs préoccupations. Tout d'abord, elle permettra à un plus grand nombre de régions des Philippines d'avoir accès aux débouchés commerciaux qu'ouvre la délocalisation internationale et il devrait en résulter un développement économique plus égal. 
En second lieu, elle limitera l'inflation salariale future, tout comme le débauchage de personnel, phénomène fréquent dans la zone métropolitaine de Manille. Enfin, la dorsale des TIC garantira un meilleur accès au réservoir de main-d'œuvre dont dispose le pays.

128. Certains critiques font valoir que le gouvernement philippin devrait s'abstenir de favoriser une industrie au détriment d'une autre et axer plutôt ses efforts sur l'amélioration du climat général des affaires aux Philippines. Les secteurs des services de soutien aux entreprises et des STI sont déjà l'un des moins touchés par les carences réglementaires et institutionnelles dont souffre le pays - voir l'annexe C - et les niveaux élevés de corruption dont sont victimes les entreprises nationales ne constituent pas un problème d'envergure pour les sociétés de services de soutien aux entreprises et de STI tournées vers l'exportation. Certains observateurs affirment il est vrai que les mesures d'incitation actuellement offertes ne bénéficient pas aux nombreuses petites entreprises nationales qui ne peuvent guère se permettre de s'établir dans les immeubles administrés par la PEZA, où les loyers sont élevés, mais d'autres (tels que Beshouri et Farrell, 2005) soutiennent au contraire que les Philippines feraient mieux d'investir leurs ressources dans l'amélioration des infrastructures et de l'éducation au lieu d'offrir des allègements fiscaux aux multinationales. Le même argument pourrait tout aussi bien être invoqué pour la Chine et l'Inde.

129. L'environnement dans lequel opère l'industrie est généralement jugé propice aux affaires et l'initiative du gouvernement philippin de réduire les obstacles aux investissements et les pesanteurs administratives a contribué à la prospérité de l'industrie.

\section{Encadré 7. SPi - histoire de la réussite exemplaire d'une société nationale}

Fondée aux Philippines en 1980 et première société philippine des TI à être cotée en bourse, SPi (auparavant dénommée SPI Technologies) est sans doute la société nationale de services de soutien aux entreprises la plus florissante des Philippines. Les 11000 salariés - dont 4500 dans les services vocaux de soutien aux entreprises et 6500 dans les services non vocaux de soutien aux entreprises - dont elle dispose en Asie, aux États-Unis et en Europe fournissent un large éventail de services de soutien aux entreprises liés aux contenus et aux données nécessaires dans le secteur de l'édition et dans les domaines juridique, des soins de santé, de la gestion de contenus et du traitement des transactions. Les principaux services proposés par SPi couvrent la numérisation de contenus (c'est-à-dire le transfert de données de supports papiers vers des bases de données électroniques), l'assistance juridique, la publication de livres et de journaux (composition, contrôle rédactionnel, scannage des illustrations et mise en page), la transcription médicale, les services de centres d'appel (entrants et sortants, appliqués à la vente comme aux relations avec la clientèle), ainsi que la maintenance et le développement de logiciels.

SPi a établi des effectifs de 1000 personnes à Coimbatore, Pondichéry, Kolkata, New Delhi et Chennai en Inde et prévoit de continuer à développer sa présence dans ce pays : elle a ainsi récemment acquis l'unité de transcription médicale de KGISTL en Inde, qui fournit des services à l'industrie américaine des soins de santé. La société possède également des centres de services au Vietnam et en Chine et elle a annoncé en avril 2005 qu'elle prévoit d'investir 50 millions de dollars pour développer ses capacités de prestation de services aux Philippines et aux États-Unis. La différenciation géographique constitue un important atout puisque les travaux peuvent alors être effectués là où il est le plus intéressant de le faire d'un point de vue financier. SPi possédait ainsi autrefois aux Philippines un effectif de 1500 personnes chargées de réaliser des travaux de saisie de données de base. Aujourd'hui, la quasi-totalité de ces tâches ont été transférées vers des pays tels que le Vietnam et la Chine.

La plupart des sociétés philippines de services de soutien aux entreprises sont des sous-traitantes de sociétés établies aux États-Unis et ne disposent guère de circuits de vente et de commercialisation dans les pays clients. SPi a mis en place ses propres circuits de vente et de commercialisation aux États-Unis et elle est parvenue à renforcer avec grand succès ses capacités internes en ce domaine, ce qui lui a permis d'être moins sensible aux pressions externes au niveau des prix. Contrairement à bien d'autres fournisseurs philippins indépendants de services de soutien aux entreprises, SPi a adopté le modèle d'entreprise approprié et mis en place une organisation parvenue à maturité, soucieuse de la qualité et qui jouit d'une grande notoriété à l'étranger.

Source : Huang (2005) et site web www.spitech.com. 


\section{Problèmes rencontrés pour répondre à la demande des marchés internationaux}

130. Les secteurs philippins des services de soutien aux entreprises et des STI sont dominés par des unités captives de multinationales étrangères, ou par des filiales de celles-ci qui couvrent leurs coûts. Le secteur des services de soutien aux entreprises est certes encore jeune mais s'est déjà transformé en une industrie de 2 milliards de dollars des États-Unis, faisant des Philippines une destination de choix pour la prestation de services vocaux de soutien aux entreprises destinés aux marchés anglophones. Certaines sociétés nationales - telles que SPi et eTelecare Global Solutions - sont devenues des multinationales internationalement reconnues dans le domaine des services de soutien aux entreprises. Créé dans les années 80 , le secteur des STI ne dispose pas encore de notables capacités d'exportation, lesquelles restent à mettre en place. Tout comme celui de la République tchèque, le secteur philippin des STI pourrait développer une expertise dans certains créneaux spécialisés mais il paraît improbable qu'il devienne un important fournisseur des marchés extérieurs dans un avenir prévisible.

131. Outre les avantages comparatifs précédemment mentionnés, la principale raison pour laquelle le secteur des services de soutien aux entreprises a connu une telle expansion tient sans doute à la relative facilité avec laquelle les sociétés Philippines peuvent fournir des services aux États-Unis. Le gouvernement philippin a mis en place des mesures d'incitation et facilité l'entrée sur le marché mais s'est abstenu de toute ingérence dans l'industrie. La plupart des sociétés nationales de services de soutien aux entreprises et de STI sont des PME et sont confrontées à des problèmes qui ne sont liés ni aux réglementations nationales ni à celles en vigueur dans les pays étrangers. Ils tiennent plutôt aux difficultés qu'elles éprouvent à recruter et retenir leurs effectifs, à développer des modèles d'entreprise viables et parvenus à maturité, et à convaincre les clients étrangers qu'il est très improbable que les risques d'instabilité politique aient une incidence sur l'activité économique. Le risque-pays a des répercussions négatives sur l'activité économique, c'est pourquoi la stabilité politique et un ordre durable revêtent une importance primordiale pour le secteur des services de soutien aux entreprises, qui fournit des services en temps réel tout au long de l'année.

132. Ce n'est qu'au cours des toutes dernières années que les secteurs des services de soutien aux entreprises et des STI ont déployé des efforts pour se vendre à l'étranger. Les multinationales étrangères qui composent une grande partie du secteur n'ont aucune incitation à vanter les mérites des Philippines en tant que lieu de prestation de services de soutien aux entreprises et de STI délocalisés. La création de $\mathrm{BPA} / \mathrm{P}$, qui fédère six autres associations professionnelles, et sa coopération avec le Bureau des investissements, lequel dépend du ministère du Commerce et de l'Industrie, commence déjà à accroître la notoriété de l'industrie. C'est en effet là une chose indispensable car rares sont les sociétés philippines qui disposent de leurs propres circuits de vente et de commercialisation à l'étranger : la plupart des sociétés travaillent avec des partenaires étrangers rémunérés à la commission, alors que ce modèle d'entreprise n'est généralement guère viable à long terme.

\section{Contraintes du côté de l'offre}

\section{Recrutement et rétention du personnel}

133. Les secteurs des services de soutien aux entreprises et des STI sont tributaires des ressources humaines. La recherche des personnes possédant les meilleures compétences possibles constitue pour les sociétés une priorité primordiale et de tous les instants, ainsi que le principal problème auquel elles sont quotidiennement confrontées. D'après BPA/P, la pénurie de personnel approprié est le problème le plus pressant pour les secteurs philippins des services de soutien aux entreprises et des STI. Le pays forme environ 70000 diplômés par an dans des disciplines en rapport avec l'informatique, mais en 2005 seulement 12000 professionnels au total ont travaillé dans le secteur des STI tourné vers l'exportation (Locsin, 2006). Une des raisons pour laquelle l'industrie des STI n'est pas parvenue à décoller tient à la 
qualité relativement modeste des étudiants en mathématiques et en sciences philippins (Rodolfo, 2005). Plusieurs sociétés des TI estiment que le gouvernement philippin doit instituer des normes minimales de qualité dans l'enseignement technique supérieur. Les étudiants qui optent pour les filières d'enseignement liées aux TI risquent sinon d'être victimes du chômage ou de devoir se rabattre sur des emplois pour lesquels ils sont surqualifiés dans des secteurs adjacents de faible valeur.

134. Une autre raison pour laquelle le secteur des STI s'est débattu dans les difficultés tient au fait que bon nombre de professionnels des logiciels possédant 4 ou 5 ans d'expérience quittent les Philippines pour travailler à l'étranger alors que rares sont ceux qui y retournent. Cela a pour effet de limiter le nombre de professionnels présents dans le pays qui disposent d'une expertise technique de haut niveau ainsi que de compétences en matière de gestion. La relative jeunesse de cette industrie a également entraîné une pénurie de cadres confirmés ayant une connaissance approfondie de ce secteur d'activité. Les unités captives des multinationales étrangères sont mieux placées pour attirer les cadres moyens et les personnes dotées d'une expertise du domaine considéré dont disposent encore les Philippines. Les obstacles à l'entrée sur le marché des STI sont relativement faibles, alors que les coûts effectifs et l'expertise requise pour répondre à la demande des marchés extérieurs sont élevés.

135. Les certifications de la qualité (ISO, SEI CMM et SEI CMMi) que les sociétés des STI peuvent obtenir pour accroître la qualité et le degré de maturité de leurs activités et pour commercialiser leurs services de qualité servent autant qu'elles desservent le secteur philippin des STI. De nos jours, les grands clients exigent normalement ce type de certifications en vue d'évaluer la maturité des processus d'une entreprise. Ces certifications sont cependant longues et coûteuses à obtenir et la plupart des sociétés philippines ne se sont guère intéressées à cet important outil de commercialisation. La situation est similaire à celle de l'industrie tchèque. Certains cadres remarquent que plus le degré de maturité des activités de délocalisation internationale des STI s'accroît, plus les obstacles à l'entrée s'accumulent sous la forme de normes de plus en plus strictes dans le domaine de la confidentialité et de la sécurité des données, mais aussi d'exigences de plus en plus grandes en matière de certification de la qualité des processus, de capacité d'évolution, d'investissement dans la formation, etc. Ces obstacles à l'entrée sont toutefois imposés par l'industrie elle-même et sont la conséquence d'une concurrence internationale croissante.

136. Les contraintes du côté de l'offre dans le secteur en pleine expansion des services de soutien aux entreprises ont entraîné une forte inflation salariale au profit des travailleurs des centres d'appel. Les emplois offerts par les centres philippins de contact avec la clientèle s'adressent à une population assez réduite de professionnels car la plupart des diplômés ne possèdent pas les compétences requises vu que l'interaction avec les clients exige une connaissance approfondie des langues ainsi que des compétences de haut niveau en matière de communication. C'est pourquoi un travailleur des centres d'appel bénéficie d'un salaire de départ plus élevé qu'un docteur en médecine, un comptable ou un programmeur logiciel. En 2005, le salaire de base des travailleurs des centres d'appel qui parlent anglais était de 14000 à 16000 pesos par mois, auxquels s'ajoutent les primes pour travail de nuit et celles de résultats. Les travailleurs des centres de contact qui parlent une seconde langue telle que le japonais ou l'espagnol peuvent obtenir un salaire représentant jusqu'à deux fois le salaire de base d'un travailleur de centre d'appel parlant anglais. Un cadre de l'industrie a fourni les estimations suivantes du salaire mensuel de départ pour les jeunes professionnels :

- développeur logiciel dans l'industrie nationale : 12000 pesos ;

- développeur logiciel dans une multinationale étrangère : 18000 pesos ;

- $\quad$ agent de centre d'appel parlant anglais : de 14000 à 16000 pesos + prime de résultats ; 
- agent de centre d'appel parlant japonais ou espagnol : de 20000 à 25000 pesos + prime de résultats.

137. L'inflation salariale a pour conséquence que le travail dans un centre de contact constitue désormais un premier emploi attractif pour la plupart des diplômés, ou pour citer un cadre ayant de nombreuses années d'expérience dans le secteur des centres d'appel en Inde comme aux Philippines: “...travailler dans un centre d'appel vous confère aujourd'hui en Asie l'image d'un jeune cadre dynamique. C'est un travail idéal pour ramener 20000 pesos par mois à la maison, c'est impressionnant." Un salaire de base de 15000 pesos représente à peine moins de 300 dollars des États-Unis et si l'on y ajoute les primes, les avantages sociaux et un $13^{\text {ème }}$ mois de salaire en décembre, la rémunération totale est élevée par rapport à d'autres professions. Mais la rapide croissance de l'industrie est en train de créer des problèmes de recrutement. Il y a cinq ans, une société philippine désireuse de recruter un travailleur qualifié dans le secteur des services de soutien aux entreprises devait le sélectionner parmi 25 à 30 personnes environ. Ajourd'hui, cette même société pourrait devoir faire passer un entretien à 60 à 80 candidats. Le risque qu'une maîtrise limitée de l'anglais restreigne la croissance potentielle de l'industrie et accroisse les investissements nécessaires pour sélectionner et former les effectifs constitue une fréquente source d'inquiétude. D'après une enquête menée par O2P et BPA/P (2006), le renforcement des compétences en anglais constitue le domaine où le gouvernement philippin peut le plus aider l'industrie, immédiatement après l'amélioration de la situation politique et de l'image extérieure du pays. ${ }^{42}$

138. Ce sont les PME qui rencontrent les plus gros problèmes. Bon nombre de petites sociétés de services de soutien aux entreprises souffrent de l'irrégularité de leurs flux de recettes et sont contraintes de faire appel à des travailleurs auxquels elles proposent des contrats de courte durée pour mener à bien des contrats ponctuels. C'est peut-être là un des rares moyens viables de faire face à l'instabilité de l'environnement dans lequel opèrent les entreprises. Le droit du travail philippin devient en effet beaucoup plus strict lorsque le salarié est employé pendant plus de six mois. Ces contrats de courte durée n'ont pas seulement pour effet d'accroître la précarité de l'emploi et les taux de rotation des effectifs, ils réduisent également les incitations qu'ont les sociétés à investir pour former leurs employés et développer ce faisant une expertise interne. Le problème est aggravé par le fait qu'il faut un temps considérable pour atteindre les niveaux de productivité indispensables pour cultiver des relations d'affaires à long terme.

139. Le secteur des logiciels tourné vers l'exportation est de faible envergure et assez peu mature mais sa croissance pourrait s'accélérer si le gouvernement parvient à accroître la qualité de l'enseignement et à améliorer les programmes d'études techniques au sein des écoles. Le secteur privé a commencé à contribuer aux efforts pour améliorer les qualifications des diplômés en TI en fournissant du matériel $\mathrm{d}$ 'enseignement et en formant des enseignants. BPA/P mène également une action de lobbying auprès du gouvernement en vue d'accroître les compétences en matière de communication et les aptitudes linguistiques des étudiants et des enseignants.

\section{Problèmes réglementaires}

140. L'environnement dans lequel opèrent les entreprises nationales pourrait certes être grandement amélioré, mais il n'en restent pas moins que les secteurs des services de soutien aux entreprises et des STI ont un meilleur sort que la plupart des autres industries aux Philippines. Les indicateurs de la Banque mondiale relatifs à la facilité de conduite des affaires (Doing business - voir l'annexe C) mettent en évidence l'inefficacité des procédures de création et de fermeture d'entreprises, la lenteur des procédures d'exécution des contracts et la faible protection des investisseurs. Toutefois, la politique spéciale dont bénéficient les sociétés opérant dans les immeubles administrés par la PEZA aident ces sociétés à éviter la

\footnotetext{
${ }^{42}$ La fourniture d'électricité est certes plus stable qu'en Inde, par exemple, mais Beshouri et Farell (2005) n'en constatent pas moins que l'électricité est aux Philippines $43 \%$ plus chère qu'en Inde et $65 \%$ plus chère qu'en Chine.
} 
plupart des problèmes liés aux réglementations nationales. Les secteurs des services de soutien aux entreprises et des STI ne sont par ailleurs confrontés qu'à de rares problèmes liés aux réglementations étrangères. Par le passé, les nouvelles réglementations adoptées aux États-Unis ont donné naissance à des industries de services entièrement nouvelles (voir l'encadré 9). Les rares problèmes réglementaires qui demeurent sont liés aux restrictions aux mouvements des travailleurs des services et à la sécurité des données.

\section{Encadré 8. Le secteur philippin des transcriptions médicales}

Le secteur philippin des transcriptions médicales est encore jeune et d'envergure relativement restreinte et constitue le segment le plus dynamique du secteur philippin des services de soutien aux entreprises. Il employait environ 5500 personnes en 2005 , dont beaucoup travaillent à leur domicile, au sein d'entreprises familiales. Le secteur a été créé à la suite de la promulgation en 1996 de la loi sur la portabilité et la responsabilité des assurances-santé (Health Insurance Portability and Accountability Act ou HIPAA) par le Sénat des États-Unis. Cette loi exige que les établissements médicaux conservent les dossiers de leurs patients. Elle impose également l'élaboration de normes nationales pour les transactions électroniques relatives aux soins de santé et elle traite dans ses dispositions de la question de la sécurité et de la confidentialité des données médicales. Les hopitaux et les dispensaires qui sous-traitent une part de leur activité à une tierce partie doivent veiller à ce que le prestataire de services ait mis en place un cadre lui permettant de se conformer aux exigences de l'HIPAA.

La naissance de l'industrie des transcriptions médicales aux Philippines peut être datée : elle remonte à l'an 2000, date où une société américaine a établi une unité captive pour fournir des services de transcription. Cette société a employé jusqu'à 700 personnes à son apogée, mais elle a été rapidement rachetée par une autre société américaine qui a décidé de transférer toutes ses activités en Inde. Confrontés au chômage, certains de ses anciens salariés ont créé leurs propres entreprises pour fournir des services au marché des États-Unis et ces entreprises composent à présent l'essentiel du secteur philippin des transcriptions médicales.

Environ $90 \%$ du marché américain des services de transcription sont contrôlés par des sociétés nationales mais le réservoir de main-d'œuvre des États-Unis a diminué de quelques pour cent par an. Ce travail est peu payé et rares sont ceux qui considèrent qu'il constitue un vrai métier aux États-Unis. La délocalisation internationale s'est avérée être une solution attractive pour les dispensaires américains et l'Inde s'est emparée d'environ $10 \%$ du marché des États-Unis. L'industrie philippine des transcriptions médicales détient actuellement moins de $1 \%$ de ce marché.

Les sociétés de transcription médicale travaillent $24 / 24 \mathrm{~h}$ et sept jours sur sept, alors que les centres d'appel opèrent principalement de nuit. Ces sociétés reçoivent en règle générale un enregistrement audio comportant la dictée du texte ainsi qu'une brève note sur le patient. Elle en assure la transcription et rédige en quelques heures un rapport assorti d'une analyse qu'elle renvoie ensuite au client. Les hôpitaux reçoivent ces rapports dans un délai de 6 à 12 heures. Les problèmes sont principalement de deux ordres : la main-d'œuvre disponible et le respect des exigencs de la HIPAA en matière de confidentialité et de sécurité des données. L'Association de l'industrie des transcriptions médicales des Philippines (Medical Transcription Industry Association of the Philippines) travaille actuellement à la mise en place d'une certification du respect des dispositions de la HIPAA à l'intention de l'industrie locale en vue d'accroître la transparence et la difffusion des normes .

Source: Bel Reyes de l'Association de l'industrie des transcriptions médicales des Philippines (Medical Transcription Industry Association of the Philippines, ou MTIAPI).

\section{Restrictions aux mouvements temporaires de professionnels des services}

141. Les secteurs philippins des services de soutien aux entreprises et des STI sont principalement composés de multinationales étrangères et ces sociétés font circuler peu de professionnels entre les Philippines et leur pays d'origine ou les pays clients. Les professionnels employés par des multinationales étrangères ne sont soumis qu'à de rares restrictions en la matière car ils peuvent obtenir des permis de travail intra-entreprise. En outre, la plupart des professionnels des services travaillent dans le secteur des centres de contact, dont les employés n'ont que rarement besoin de se déplacer à l'étranger. Les problèmes 
liés aux mouvements des personnes physiques sont toutefois plus important pour certaines des sociétés nationales de services de soutien aux entreprises axées sur les exportations. Elles demeurent certes peu nombreuses pour l'instant, mais celles qui se heurent à des restrictions rencontrent les mêmes problèmes que les professionnels indiens des logiciels, à savoir les limitations imposées par les systèmes de quotas, les difficultés d'obtention des papiers nécessaires, ainsi que les problèmes de délais et d'imprévisibilité liés au processus de demande de visas d'affaires et de permis de travail.

142. La plupart des sociétés philippines des STI ont adopté un autre modèle d'entreprise que la plupart des sociétés indiennes. Les sociétés philippines s'associent généralement à des partenaires établis dans les pays clients qui assurent la vente et la commercialisation et se chargent d'effectuer la part du travail qui doit être réalisée sur place. D'autres parmi elles préfèrent faire venir leurs clients aux Philippines afin de réduire les coûts ainsi que les tracasseries administratives liées à l'obtention des visas et des permis de travail. Bien que certaines déclarent être parfois contraintes de renoncer à certaines opportunités commerciales en raison des délais d'obtention des visas et des permis de travail, les préoccupations dont il est fait état sont plus souvent trait à la taille limitée des sociétés philippines.

143. Plusieurs sociétés indiennes de services de soutien aux entreprises et de STI ont engagé des négociations avec les autorités philippines en vue de l'implantation de centres de développement aux Philippines et certaines des plus grandes d'entre elles ont créé des filiales à Manille. Les IDE indiens sont toutefois limités, car les citoyens indiens soumis à des restrictions par la législation philippine à raison de leur nationalité. En vertu de cette réglementation, seul un très faible quota d'Indiens est autorisé chaque année à visiter les Philippines. Les restrictions aux échanges sud-sud sont souvent importantes mais il ne leur est en général guère prêté attention. Plusieurs nationalités sont ainsi soumises à des restrictions à l'entrée sur le territoire des Philippines en vertu de cette politique.

\section{Restrictions à la circulation des informations}

144. Les réglementations liées à la confidentialité et à la sécurité des données qui ont une incidence sur les secteurs philippins des services de soutien aux entreprises et des STI sont les même que celles auxquelles sont soumis leurs concurrents indiens (voir ci-dessus). Les sociétés philippines sont toutefois plus tributaires du marché des États-Unis. Ces réglementations n'ont pas pour seul effet d'accroître les frais généraux : elles peuvent également créer d'importants débouchés commerciaux. L'adoption par les États-Unis de la loi sur la portabilté et la responsabilité des assurances-santé, qui exige que les établissements médicaux conservent sous forme numérique les dossiers de leurs patients a donné naissance à l'industrie des transcriptions médicales aujourd'hui en pleine expansion en Inde et aux Philippines.

145. Les sociétés philippines interrogées pour les besoins de cette étude déclarent que la législation relative à la confidentialité et à la sécurité des données a généré certaines normes professionnelles utiles : il peut certes être coûteux de s'y conformer, mais cela ne constitue pas un problème compte tenu que toutes les sociétés sont soumises à cette même obligation. Les clients exigent des garanties de sécurité des informations plus strictes que ne l'imposent les législations nationales et les prestataires de services se conforment à ces exigences afin de pouvoir poursuivre leur activité. 


\section{GRANDES CONCLUSIONS ET REMARQUES FINALES}

\section{Caractéristiques du marché et échanges}

146. Les études de cas par pays portant sur les secteurs des services de soutien aux entreprises et des STI en Chine, en Inde, aux Philippines et en République tchèque ont montré comment les économies émergentes sont en passe de s'intégrer dans les chaînes mondiales d'approvisionnement des pays de l'OCDE dans le domaine des services. En 2005, le volume global des recettes d'exportation des quatre pays était estimé à 8.7 milliards de dollars des États-Unis pour les services de soutien aux entreprises et à 14.5 milliards de dollars des États-Unis pour les STI. La plupart de ces exportations étaient destinées aux économies de l'OCDE. ${ }^{43}$ Ces chiffres peuvent paraître modestes par rapport à la valeur totale des exportations de marchandises (948 milliards des États-Unis) mais la contribution économique des secteurs des services de soutien aux entreprises et des STI s'est sensiblement accrue en Inde et aux Philippines.

147. L'Inde se classe au premier rang des économies émergentes grâce à son secteur des STI parvenu à maturité et compétitif au plan international. Le secteur indien des STI a réussi à créer une industrie extrêmement performante en s'appuyant sur un modèle de fourniture de services dans le monde entier sans cesse amélioré au cours de la dernière décennie. Il réalise un important volume d'exportations à destination de l'Amérique du nord et de l'Europe mais demeure fortement tributaire des marchés anglophones. Certains éléments donnent à penser que la Chine est en train de devenir la destination étrangère préférée des sociétés japonaises. Il reste cependant à savoir si quelque économie émergente que ce soit pourra un jour prétendre rivaliser par la taille avec l'Inde.

148. Le marché des services de soutien aux entreprises délocalisés à l'étranger est jeune et en rapide développement et la concurrence entre les quatre pays y est plus égale que dans celui des STI. L'Inde est le principal pays exportateur mais les Philippines en sont désormais un important concurrent dans le domaine des services en anglais, en particulier lorsqu'ils sont vocaux. Le secteur des services de soutien aux entreprises axé sur les exportations poursuivra sans doute dans un proche avenir son expansion dans les quatre pays examinés. Certaines des multinationales qui donnent le ton ont déjà recours à l'ensemble de ces quatre pays pour fournir des services de soutien aux entreprises dans les différentes zones géographiques au sein desquelles ils jouissent d'un avantage comparatif.

149. Les conclusions suivantes peuvent être tirées des études de cas par pays :

$>$ Les secteurs des services de soutien aux entreprises et des STI des quatre pays s'adressent à des clients différents : seuls 10 à $15 \%$ des services de soutien aux entreprises et des STI de la Chine et de la République tchèque sont exportés, alors que près de $80 \%$ de ceux de l'Inde et des Philippines sont fournis à des clients établis à l'étranger.

$>$ La proximité linguistique et culturelle constitue un facteur décisif pour ce qui est de la fourniture internationale de services de soutien aux entreprises et de STI. Du point de vue des échanges, la Chine et la République tchèque sont essentiellement vouées à la fourniture de proximité de ces deux types de services aux entreprises d'Asie orientale et d'Europe respectivement. L'Inde et les Philippines se consacrent au contraire à la fourniture à distance de ces mêmes services à des marchés plus lointains.

\footnotetext{
${ }^{43}$ En Inde, l'année financière s'étend du $1^{\mathrm{er}}$ avril 2005 au 31 mars 2006.
} 
- Les marchés d'exportation de la République tchèque sont ceux des pays de l'UE, et notamment celui du Royaume-Uni, ainsi que ceux de l'Allemagne, de l'Autriche et de la Slovaquie voisines.

- Les exportations chinoises sont dans une large mesure absorbées par le Japon (les deux tiers environ du total). Les autres marchés d'exportation de la Chine incluent la Corée, les États-Unis et les pays de la région Asie-Pacifique.

- Les exportations indiennes sont principalement destinées aux États-Unis (66\%) et au Royaume-Uni (14\%). Les autres marchés d'exportation de l'Inde incluent le Japon, Singapour et l'Allemagne.

- Les exportations philippines sont essentiellement absorbées par les États-Unis (90\%). Les autres pays anglophones forment une bonne partie du reste.

Les échanges de services de soutien aux entreprises et de STI sont dominés par des multinationales de la zone de l'OCDE mais les sociétés nationales des économies non membres y prennent une part croissante :

- Les exportations tchèques de services de soutien aux entreprises et de STI sont essentiellement assurées par des multinationales étrangères.

- Les exportations philippines de services de soutien aux entreprises et de STI sont elles aussi principalement assurées par des multinationales étrangères. Les sociétés nationales fournissent de plus en plus de services de soutien aux entreprises et de STI aux marchés étrangers.

- Les exportations chinoises de services de soutien aux entreprises et de STI sont aussi bien réalisées par des sociétés nationales que par d'autres sous contrôle étranger.

- Les exportations indiennes de services de soutien aux entreprises sont assurées à parts égales par des sociétés nationales et par d'autres sous contrôle étranger, bien que les premières réalisent les deux tiers des exportations indiennes de STI.

Les quatre pays ont développé des capacités d'exportation différentes dans le domaine des services de soutien aux entreprises et des STI :

- La République tchèque constitue principalement un centre de fourniture de services de soutien aux entreprises et de développement d'applications logicielles.

- La Chine s'est dotée de capacités aux deux extrémités de la chaine de valeur : elle jouit d'une position de force à l'extrémité des services de soutien aux entreprises et des STI de plus faible valeur tels que les activités de saisie et de contrôle de données, alors que les multinationales étrangères font de plus en plus appel à elle pour se procurer des services de R-D dont la valeur est élevée.

- L'Inde domine actuellement le secteur des services de soutien aux entreprises et elle repousse les limites existantes en ce qui concerne les types de services susceptibles de faire l'objet d'une fourniture transfrontières. Sous l'angle de la délocalisation, elle constitue un fournisseur de services complet. Dans le secteur des STI, l'Inde jouit d'une position de force dans les services de développement d'applications logicielles et de maintenance des applications. Elle pose actuellement les premiers jalons de la création de points forts dans le domaine de l'intégration de systèmes et dans celui du conseil en TI.

- Les Philippines jouissent actuellement d'une position de force en ce qui concerne la fourniture de services de soutien aux entreprises, en particulier pour ce qui est des services vocaux. 


\section{Problèmes relatifs aux échanges et à l'activité économique}

150. Les problèmes les plus pressants dans les secteurs des services de soutien aux entreprises et des STI axés sur les exportations ont trait à des préoccupations telles que celles d'assurer l'efficience des activités, de faire face à la complexité des relations avec la clientèle internationale, de mettre en place des circuits de vente et de commercialisation à l'étranger, etc. L'industrie est confrontée à des obstacles réglementaires relativement peu nombreux dans les pays d'origine comme dans ceux des clients. Cependant, le recrutement, la formation et la rétention du personnel constituent des problèmes majeurs au sein de l'industrie. Les sociétés de services de soutien aux entreprises et de STI peuvent généralement surmonter les obstacles administratifs dont souffre l'environnement local des entreprises grâce à des zones spéciales à vocation exportatrice au sein desquelles les contraintes administratives excessives sont supprimées et où il est remédié aux lacunes en matière d'infrastructures. Cependant, si les gouvernements prenaient des mesures pour améliorer l'environnement global des entreprises et libéralisaient les marchés pour les principaux services entrants, cela rendrait superflus des investissements lourds dans ces zones. Certains problèmes sont également liés aux mouvements temporaires des travailleurs des services dans le secteur des STI et aux réglementations relatives aux données dans celui des services de soutien aux entreprises.

\section{Recrutement et rétention du personnel}

$>$ Les quatre pays se heurtent à d'importantes contraintes du côté de l'offre dans leur effort pour fournir des services de soutien aux entreprises et des STI aux marchés internationaux. Les contraintes du côté de l'offre sont particulièrement fortes dans le secteur des STI. Le problème est moins aigu pour les multinationales étrangères qui proposent d'avantages salariaux en vue de recruter les meilleurs. La perspective de travailler dans les secteurs des services de soutien aux entreprises et des STI de ces quatre pays attire des travailleurs hautement qualifiés. Il en est tout autrement de certains postes proposés dans le secteur des services de soutien aux entreprises des pays de l'OCDE, notamment dans le domaine des services vocaux, où le travail est mal rémunéré et les taux de départ élevés.

- Recrutement et rétention de personnel débutant : bien que la Chine, l'Inde et les Philippines forment de grands nombres de diplômés de l'université, rares sont ceux à même de travailler dans l'industrie et de fournir des services à des clients étrangers. La plupart des diplômés n'ont pas d'aptitudes linguistiques suffisantes, ni ne disposent des compétences en matière de communication et du sens des affaires qui sont nécessaires à l'interaction avec les clients, pas plus qu'ils ne possèdent le niveau de formation technique indispensable. Le montant des rémunérations n'en incite pas moins de nombreux étudiants et diplômés de l'université à chercher à s'employer dans l'industrie. L'identification des travailleurs qui conviennent exige l'investissement d'importantes ressources dans le processus de recrutement. Dans le secteur des STI, de considérables ressources doivent également être consacrées à la formation. Aussi la rétention des effectifs est-elle essentielle compte tenu que les jeunes professionnels ne deviennent productifs qu'avec l'expérience. Les taux de rotation des effectifs sont élevés dans le secteur des services de soutien aux entreprises tout comme dans de nombreuses sociétés du secteur des STI.

- Recrutement et rétention de personnel confirmé : les secteurs des services de soutien aux entreprises et des STI axés sur les exportations ne sont apparus qu'il y a quelques années en Chine, aux Philippines et en République tchèque. Les directeurs de projets et les cadres supérieurs n'ont donc guère eu la possibilité d'acquérir une expérience spécifique dans ces secteurs. Ceux qui disposent d'une telle expérience travaillent dans une large mesure pour des multinationales étrangères. Aussi de nombreuses sociétés recrutent-elles du personnel confirmé à l'étranger, ce qui impose des coûts élevés. Ce problème est particulièrement 
aigu en Chine où l'industrie est pour une large part tributaire du retour des membres de la diaspora chinoise. La situation est moins grave en Inde, où l'industrie a eu davantage de temps pour renforcer ses capacités. Une forte demande a abouti à une rapide inflation des salaires des professionnels expérimentés.

\section{Problèmes réglementaires}

L'environnement local des entreprises souffre de considérables problèmes réglementaires et administratifs dans tous les pays étudiés, à l'exception de la République tchèque. Ces problèmes touchent aussi bien les sociétés nationales que celles sous contrôle étranger qui opèrent en Chine, en Inde et aux Philippines. Le marché intérieur des services est certes très protégé dans les trois pays asiatiques, mais les pouvoirs publics accordent un degré de priorité élevé à la création d'une puissante industrie nationale axée sur les exportations. Les effets négatifs que l'environnement local des entreprises exerce sur les sociétés de services de soutien aux entreprises et de STI axées sur les exportations est très réduit compte tenu de l'environnement dans lequel elles opèrent : les parcs et centres logiciels et technologiques qui hébergent ces sociétés offrent souvent des infrastructures prêtes à l'emploi sous la forme de locaux à usage de bureau, de services d'utilité publique et de services des TIC, mais aussi une administration rationalisée du secteur des entreprises ainsi que des incitations financières. Les politiques qui visent à améliorer le climat des investissements dans certaines industries risquent de défavoriser d'autres secteurs de l'économie. Elles n'en ont pas moins eu un impact positif sur les secteurs locaux des services de soutien aux entreprises et des STI étudiés dans ce document.

$>$ Dans le secteur des STI, les mouvements temporaires de personnel entre le pays d'origine et celui du client peuvent poser de graves difficultés dans le cas des activités de délocalisation externe à l'étranger. Le problème est particulièrement aigu dans le secteur indien des STI, qui est dans une large mesure tributaire du modèle de fourniture de services dans le monde entier, lequel implique l'envoi de professionnels pour des visites de plus longue durée dans les locaux des clients. L'imprévisibilité, la lenteur et le coût des procédures administratives de délivrance de visas d'affaires et de permis de travail, ainsi que les limitations imposées par le système de quotas au nombre de permis de travail accordés posent désormais de graves problèmes à certaines sociétés.

$>$ Dans le secteur des services de soutien aux entreprises comme dans une moindre mesure dans celui des STI, la législation sur la confidentialité et la sécurité de certaines données pourrait avoir un effet négatif sur la délocalisation externe à l'étranger. Les nouvelles réglementations ont également créé des débouchés commerciaux totalement nouveaux, par exemple dans le secteur des transcriptions médicales. Les réglementations relatives à la confidentialité et à la sécurité des données ne sont pas nécessairement réputées avoir une incidence négative pour autant qu'elles ne soient pas de nature discriminatoire. Des solutions technologiques permettent dans la plupart des cas aux sociétés de se conformer aux exigences réglementaires et les clients exigent généralement que leurs fournisseurs respectent des normes plus strictes que celles imposées par la législation en vigueur. 
Tableau 3. Résumé : quelques indicateurs du marché et profils commerciaux, $2005^{44}$

\begin{tabular}{|c|c|c|c|c|}
\hline & Chine & République tchèque & Inde & Philippines \\
\hline Exportations de STI (milliards d'USD) & 1.0 & $0.06^{*}$ & 13.2 & 0.2 \\
\hline $\begin{array}{l}\text { Exportations de services de soutien aux } \\
\text { entreprises (milliards d'USD) }\end{array}$ & 0.3 & $0.04^{*}$ & 6.3 & 2.0 \\
\hline $\begin{array}{l}\text { Exportations en pourcentage de } \\
\text { l'ensemble des prestations de services }(\%)\end{array}$ & $10-15$ & 10 & 79 & $79^{*}$ \\
\hline Activités de délocalisation & $\begin{array}{c}\text { Délocalisation interne à } \\
\text { l'étranger ; part relativement } \\
\text { faible mais en augmentation } \\
\text { de délocalisation externe à } \\
\text { l'étranger }\end{array}$ & $\begin{array}{l}\text { Délocalisation interne à } \\
\text { l'étranger }\end{array}$ & $\begin{array}{l}\text { Délocalisation interne et } \\
\text { externe à l'étranger }\end{array}$ & $\begin{array}{c}\text { Délocalisation interne à } \\
\text { l'étranger ; part relativement } \\
\text { faible mais en augmentation } \\
\text { de délocalisation externe à } \\
\text { l'étranger }\end{array}$ \\
\hline $\begin{array}{l}\text { Priorités des secteurs des services de } \\
\text { soutien aux entreprises et des STI }\end{array}$ & $\begin{array}{l}\text { Marché intérieur et } \\
\text { délocalisation de proximité }\end{array}$ & $\begin{array}{l}\text { Marché intérieur et } \\
\text { délocalisation de proximité }\end{array}$ & Délocalisation & Délocalisation \\
\hline $\begin{array}{l}\text { Principaux marchés d'exportation } \\
\text { (\% des exportations totales) }\end{array}$ & $\begin{array}{c}\text { Japon : } 60-70 \\
\text { Autres pays de la région Asie- } \\
\text { Pacifique : } 15\end{array}$ & UE & $\begin{array}{l}\text { États-Unis : } 66 \\
\text { Royaume-Uni : } 14\end{array}$ & États-Unis : 90 \\
\hline $\begin{array}{l}\text { Emplois dans les secteurs exportateurs de } \\
\text { services de soutien aux entreprises et de } \\
\text { STI (en millions) }\end{array}$ & $0.1-0.2^{45}$ & .. & $\begin{array}{c}0.38 \text { dans les } \mathrm{STI}^{46} \\
0.41 \text { dans les services de } \\
\text { soutien aux entreprises }\end{array}$ & $\begin{array}{c}0.01 \text { dans les STI } \\
0.16 \text { dans les services de } \\
\text { soutien aux entreprises }\end{array}$ \\
\hline Villes de première importance (exemples) & Beijing, Shanghai, Shenzhen & Prague & $\begin{array}{l}\text { Bangalore, Hyderabad, } \\
\text { Chennai, Mumbai, New Delhi }\end{array}$ & Zone métropolitaire de Manille \\
\hline Villes de seconde importance (exemples) & $\begin{array}{l}\text { Dalian, Guangzhou Nanjing, } \\
\text { Xian }\end{array}$ & Brno, Plzen & $\begin{array}{c}\text { Gurgaon, Kolkata, Mangalore, } \\
\text { NOIDA, Pune }\end{array}$ & Cebu, Clark, Davao \\
\hline $\begin{array}{l}\text { Dépendance à l'égard des mouvements } \\
\text { temporaires de professionnels du secteur } \\
\text { des services (travail sur place) }\end{array}$ & Faible & Faible & Forte & Faible \\
\hline
\end{tabular}

* 2004

${ }^{44}$ Certaines des données présentées dans ce tableau correspondent aux meilleures estimations disponibles et elles n'y figurent que faute d'autres sources de données exhaustives qui fassent autorité. Les sources des données sont indiquées dans les chapitres par pays. Pour 1'Inde, "2005” couvre la période allant du $1^{\text {er }}$ avril 2005 au 31 mars 2006.

${ }^{45}$ Environ 900000 personnes étaient au total employées par les entreprises de cette industrie, qu'elles soient tournées vers le marché intérieur ou axées sur les exportations. La valeur des exportations de services de mise au point de logiciels était d'environ 960 millions de dollars des États-Unis, alors que celle du marché national pour ce type de services atteignait 8,7 milliards de dollars des États-Unis. La valeur des exportations de services de soutien aux entreprises s'élevait à 320 millions de dollars des États-Unis. On estime à approximativement 0.1 à 0.2 million le nombre de travailleurs employés dans ce secteur.

${ }^{46}$ Ce chiffre est estimé à partir des données fournies par Nasscom (2006). Les effectifs combinés des secteurs axés sur les exportations des STI, des services d'ingénierie et de RD, et des produits logiciels étaient estimés à 0.51 million en mars 2006. Les recettes générées dans le secteur des STI représentaient $75 \%$ des recettes totales de l'ensemble de ces secteurs. $75 \%$ de 0.51 million nous donnent 0.38 million. 


\section{Remarques additionnelles}

151. Dans le futur, de plus en plus de multinationales opérant dans les secteurs des services de soutien aux entreprises et des STI mèneront à bien leurs activités là où elles sont le plus performantes et où cela a le plus de sens d'un point de vue financier. Il s'ensuivra probablement (et entre autres) les conséquences suivantes :

- La très grande majorité des travailleurs employés dans le secteur des services de soutien aux entreprises continueront d'être basés à très grande proximité de leurs clients.

- La fourniture de services de soutien aux entreprises et de STI aura un caractère plus international :

- Les multinationales de la zone de l'OCDE renforceront leur présence dans les économies émergentes, ce qui leur permettra de tirer parti de la rapide expansion de leur demande intérieure de services délocalisés et de s'assurer l'accès à un réservoir mondial de compétences. La délocalisation externe à l'étranger donnera avec le temps naissance à des secteurs de services totalement nouveaux compte tenu de la multitude de modèles d'entreprise qui deviennent économiquement viables.

- Les principales sociétés de services de soutien aux entreprises et de STI des économies émergentes s'implanteront sur les marchés de l'OCDE pour y établir des capacités locales leur permettant de leur fournir des prestations lorsque les marchés limités des services les plus aisément "délocalisables" seront saturés. Aussi de plus en plus de travailleurs des pays de l'OCDE travailleront-ils pour des sociétés originaires d'économies non membres.

- L'intensification de la concurrence dans le secteur des services faisant l'objet d'échanges internationaux permettra à un plus grand nombre de sociétés d'accroître leur productivité grâce à l'achat de services moins chers et de meilleure qualité - ce qui contribuera à son tour à stimuler la croissance des industries qui ont largement recours aux TI.

- L'intégration croissante des économies émergentes dans les chaînes internationales d'approvisionnement stimulera la croissance économique de ces pays et elle les dotera de l'expertise nationale en matière de TI indispensable pour combler certains des écarts de productivité avec les marchés de l'OCDE.

- Les échanges sud-sud commencent tout juste à décoller dans les secteurs des services de soutien aux entreprises et ils connaîtront une rapide expansion dans le futur.

\section{Délocalisation internationale des STI et conséquences potentielles pour les marchés du travail}

152. L'OCDE (2005b) a déjà identifié les principaux problèmes d'ajustement auxquels pourraient être confrontés les pays de l'OCDE du fait de l'intégration des économies non membres dans les chaînes internationales d'approvisionnement. Il a examiné en particulier quels en sont les effets prévisibles sur les marchés du travail des États-Unis et de l'UE et il est parvenu à la conclusion que le recours à la délocalisation internationale peut être mutuellement bénéfique pour les pays à faible revenu comme pour ceux à revenu élevé mais que l'ouverture des marchés est indispensable si l'on veut en recueillir les fruits et mener à bien l'ajustement. Il est tout aussi important d'assurer le bon fonctionnement du marché du travail afin qu'il facilite l'ajustement de 
la main-d'œuvre à la suite de la libéralisation des échanges et de la rapide diffusion des technologies.

153. Les échanges de services de soutien aux entreprises et de STI ont principalement lieu entre les pays de l'OCDE, mais ces services n'en font pas moins l'objet d'échanges croissants entre ces derniers et les économies non membres. ${ }^{47}$ Selon le taux de croissance globale des secteurs des services en question, la délocalisation internationale pourrait potentiellement aboutir à une perte nette d'emplois dans certaines professions ou à une moindre création d'emplois que ce n'aurait autrement été le cas. L'OCDE (2005a) est parvenue à la conclusion que, bien que réelles, les pressions en faveur de l'ajustement devraient probablement demeurer modestes sur les marchés du travail des pays de l'OCDE. Il y a plusieurs raisons à cela :

1. La plupart des services de soutien aux entreprises et des STI continueront de ne pouvoir faire l'objet d'échanges internationaux compte tenu que leur fourniture exige des contacts directs ou de fréquentes communications avec les clients, ce qui exclut d'en être éloigné.

2. Les diverses prévisions relatives au nombre de suppressions d'emplois que pourrait entraîner la délocalisation internationale aboutissent à des chiffres minimes par rapport au nombre global de suppressions et de créations d'emplois sur les marchés du travail.

3. La délocalisation internationale est une situation à somme positive : de nombreux emplois sont sauvegardés ou créés au cours du processus de délocalisation internationale et les gains d'efficience sont soit transférés aux consommateurs sous la forme d'une baisse des prix soit réinvestis dans de nouvelles activités.

4. L'incitation fournie par les avantages offerts au niveau des coûts de main-d'œuvre diminue à mesure que les prestataires des pays à faible revenu exportent des services de plus en plus complexes et de prix plus élevé.

154. De nombreux travaux analytiques se sont intéressés à l'impact que la délocalisation des secteurs des services de soutien aux entreprises et des STI exerce sur les économies de l'OCDE. Certaines études se sont attachées à estimer quelle est la part maximale de l'ensemble des emplois du secteur des services qui pourraient être exposés à la concurrence internationale. ${ }^{48}$ Ces estimations montrent que la grande majorité des emplois du secteur des services demeureront à l'abri de la concurrence internationale. Selon les hypothèses sur lesquelles reposent les évaluations, ces estimations se situent dans une fourchette de $5 \%$ à $19 \%$. Les prestations susceptibles d'être fournies depuis des lieux éloignés sont très différentes de celles qui peuvent être assurées avec un modèle d'entreprise économiquement incontestable et avec une qualité de service satisfaisante. Certains services ou fragments de services aisément identifiables, numérisables et standardisables feront peut-être l'objet d'échanges dans le futur. La plupart des tâches de travail ne présentent toutefois pas ces caractéristiques et la fourniture transfrontières à distance n'en est que plus complexe et donc plus coûteuse à assurer.

155. Certaines études se sont attachées à prévoir le nombre d'emploi que la fourniture transfrontières pourrait créer dans le futur. ${ }^{49} \mathrm{D}$ 'autres ont tenté de quantifier l'impact économique

\footnotetext{
${ }^{47}$ Voir OCDE (2004a) pour un examen détaillé.

${ }^{48}$ Voir par exemple Blinder (2005), van Welsum et Vickery (2005), Bardhan et Kroll (2003), OIT (2001) et Banque mondiale (1995). Voir également l'examen présenté par Bhagwati et al. (2004).

${ }^{49}$ Voir Engman (2005) pour une vue d'ensemble. MGI (2005c)
} 
de la délocalisation internationale au niveau des pays. ${ }^{50}$ Ces efforts de quantification ont généralement abouti à la conclusion que les craintes initiales que la délocalisation des services ait de graves conséquences pour les marchés du travail des pays de l'OCDE sont dans une large mesure infondées. ${ }^{51}$ Les économies émergentes accroitront leur part dans les échanges mondiaux de services de soutien aux entreprises et de STI et il pourrait dans l'ensemble en résulter d'importants avantages économiques tant pour les pays importateurs que pour les pays exportateurs. De nombreux pays en développement ont pris conscience des nouveaux débouchés que ce type d'échanges crée et certains d'entre eux s'efforcent de mettre en œuvre des mesures plus actives de libéralisation des marchés de services. Toutefois, et bien qu'ils puissent offrir d'importants avantages aux deux parties prenantes dans la transaction, il est probable que les échanges internationaux de services de soutien aux entreprises et de STI réduisent la demande de certaines catégories d'emplois dans les économies de l'OCDE.

\section{Possibilités d'ajustement du marché du travail dans le secteur des $S T I^{52}$}

156. Certains des problèmes les plus pressants auxquels doivent faire face les sociétés de services de soutien aux entreprises et de STI qui opèrent sur les marchés émergents sont liées aux contraintes qui s'exercent du côté de l'offre. Le McKinsey Global Institute a présenté une série d'études de grande ampleur qui examinent l'offre et la demande de travail dans un certain nombre de secteurs de services (MGI, 2005a-b). Il prévoit que le taux de croissance annuelle des dépenses de STI au cours de la période 2003-2008 sera de 4\% en Europe occidentale, de 5\% aux États-Unis et de $9 \%$ dans la région Asie-Pacifique. ${ }^{53}$ Il en résulte que la demande globale de STI des principaux marchés pour ce type de services progressera d'environ 20 milliards de dollars des États-Unis par an. Ce chiffre est nettement supérieur à la valeur globale de l'ensemble des exportations de STI de la Chine, de l'Inde, des Philippines et de la République tchèque.

157. La concurrence des économies émergentes se trouve presque exclusivement concentrée dans le domaine du développement d'applications douanières et de la maintenance des applications, et dans une moindre mesure dans celui de l'intégration de systèmes. D'après les estimations $10 \%$ des emplois offerts dans le secteur des STI au sein des pays à revenu élevé ont été couverts par les pays à bas coûts en 2006. Cette proportion devrait s'accroître dans le futur mais compte tenu de l'augmentation escomptée de la demande de STI, le nombre annuel d'emplois offerts dans le secteur des STI des pays à revenu élevé devrait s'accroître de $1 \%$ par an entre 2003 et 2008.

158. Les pressions sur l'ensemble des emplois du secteur des STI seront sans doute modestes, mais des problèmes de coûts pourraient apparaitre, tout comme pourrait se produire un déplacement de la demande de certains emplois dans le secteur des STI à mesure que les entreprises des pays de l'OCDE recentrent leurs activités sur les services de valeur plus élevée. ${ }^{54}$

\footnotetext{
${ }^{50}$ Voir par exemple Blanco et al. (2005), Mann (2003), MGI (2003, 2004), Evalueserve (2003, 2004), Deloitte Research (2003).

${ }^{51}$ Voir par exemple OMC (2005), OCDE (2005a), Bhagwati et al. (2004), Drezner (2004).

52 En 2005, les exportations de STI ont représenté en Chine, en Inde, aux Philippines et en République tchèque $60 \%$ du volume global des exportations de services de soutien aux entreprises et de STI.

${ }^{53}$ D'après ses conclusions, les États-Unis comptaient pour environ $41 \%$ de la demande mondiale de STI, suivis par le Japon avec 13\% et l'Allemagne avec 7\%. Les emplois dans le secteur des STI représentaient $1.2 \%$ des emplois non agricoles en Europe occidentale, $1.3 \%$ aux États-Unis et $0.9 \%$ au Japon.

${ }^{54}$ De nombreux pays de l'OCDE n'importent pas de services de soutien aux entreprises ni de STI en provenance des pays étudiés dans le présent document.
} 
Aux États-Unis, principal pays importateur de services de soutien aux entreprises et de STI en provenance des économies émergentes, la part des emplois du secteur des STI de valeur élevée (analystes systèmes, ingénieurs logiciels) s'est accrue alors que celles des emplois de valeur moyenne (programmeurs de logiciels, administrateurs de réseaux et de bases de données) et de faible valeur (spécialistes de l'assistance informatique, aides programmeurs) ont diminué (MGI, 2005a-b). Cette évolution tendancielle concorde avec le développement de la délocalisation des travaux de plus faible valeur vers les pays d'Asie qui offrent un bon rapport qualité-prix.

159. Les problèmes de recrutement observés en Chine, en Inde et aux Philippines découlent du fait que relativement peu de diplômés possèdent l'ensemble des compétences nécessaires pour travailler pour des multinationales étrangères ou répondre à la demande des marchés internationaux. Le graphique 5, qui est fondé sur des entretiens avec 83 responsables des ressources humaines de sociétés multinationales, met en évidence que seul un ingénieur chinois sur dix possède les qualifications nécessaires pour être engagé. Un pourcentage légèrement supérieur d'ingénieurs est apte à travailler pour des multinationales en Inde et aux Philippines, et il est encore plus élevé en République tchèque. Les Philippines et la République tchèque possèdent toutes deux d'assez fortes compétences dans le domaine des finances et de la comptabilité. Le graphique 6 montre que les qualifications limitées que possèdent les jeunes professionnels en Chine et en Inde réduisent considérablement les réservoirs de compétences disponibles. Aussi les vastes populations des pays tels que la Chine et l'Inde sont-elles sans commune mesure avec le nombre de professionnels du secteur des services qu'ils peuvent fournir. Ce n'est pas la quantité mais la qualité qui dans leur cas pose problème.

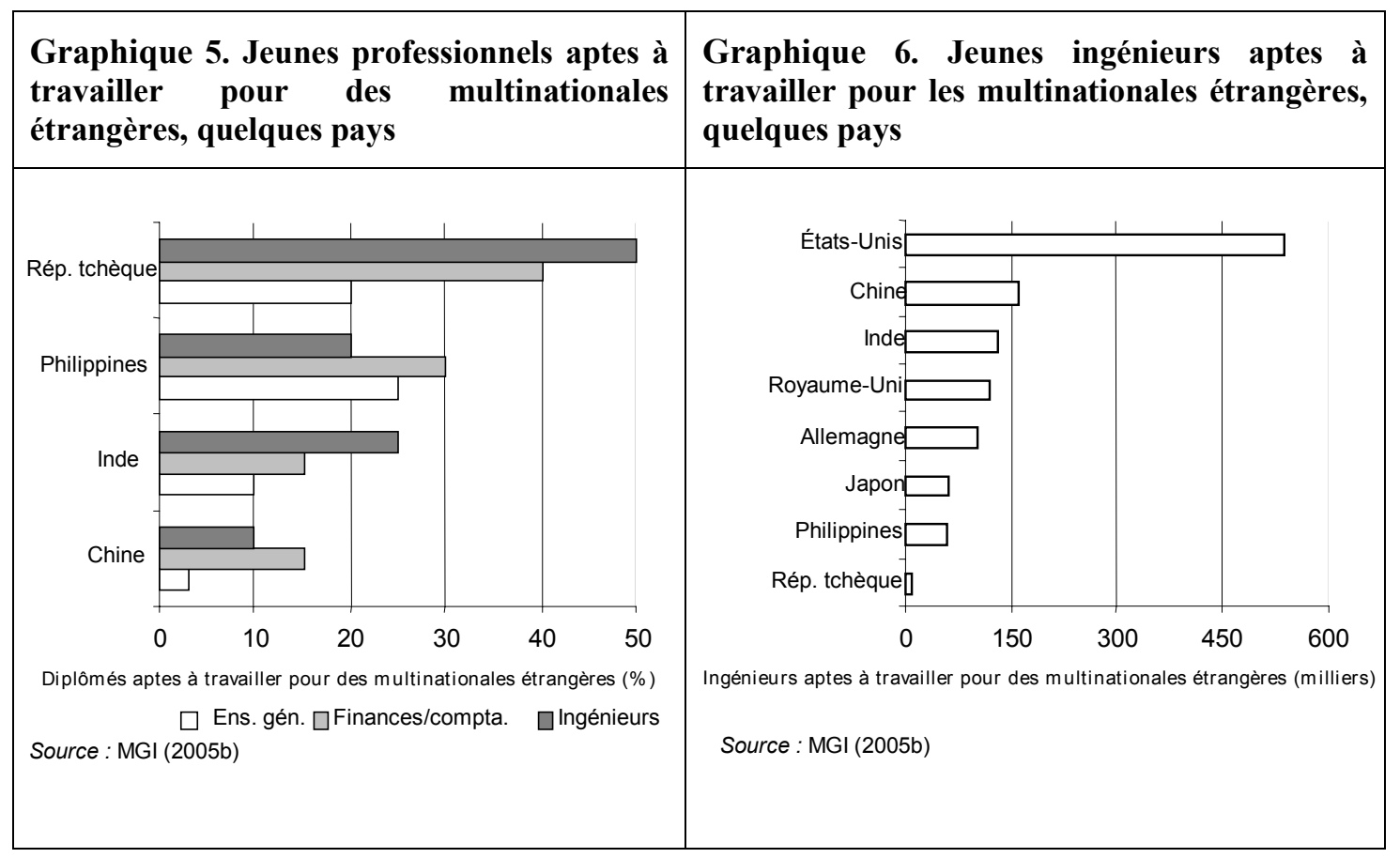


160. Le travail de l'OCDE (2006c, à paraitre) offrira une analyse approfondie des échanges et de l'ajustement des marchés du travail dans le secteur des services aux entreprises. Elle étudiera comment l'interaction entre les échanges, la politique commerciale et la technologie détermine les structures de l'emploi, les taux de rotation des effectifs et les salaires relatifs. Elle examinera également comment les politiques commerciales et celles du marché du travail peuvent faciliter l'ajustement structurel tout en réduisant les coûts d'ajustement liés aux échanges et aux IDE. 


\section{RÉFÉRENCES}

Analysys International (AI) (2006a), "China Software Industry to Grow 30\% Over Next 5 Years", Communiqué du 2 juin 2006.

- (2006b), “Analysys International says China's IT Services Market Reached RMB 12.06 Billion in Q2 2006", Communiqué du 24 août 2006.

Aquino, Thomas G. (2006), "Philippines", note de présentation remise au Secrétariat de l'OCDE par le gouvernement des Philippines.

Aron, Ravi (2005), "Move over, India: The Shifting Geography of Offshore Outsourcing Creates New Challenges", 14 janvier 2005, India knowledge @ Wharton.

Athreye, S.S. (2003), "Multinational Firms and the Evolution of the Indian Software Industry", East-West Center Working Papers n 51 , Economics Series.

A.T. Kearney (2004), "The Changing Face of China: China as an Offshore Destination for IT and Business Process Outsourcing", http://atkearney.com/shared_res/pdf/ChinaOffshore_S.pdf.

- (2005), "Making Offshore Decisions: A.T. Kearney's 2004 Offshore Location Attractiveness Index", www.atkearney.com/shared_res/pdf/Making_Offshore_S.pdf.

- (2006), “A.T. Kearney Global Services Location Index 2005”, www.atkearney.com/shared res/pdf/GSLI Figures.pdf.

Banque mondiale (2006), "Anticorruption in Transition 3: Who is Succeeding and Why?", www.worldbank.org/eca/act3.

Bardhan, A.B. et C. Kroll (2003), "The New Wave of Outsourcing”, Fisher Center Research Reports, Paper 1103, http://repositories.cdlib.org/iber/fcreue/reports/1103.

Beshouri, C. et D. Farrell (2005), “The Philippines' Offshoring Opportunity”, McKinsey Global Institute, septembre 2005.

Bhagwati, J., Panagariya, A. et Srinivasan, S.N. (2004), "The Muddles over Outsourcing", Journal of Economic Perspectives, vol. 18, n 4, pp. 93-114.

Blanco, T., Farrell, D. et Labaye, E. (2005), "How France Can Win From Offshoring”, The McKinsey Quarterly, août 2005.

Blinder, A.S. (2005), "Fear of Offshoring", Centre d'étude des politiques économiques de l'Université de Princeton, document de travail n 119.

Booz Allen Hamilton (2006), "Information Security Risk a Top Concern Among Outsourcing Executives", 23 mars 2006. 
Bureau des technologies de l'information des États-Unis (United States Information Technology Office ou USITO) (2003), "Written Comments to the U.S. Government Interagency Trade Policy Staff Committee in Response to Federal Register Notice 03-18467 Regarding China's Compliance with its Accession Commitments to the World Trade Organization (WTO)", 10 septembre 2003.

Cermak, J. et B. Dackiw (2006), "US Czech Cooperation to Advance Research and High Technology", présentation effectuée par Baker McKensie, 19 mai 2006.

Chanda, R. (2006), "Inter-Modal Linkages in Services Trade", Documents de travail de l'OCDE sur la politique commerciale $\mathrm{n}^{\circ} 30, \mathrm{TD} / \mathrm{TC} / \mathrm{WP}(2004) 41 / \mathrm{FINAL}, \mathrm{OECD}$, Paris.

ChinaTechNews (2003), "Torch Center Launches Offshore Software Engineering Project through ExperExchange", 3 novembre 2003, www.chinatechnews.com/2003/11/05/169-torchcenter-launches-offshore-software-engineering-project-through-experexchange/.

Citigroup (2005), “A Passage to India: India Tech Tour 2005”, Industry Report, 29 avril 2005.

Commission nationale indienne pour la coopération avec l'UNESCO (1998), "Higher Education in India: Vision and Action Country Paper", document présenté à la Conférence mondiale sur l'enseignement supérieur au XXIème siècle organisée par l'UNESCO, qui s'est tenue à Paris du 5 au 9 octobre 1998. Disponible à l'adresse suivante: www.education.nic.in/htmlweb/unhighedu.htm.

Computerworld (2003), "Country Analysis: China”, 15 septembre 2003.

Czech Focus (2005), vol. 2, n 3.

CzechInvest (2004), "Czech ICT Market in 2004", document conjoint publié par CzechInvest et le réseau d'entreprises TUESDAY Business Network.

— (2005), "IT \& Software Development in the Czech Republic", janvier 2005.

- (2006), "Investment Climate in the Czech Republic", octobre 2006.

Dange, A. et B. Vajpayee (2005) "Analysing Attrition", CLSA Asia Pacific Markets, 17 février 2005.

de Filippo, G., J. Hou et C. Ip (2005), “Can China Compete in IT Services?”, The McKinsey Quarterly, $\mathrm{n}^{\circ} 1$.

Deloitte Research (2003), "Survey: Financial Institutions to Reduce Costs by Moving 2 Million Jobs Offshore".

- (2006), "China and India: The Reality beyond the Hype", www.deloitte.com/dtt/cda/doc/content/US_ChinaIndiaReality_Research.pdf.

DeWoskin, Kenneth J. (2005), "Intellectual Property Knowledge Economy China - 2005", PriceWaterHouseCoopers.

DiamondCluster (2005), Global IT Outsourcing report 2005.

Drezner, D. (2004), "The Outsourcing Bogeyman", Foreign Affairs, livraison de mai/juin, www.foreignaffairs.org/20040501faessay83301/daniel-w-drezner/the-outsourcingbogeyman.html.

Economist (2005), "The Rise of Nearshoring", 3 décembre 2005.

Economist Intelligence Unit (EIU) (2005), “CEO Briefing: Corporate Priorities for 2005”, janvier 2005. 
— (2006), "The New Face of Offshoring: Closer to Home?", mai 2006.

Eisenhauer, M.P. (2005), "Privacy and Security Law Issues in Off-shore Outsourcing Transactions", Hunton \& Williams, Atlanta, Géorgie, 15 février 2005.

Engman, Michael (2005), "International sourcing of IT and business process services: experiences from the United States, the European Union and India", document présenté au Symposium de l'OMC sur la fourniture transfrontières de services, 28-29 avril 2005, Genève.

Evalueserve - NASSCOM (2003), "Impact of Global Sourcing on the US Economy, 2003-2010".

- (2004), "Impact of Global Sourcing on the UK Economy 2003-2010".

Forrester Research (2002), "3.3 Million US Services Jobs to Go Offshore", www.forrester.com/ER/Research/Brief/Excerpt/0,1317,15900,FF.html.

- (2004), “Two-Speed Europe: Why 1 Million Jobs Will Move Offshore", www.forrester.com/Research/Document/Excerpt/0,7211,35212,00.html.

Gartner (2003), "US Offshore Outsourcing: Structural Changes, Big Impact".

Government Accountability Office (GAO) (2005), "U.S. and India Data on Offshoring Show Significant Differences”, Rapport aux Commissions du Congrès des États-Unis, GAO06-116, octobre 2005.

Hira, R. (2003), "Utilizing Immigration Regulations as a Competitive Advantage: An Additional Explanation for India's Success in Exporting Information Technology Services", polycopié, Université de Columbia, 3 mars 2003.

Huang, Francis L. (2005), “At the Forefront of Back-Office Services: An Interview with SPI's Ernest Cu", The SGV Review, www.spitech.com

Ilett, Dan (2006), "BPO in China - Beyond the Cities You Know", www.silicon.com/research/specialreports/china/0,3800011742,39160014,00.htm.

International Data Corporation (IDC) (2006a), Market Analysis: China-Based Offshore Software Development 2006-2010 Forecast and Analysis, février 2006.

- (2006b), Market Analysis: Czech Republic IT Services 2006-2010 Forecast and 2005 Vendor Shares, avril 2006, IDC\#ES03N, Volume 1.

IT Outsourcing Center (2005), "Czech Republic: 2005 Offshore IT Outsourcing Market Overview", 7 mars 2005.

JP Morgan (2006), "Indian IT Services”, Asia Pacific Equity Research, n 9, 7 septembre 2006.

Kumra, G. et J. Sinha (2003), "The Next Hurdle for Indian IT”, The McKinsey Quarterly 2003 Special Edition: Global directions.

Lipana, T.H. et Cooper, P.R. (2005), Doing Business and Investing in the Philippines", PricewaterhouseCoopers International.

Locsin, Mitch (2006), “BPAP: Representing the Country's IT-Enabled Services Industry”, note de présentation remise au Secrétariat de l'OCDE.

Mann, C.L. (2003), "Globalization of IT Services and White Collar Jobs: The Next Wave of Productivity Growth", International Economics Policy Briefs, n PB03-11.

Mapa, Damian (2006), "DOLE Workforce Development Summit Cyberservices - The Sectoral Picture", présentation effectuée en qualité de membre de la Commission des 
technologies de l'information et de la communication des Philippines (Commission of Information and Communications Technology - CICT), mars 2006.

Mattoo, A. et S. Wunsch (2004), "Securing Openness of Cross-Border Trade in Services: A Possible Approach", Centre du développement international de l'Université de Harvard, www.cid.harvard.edu/cidtrade/Papers/mattoo-wunsch.pdf.

McCue, Andy (2004), "DHL 'Offshores' UK IT Work to the Czech Republic”, www.silicon.com, 11 octobre 2004.

McKinsey (2006), "The Overlooked Potential for Outsourcing in Eastern Europe", the McKinsey Quarterly, décembre 2006.

McKinsey Global Institute (MGI) (2003), “Offshoring: Is It a Win-Win Game?”, août 2003.

- (2004), “Can Germany Win from Offshoring?”, juillet 2004.

- (2005a), The Emerging Global Labor Market: Part I-The Demand for Offshore Talent in Services, juin 2005.

- (2005b), The Emerging Global Labor Market: Part II-The Supply of Offshore Talent in Services, juin 2005.

- (2005c), "Sizing the Emerging Global Labor Market", The McKinsey Quarterly, n 3.

Ministère de l'Industrie de l'information (MII), République populaire de Chine (2006), 2005 Annual Report: China's Information Industry, ISBN 7-115-1245/06-66.

Ministère de l'Informatique de la République tchèque (2006), “2005 ICT Market Overview”, document conjoint du ministère de l'Informatique de la République tchèque et le réseau d'entreprises "TUESDAY Business Network", 30 mars 2006.

NASSCOM (2005), Strategic Review 2005: The IT Industry in India, NASSCOM, New Delhi.

- (2006), Strategic Review 2006: The IT Industry in India, NASSCOM, New Delhi.

neoIT (2004), "Offshoring in Central and Eastern Europe: A Closer Look at the Czech Republic, Poland and Hungary”, Market Reports, vol. 2, $\mathrm{n}^{\circ} 3$.

- (2005), "Research Summary: Mapping Offshore Markets Update 2005", Offshore Insights Market Report Series, Volume 3, $\mathrm{n}^{\circ} 8$.

- (2006) “Offshore insights: Market Report Series", juin 2006, Volume 4, n 4.

OCDE (2003a), "La mobilité internationale des prestataires de services : l'impact économique du mode 4", TD/TC/WP(2002)12/FINAL, Paris.

- (2003b), "Circulation des prestataires de services: accords de reconnaissance mutuelle", TD/TC/WP(2002)48/FINAL, Paris.

- (2004a), Perspectives des technologies de l'information de l'OCDE, Éditions de l'OCDE, Paris.

- (2004b), Échanges et migrations : pour une main-d'œuvre mobile à l'échelle mondiale, OCDE, Banque mondiale, Organisation internationale pour les migrations (OIM), Éditions de l'OCDE, Paris.

- (2005a), Enhancing the Performance of the Services Sector, Éditions de l'OCDE, Paris.

- (2005b), Les échanges et l'ajustement structurel : Les enjeux de la mondialisation, Éditions de l'OCDE, Paris. 
TD/TC/WP(2007)2/FINAL

- (2006a), "Export Processing Zones: Past and Future Role in Trade and Development", $\mathrm{TD} / \mathrm{TC} / \mathrm{WP}(2006) 39$.

- (2006b), Perspectives des technologies de l'information de l'OCDE, Éditions de l'OCDE, Paris.

- (2006c), "Trade and Labour Market Adjustment", TD/TC/WP(2006)21/FINAL, Paris.

OMC (1991), "Classification sectorielle des services", MTN/GNS/W/120, Note du Secrétariat.

- (2002), "Commerce des services - République populaire de Chine - Liste d'engagements spécifiques”, GATS/SC/135, 14 février 2002.

- (2005), Rapport sur le commerce mondial 2005, Genève.

Optel (2006), Philippine IT-Enabled Services Industry Perspective.

Organisation internationale du travail (OIT) (2001), Rapport sur l'emploi dans le monde 2001: Vie au travail et économie de l'information.

Outsource2philippines.com (O2P) et BPA/P (2006), "O2P and BPA/P Periodic Survey \#2: Constraints to Growth", juin 2006.

OutSourcingWorld (OSW) (2005), "East China Software Export to Surpass Northeast, Says Analyst".

Pai, A.K. et Basu, A. (2005), "Offshore Outsourcing: Weighing the Risks of Data Protection and Security”, http://people.miu-ft.org/ sama/bileta2005/outsourcing/bileta belfast 2005.pdf.

Rodolfo, C.S. (2005), "Sustaining Philippine Advantage in Business Process Outsourcing", document présenté en septembre 2005 au Philippine Institute for Development Studies.

Rohlmeier, J. et T.T. Phan (2003), "Information Technology and E-commerce Opportunities in China", note de présentation remise au ministère du Commerce des États-Unis, Bureau des technologies de l'information et du commerce électronique, 5 juin 2003.

Saxenian, Annalee (2003), "Government and Guanxi: The Chinese Software Industry in Transition", DRC Working Papers, $\mathrm{n}^{\circ} 19$, Centre for New and Emerging Markets, London Business School, mars 2003.

Shah, A. et V. Parikh (2002), "Movement of Natural Persons under the GATS in the Software Services Sector", Movement of Natural Persons (Mode 4) under the GATS: Joint WTO-World Bank Symposium, Genève, 11-12 avril 2002.

Simon, Dennis F. (2005), "Hearing on China's High Technology Development", 21-22 avril 2005, Université de Stanford, www.uscc.gov/hearings/2005hearings/written_testimonies/05_21_22wrts/simon_denis_wrt s.htm.

Srinivasan, T.N. (2005), "Information Technology Enabled Services and India's Growth Prospects", document présenté au Brookings Trade Forum 2005, www.brookings.edu/es/commentary/journals/tradeforum/2005btf_srinivasan.pdf.

Suri, N. (2005), "Trade in Professional Services: India's Experience”, Expert Meeting on Trade and Development Aspects of Professional Services and Regulatory Frameworks, Genève, 18 janvier 2005, CNUCED.

Tschang, T. et L. Xue (2003), “The Chinese Software Industry: A Strategy of Creating Products for the Domestic Market”, ADB Institute Working Paper, 15 janvier 2003. 
Vandrevala, Phiroz (2006), "Putting China on the TCS Map", The Financial Express.

Vashistha, A., J. Cermak, I. Radmilovic, M. Rosinski et M. Mensik (2005), "Global Sourcing: Destination Central Europe", présentation conjointe de Baker \& McKensie et neoIT, 29 septembre 2005.

Van Welsum, D. et G. Vickery (2005), "Potential Offshoring of ICT-Intensive Using Occupations", DSTI Information Economy Working Paper, DSTI/ICCP/IE(2004)19/FINAL, OCDE, Paris.

- (1995), Global Economic Prospects and Developing Countries, Banque mondiale, Washington D.C.

- (2004), "Sustaining India's Service Revolution: Access to Foreign Markets, Domestic Reform and International Negotiations", Région Asie du Sud de la Banque mondiale, Inde 2004.

Yearbook of Immigration Statistics 2004, http://uscis.gov/graphics/shared/statistics/yearbook/index.htm.

Zahradnik, Jaroslav (2006), “Czech Republic: Offshore IT Outsourcing Market”, présentation réalisée par IT Outsourcing Center, 28 février 2006. 
TD/TC/WP(2007)2/FINAL

\section{ANNEXE A : LISTE INDICATIVE DES SERVICES DÉLOCALISÉS À L'ÉTRANGER}

\section{Services des technologies de l'information (Services informatiques et connexes)}

Services de développement et de réalisation de logiciels, services de traitement des données et de bases de données, services d'assistance informatique, mise au point d'applications, essais et maintenance, veille économique et stockage de données, gestion des contenus, marchés d'approvisionnement électronique et interentreprises, sécurité des entreprises, application de progiciels, intégration de systèmes, gestion de la chaîne d'approvisionnement, intégration des applications d'entreprise, externalisation totale des infrastructures, services web (préparation de contenus Internet, etc.), hébergement de sites web et de fournisseurs de services d'applications, ingénierie des cahiers des charges.

\section{Services de soutien aux entreprises}

\begin{tabular}{l|l} 
Services & Soutien des ventes, gestion des adhésions, réclamations, réservations de billets
\end{tabular} d'interaction avec d'avion et d'hôtels, renouvellement des abonnements, traitement des commandes, la clientèle $\quad$ gestion des garanties, lignes d'assistance téléphonique à la clientèle, gestion de problèmes de crédit et de facturation, etc., services de vente par téléphone et d'études de marché.

Activités de backoffice

Saisie et gestion des données, services de traitement de données et de bases de données, transcriptions médicales, services de paiement, traitement financier (traitement/gestion des informations et données financières), traitement des chèques et des cartes de crédit ou de paiement à débit immédiat, services de gestion des ressources humaines, services de paie, administration des soins de santé, services d'entreposage, de logistique et d'expédition, d'inventaire, de gestion de la chaîne d'approvisionnement, achats directs et indirects, billetterie, traitement des demandes d'indemnisation, gestion des hypothèques.

Autres services Gestion des ressources humaines (recrutement, planification des avantages et feuilles aux entreprises ou aux professionnels independants de paie, etc.), services financiers et comptables (y compris les services d'audit et de contrôle, de comptabilité, d'imposition, etc.), analyse et extraction de données, gestion de données/connaissances, services de marketing, conception et mise au point de produits.

Source : D'après Mattoo et Wunsch (2004). Cette liste d'activités n'est pas exhaustive et les catégories ne s'excluent pas mutuellement. 


\section{ANNEXE B : LISTE DES PERSONNES INTERVIEWÉES :}

Pour le chapitre sur la Chine (sept. 2006):

Michael Chen, du Parc logiciel de Dalian; Qian Chen, Leo Curtis, Cory M. Grenier, Annie Jiang, Jerome Ma et Jun Tang, de Lenovo; Sheng Chen, de Hewlett-Packard; John Chiang, de DragonBridge; Chen Chong, Gu Changjiang, Han Shengzhi et Penny Peng de l'Association chinoise de l'industrie des logiciels; Matthew Cule de M\&Y Data Solutions; Walter Fang, de Neusoft Group ; Fu Jianqi et Xu Chaofeng du ministère chinois de l'Industrie de l'information ; Ramalingam Hariharan, de Nokia China Investment; Hong Gang, de Gartner; Jacob Hsu, de Symbio Group ; Hui Zhang, de Huawei Technologies ; Jackson Lam, de TCS China ; Jingmei Li, de Beyondsoft; Leon Liu et Xu Xing Feng, du ministère chinois du Commerce; T.W. Liu et John Peng, d'iSoftStone Information Service; Ralph Lofdahl, d'Ericsson China Communications ; Jim Mai, de Kingdee Software Technology; Jean-Marc Serayssol, de Dell ; Raghvendra Tripathi, de Satyam Computer Systems ; Chen Yue, de BT Global Services ; Max von Zedtwitz, de l'Université de Tsinghua.

Pour le chapitre sur la République tchèque (juil. 2006):

Jiř́ Čermák de Baker \& McKenzie ; Chris Garlick de Garlick s.r.o. ; Jana Herzová, de l’Agence tchèque de promotion des échanges commerciaux (Czech Trade Promotion Agency); Petr Kučera de Komix ; Petr Mýtina de Ness Technologies ; Petr Niedoba de CN Resources International ; Ota Novotný, de l'Université d'économie de Prague ; Jan Pavelka de DCIT ; Robert Pinkas de Grisoft ; Jan Rancak, de Czech Invest ; Jaroslav Zahradnik de Centrum pro Outsourcing IT ; Michal Zálešák de l'“Alliance tchèque des technologies de l'information et de la communication" (Czech ICT Alliance).

Pour le chapitre sur les Philippines (janv. 2006) :

Manolo E. Aquino et Joel A. Layson, de Summersault; Jeanette S. Carrillo, du Bureau des investissements des Philippines (Philippine Board of Investments); Arnel Galo S. Esquerra, d'ADEC Solutions; Harry Fozzard, d'Epixtar Corp.; Michael Alan Hamlin, d'Outsource2Philippines ; Benedict C. Hernandez d'eTelecare Global Solutions ; Chang Huh, de la Banque asiatique de développement; Joel Layson, de Summersault; Mitch L. Locsin, de l'Association des services de soutien aux entreprises des Philippines (Business Processing Association Philippines); Damian Domingo O. Mapa, de la Commission des technologies de l'information et des communications; Charina Quizon, d'Ambergris Solutions; Renato B. Quizon, de Pointwest Technologies ; Beau Rudd, de Global Sky ; Evelyn Suaco-Abat, d'eData Services Phils; Fermin Taruc, de l'Association de l'industrie des logiciels des Philippines (Philippine Software Industry Association) ; Lito T. Tayag, d'Accenture ; Leland B. Verceles, de Virtual Assistants Philippines ; Lauro Vives, Gio Pojida et Cesar Tolentino, de XMG.

Pour le chapitre sur l'Inde (sept. 2005) :

Balasubrahmanyam Juturi et Badree Komandur, de Wipro ; Rupa Chanda, de l'Institut indien de gestion (Indian Institute of Management); Akash Chander, de LogicaCMG; Avinash Chandrakar, Sanjay Jalona, Rajesh Khandelwal, Nitin Kulkarni, Deependra Moitra et Alok Ranjan Tripathy, d'Infosys ; Mikael Gislen, de Gislen Software ; Praveen Kanipakam, de Sharp ; Niranjan Kalyandurg, d'Honeywell ; Krishna Kumar, de Hexaware ; Rajesh Rao, de Nature Soft ; N R K Raman et Peter Yorke, d'I-flex Solutions ; S. Ranganathan et Swaminathan Krishnan, de Sasken; Dravida Seetharam, d'IBM ; Gaurav Singh, de l'Association nationale des sociétés de logiciels et de services (National Association of Software and Service Companies); Brijesh Pazhayathodi, de la Banque de réserve de l'Inde (Reserve Bank of India); Sampath Kumar, Capt. 
TD/TC/WP(2007)2/FINAL

Girish, Deepti Vijaya, de TCS ; Nikhil Tikekar, d'Ericsson ; Navendu Yajnik, de Patni Computer Systems. 
ANNEXE C. EFFICIENCE RÉGLEMENTAIRE ET INSTITUTIONNELLE : CONDUITE DES AFFAIRES EN 2006

\begin{tabular}{|c|c|c|c|c|c|}
\hline & Chine & $\begin{array}{l}\text { République } \\
\text { tchèque }\end{array}$ & Inde & Philippines & OCDE \\
\hline \multicolumn{6}{|l|}{ Création d'entreprises } \\
\hline Procédures (nombre) & 13 & 10 & 11 & 11 & 6 \\
\hline Durée (jours) & 35 & 24 & 35 & 48 & 17 \\
\hline Coût (\% du revenu/habitant) & 9 & 9 & 74 & 19 & 5 \\
\hline Capital min. (\% du revenu/habitant) & 213 & 37 & 0 & 2 & 36 \\
\hline \multicolumn{6}{|l|}{ Embauche de travailleurs } \\
\hline Indice de difficulté d'embauche & 11 & 33 & 33 & 56 & 27 \\
\hline Indice de rigidité des horaires & 20 & 20 & 20 & 40 & 45 \\
\hline Indice de difficulté de licenciement & 40 & 30 & 70 & 20 & 27 \\
\hline Indice de rigidité de l'emploi & 24 & 28 & 41 & 39 & 33 \\
\hline Coûts de l'embauche (\% du salaire) & 44 & 35 & 17 & 9 & 21 \\
\hline $\begin{array}{l}\text { Coûts du licenciement (semaines de } \\
\text { salaire) }\end{array}$ & 91 & 22 & 56 & 91 & 31 \\
\hline \multicolumn{6}{|l|}{ Obtention de crédits } \\
\hline Indice des droits légaux & 2 & 6 & 5 & 3 & 6 \\
\hline $\begin{array}{l}\text { Indice de divulgation d'informations } \\
\text { sur les crédits }\end{array}$ & 4 & 5 & 3 & 3 & 5 \\
\hline $\begin{array}{l}\text { Couverture par les registres publics } \\
\text { (\% adultes) }\end{array}$ & 10 & 4 & 0 & 0 & 8 \\
\hline $\begin{array}{l}\text { Couverture par les bureaux privés } \\
(\% \text { adultes) }\end{array}$ & 0 & 51 & 6 & 5 & 61 \\
\hline \multicolumn{6}{|l|}{ Protection des investisseurs } \\
\hline Indice de divulgation d'informations & 10 & 2 & 7 & 1 & 6 \\
\hline Indice de responsabilité du directeur & 1 & 5 & 4 & 2 & 5 \\
\hline $\begin{array}{l}\text { Indice de recours en justice des } \\
\text { actionnaires }\end{array}$ & 4 & 8 & 7 & 7 & 7 \\
\hline $\begin{array}{c}\text { Indice de protection des } \\
\text { investisseurs }\end{array}$ & 5 & 5 & 6 & 3 & 6 \\
\hline \multicolumn{6}{|l|}{ Paiement d'impôts et de taxes } \\
\hline Paiements (nombre) & 44 & 14 & 59 & 59 & 15 \\
\hline Durée (heures) & 872 & 930 & 264 & 94 & 203 \\
\hline $\begin{array}{l}\text { Taux d'imposition totale }\left(\begin{array}{ll}\% & \text { des } \\
\text { bénéfices) }\end{array}\right.\end{array}$ & 77 & 49 & 81 & 53 & 48 \\
\hline \multicolumn{6}{|l|}{ Exécution des contrats } \\
\hline Procédures (nombre) & 31 & 21 & 56 & 25 & 22 \\
\hline Durée (jours) & 292 & 820 & 1,420 & 600 & 351 \\
\hline Coût (\% de la créance) & 27 & 14 & 36 & 16 & 11 \\
\hline \multicolumn{6}{|l|}{ Fermeture d'entreprises } \\
\hline Durée (jours) & 2.4 & 9.2 & 10.0 & 5.7 & 1.4 \\
\hline Coût (\% de la valeur de l'entreprise) & 22 & 15 & 9 & 38 & 7 \\
\hline $\begin{array}{l}\text { Taux de recouvrement (cents par } \\
\text { dollar) }\end{array}$ & 32 & 19 & 13 & 4 & 74 \\
\hline
\end{tabular}

Source : Banque mondiale (2006) www.doingbusiness.org 
TD/TC/WP(2007)2/FINAL

ANNEXE D. INDICATEURS DES SALAIRES DES TRAVAILLEURS DU SAVOIR, 2005

\begin{tabular}{|l|c|c|c|c|}
\hline & Chine & $\begin{array}{c}\text { République } \\
\text { tchèque }\end{array}$ & Inde & Philippines \\
\hline Salaires annuels moyens dans les STI (USD) & \\
\hline Début de carrière & 5,700 & 12,000 & 5,700 & 7,300 \\
\hline Chef d'équipe & 9,600 & 19,500 & 9,400 & 11,900 \\
\hline Directeur de projet & 15,000 & 36,100 & 14,600 & 18,400 \\
\hline Salaires annuels moyens dans les services non vocaux de soutien aux entreprises (USD) \\
\hline Début de carrière & 4,300 & 9,600 & 4,500 & 5,700 \\
\hline Chef d'équipe & 7,500 & 15,600 & 7,600 & 9,600 \\
\hline Directeur de projet & 11,700 & 28,800 & 11,800 & 14,900 \\
\hline Salaires annuels moyens dans les services vocaux de soutien aux entreprises (USD) \\
\hline Début de carrière & 4,100 & 9,100 & 4,300 & \\
\hline Chef d'équipe & 7,100 & 14,600 & 7,200 & 9,500 \\
\hline Directeur de projet & 11,100 & 27,100 & 11,200 & 14,200 \\
\hline
\end{tabular}

Source : neoIT (2006).

\section{ANNEXE E. RÉSULTATS DE L'ENQUÊTE}

Quelles fonctions votre société sous-traite-t-elle déjà et quelles sont celles qu'elle prévoit de sous-traiter dans les trois prochaines années ? (\% des personnes interrogées)

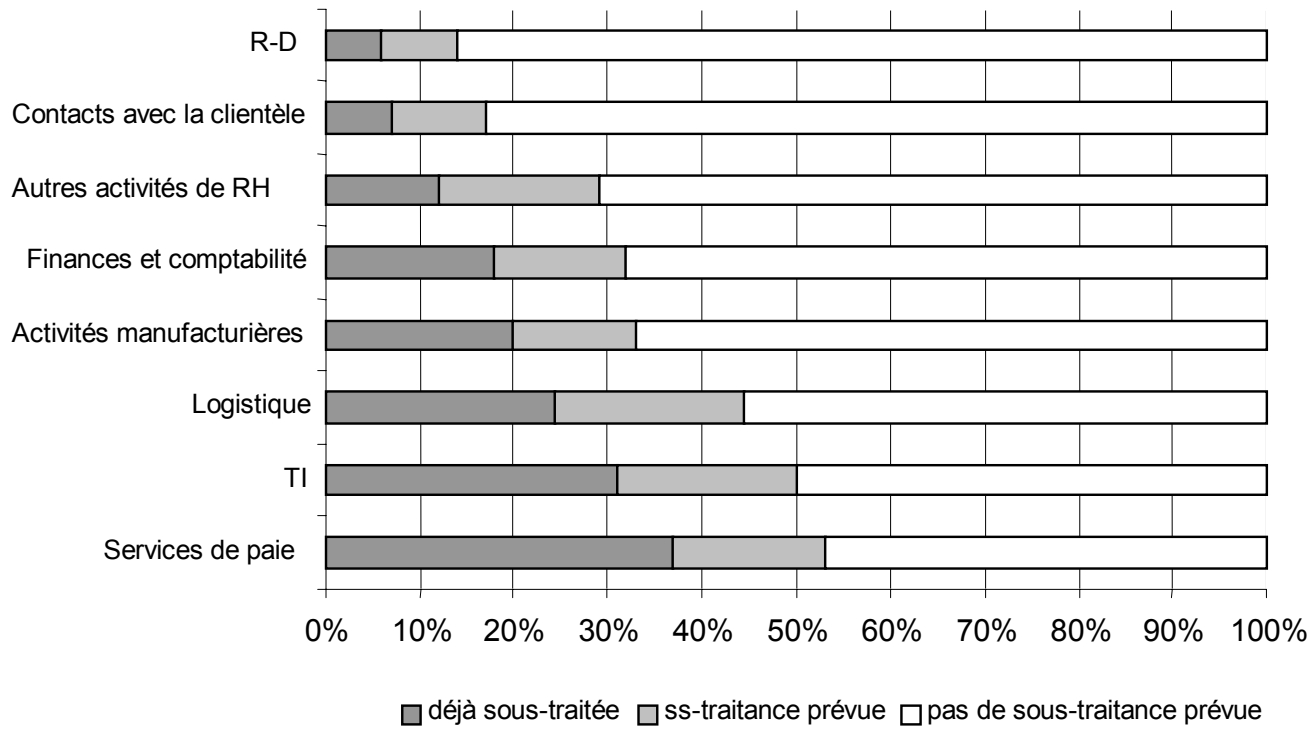

Source : EIU (2005) 

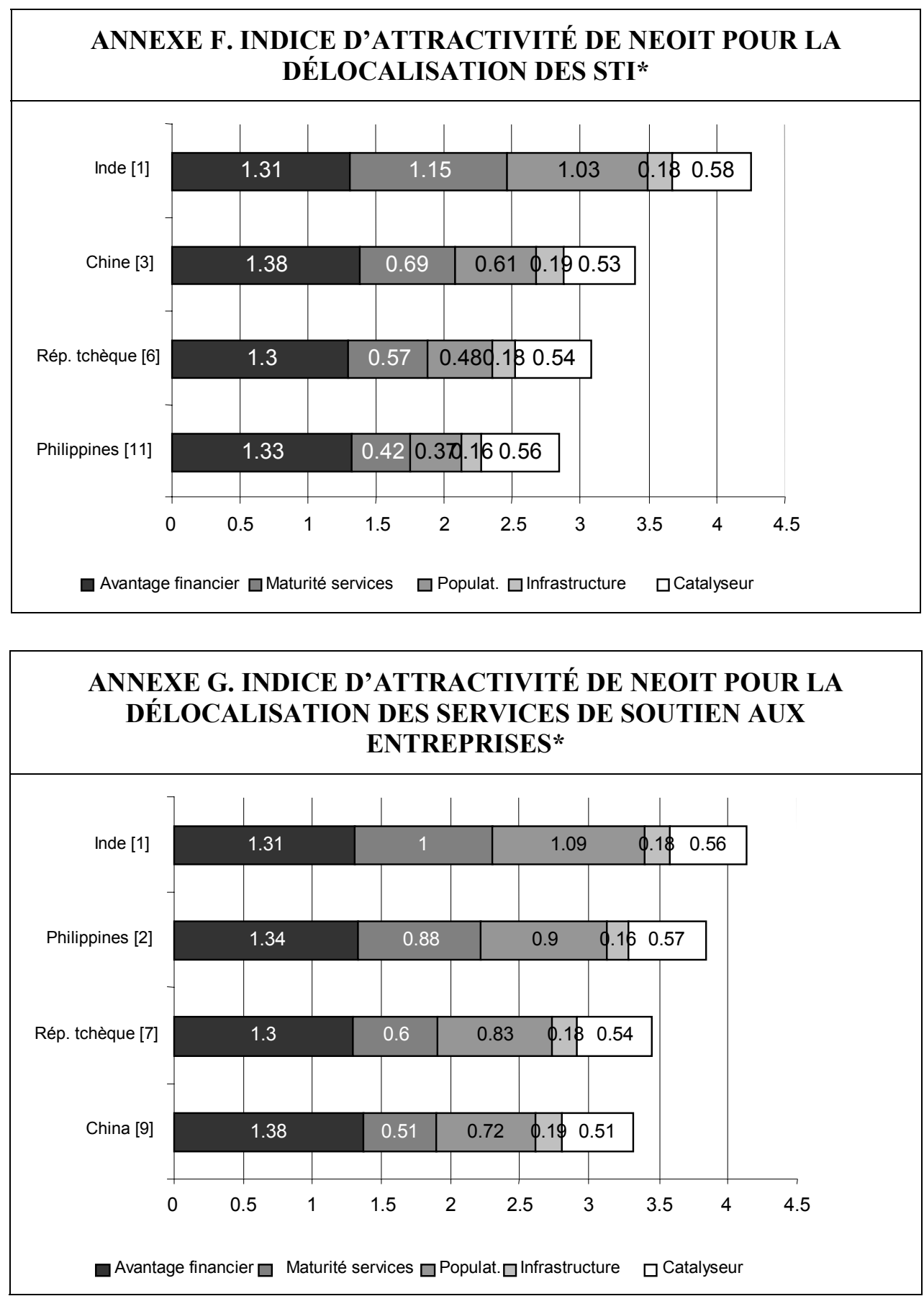

* Avantage financier (coûts de main-d'œuvre, dépenses de fonctionnement et d'équipement) : coefficient de pondération de $30 \%$; maturité des services (maturité des processus et compétence des fournisseurs, taille et taux de croissance de l'industrie, securité/protection des informations à caractère personnel) : coefficient de pondération de $25 \%$; population (volume et degré de qualification du réservoir de main-d'œuvre, aptitudes linguistiques, ressources humaines, système éducatif) : coefficient de pondération de $25 \%$; infrastructure (TIC et infrastructure physique): coefficient de pondération de $5 \%$; catalyseur (soutien public, environnement géopolitique, distance physique et décalage horaire, compatibilité culturelle) : coefficient de pondération de $15 \%$.

Source : neoIT (2005) 
TD/TC/WP(2007)2/FINAL

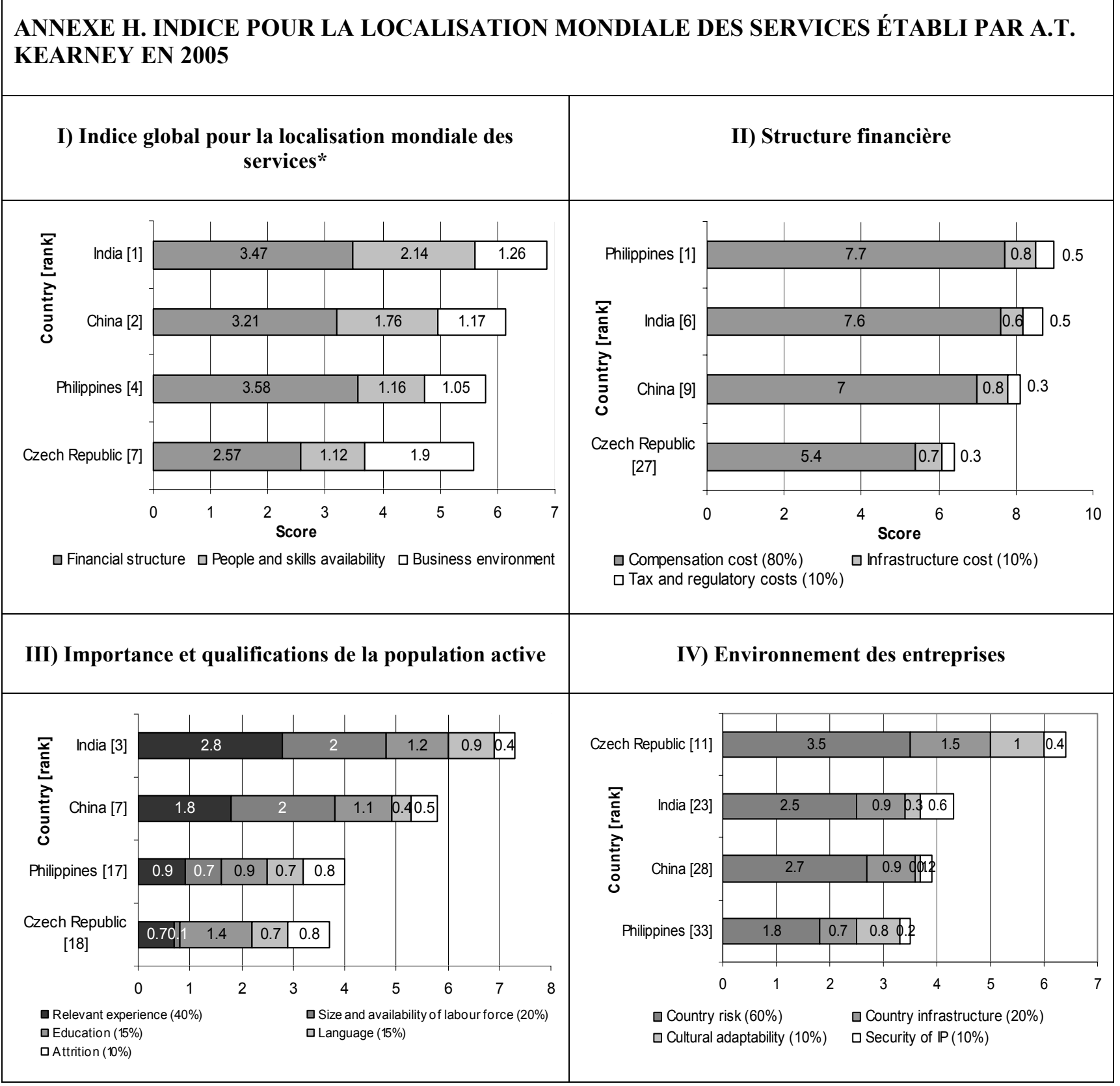

* Les chiffres indiqué dans les barres horizontales sont des indices dont les coefficients de pondération sont respectivement de 40 , 30 et 30. La structure financière est donc notée sur une échelle de 1 à 4 alors que l'environnement des entreprises et l'importance et les qualifications de la population active sont notées sur une échelle de 1 à 3 .

Source : A.T. Kearney $(2005,2006)$ 
TD/TC/WP(2007)2/FINAL

ANNEXE I. INDICATEURS COMPARATIFS ÉCONOMIQUES ET COMMERCIAUX, 2005

\begin{tabular}{|c|c|c|c|c|}
\hline & Chine & République tchèque & Inde & Philippines \\
\hline Population (millions d'habitants) & $1,307^{\mathrm{a}}$ & 10.2 & $1,095^{\mathrm{a}}$ & $87.9^{\mathrm{a}}$ \\
\hline PIB (milliards d'USD) & 1,914 & 124 & $798^{\mathrm{a}}$ & 98 \\
\hline PIB par habitant (USD) & 1,460 & 12,086 & $728^{a}$ & $1,120^{\mathrm{a}}$ \\
\hline PIB par habitant (USD en PPA) & 6,200 & 18,005 & $3,492^{\mathrm{a}}$ & $4,734^{\mathrm{a}}$ \\
\hline Entrées d'investissements directs (milliards d'USD) & $54.94^{b}$ & $4.45^{\mathrm{b}}$ & $4.32^{\mathrm{c}}$ & 1.13 \\
\hline Sorties d'investissements directs (milliards d'USD) & $1.81^{\mathrm{b}}$ & $0.57^{\mathrm{b}}$ & $1.88^{\mathrm{c}}$ & 0.15 \\
\hline Exportations de biens et services (\% du PIB) & $38.5^{\mathrm{c}}$ & $71.2^{\mathrm{b}}$ & 19.0 & 47.3 \\
\hline Importations de biens et services (\% du PIB) & $40.4^{\mathrm{c}}$ & $71.7^{\mathrm{b}}$ & 21.0 & 52.0 \\
\hline Balance commerciale, marchandises (milliards d'USD) & $59.0^{\mathrm{b}}$ & $-0.88^{b}$ & $-14.6^{c}$ & -7.55 \\
\hline Balance commerciale, services (milliards d'USD) & $-9.7^{\mathrm{b}}$ & $0.48^{\mathrm{b}}$ & $6.5^{\mathrm{c}}$ & -1.40 \\
\hline Principales exportations (\% du total) & $\begin{array}{lr}\text { Machines de bureau } & \& \text { de } \\
\text { traitement de données : } & 14.5 \\
\text { Produits de télécom.: } & 12.4 \\
\text { Machines électriques : } & 9.9 \\
\text { Habillement : } & 9.7\end{array}$ & $\begin{array}{lrr}\text { Machines \& } & \text { matériel } & \text { de } \\
\text { transport: } & & 51.1 \\
\text { Produits } & & \text { manufacturés } \\
\text { intermédiaires : } & 21.7 \\
\text { Produits chimiques : } & 6.3 \\
\text { Matières premières } & \& \\
\text { combustibles : } & 5.6 \\
\end{array}$ & $\begin{array}{lr}\text { Produits d'ingénierie : } & 21.0 \\
\text { Textiles \& produits textiles : } 15.6 \\
\text { Pierres précieuses \& joaillerie : } \\
& 15.1 \\
\text { Produits du pétrole : } & 11.2\end{array}$ & $\begin{array}{lr}{ }^{\mathrm{d}} \text { Composants électroniques : } & 52.4 \\
\text { Habillement : } & 8.6 \\
\text { Huile de noix de coco : } & 1.5 \\
\text { Produits du pétrole : } & 1.4\end{array}$ \\
\hline Principales importations (\% du total) & $\begin{array}{lr}\text { Machines électriques : } & 19.7 \\
\text { Pétrole brut \& combustibles : } 7.9 \\
\text { Machines de bureau } \quad \text { \& de } \\
\text { traitement de données : } & 5.3 \\
\text { Sidérurgie : } & 4.0\end{array}$ & $\begin{array}{lrr}\text { Machines \& } & \text { matériel } & \text { de } \\
\text { transport : } & & 40.5 \\
\text { Produits } & & \text { manufacturés } \\
\text { intermédiaires : } & 20.3 \\
\text { Produits chimiques : } & 12.0 \\
\text { Matières premières } & \& \\
\text { combustibles : } & 11.1 \\
\end{array}$ & $\begin{array}{lr}\text { Produits du pétrole : } & 30.9 \\
\text { Produits électroniques, logiciels } \\
\text { compris : } & 9.9 \\
\text { Or et argent : } & 7.9 \\
\text { Machines (à l'exclusion } & \text { des } \\
\text { produits électriques } & \text { et } \\
\text { électroniques): } & 6.9 \\
\end{array}$ & $\begin{array}{lr}{ }^{\mathrm{d}} \text { Composants électroniques : } & 24.4 \\
\text { Machines de bureau \& de } \\
\text { traitement de données : } & 10.3 \\
\text { Combustibles minéraux : } & 9.0 \\
\text { Produits de télécom. : } & 7.6\end{array}$ \\
\hline $\begin{array}{l}\text { Principaux partenaires commerciaux, exportations fab } \\
\text { (\% du total) }\end{array}$ & $\begin{array}{lr}\text { États-Unis : } & 21.4 \\
\text { Hong Kong : } & 16.3 \\
\text { Japon : } & 11.0 \\
\text { Corée du Sud : } 4.6 \\
\end{array}$ & $\begin{array}{lr}\text { Allemagne : } 33.6 \\
\text { Slovaquie : } 8.7 \\
\text { Autriche : } & 5.5 \\
\text { France: } & 5.3 \\
\end{array}$ & $\begin{array}{lr}\text { États-Unis : } & 19.2 \\
\text { Chine : } & 9.5 \\
\text { EAU : } & 8.4 \\
\text { R-U : } & 4.9 \\
\end{array}$ & $\begin{array}{lr}\text { États-Unis : } & 20.7 \\
\text { Japon : } & 17.4 \\
\text { Hong Kong : } & 10.4 \\
\text { Chine : } \quad 9.9 \\
\end{array}$ \\
\hline $\begin{array}{l}\text { Principaux partenaires commerciaux, importations fab } \\
\text { (\% du total) }\end{array}$ & $\begin{array}{lr}\text { Japon : } & 15.2 \\
\text { Corée du sud : } & 11.6 \\
\text { Taiwan : } & 11.3 \\
\text { États-Unis : } & 7.4 \\
\end{array}$ & $\begin{array}{lc}\text { Allemagne : } & 33.0 \\
\text { Russie : } & 6.3 \\
\text { Slovaquie : } & 6.0 \\
\text { Chine : } & 5.7\end{array}$ & $\begin{array}{ll}\text { Chine : } & 7.4 \\
\text { États-Unis : } & 6.6 \\
\text { Belgique : } & 5.2 \\
\text { Singapour : } & 4.9\end{array}$ & $\begin{array}{l}\text { Japon : } \\
\text { États-Unis : } \\
\text { Singapour : } \\
\text { Chine : }\end{array}$ \\
\hline
\end{tabular}

Source: The Economist Intelligence Unit (2006a, 2006b, 2006c, 2006d) ${ }^{a}$ estimations de The Economist Intelligence Unit, ${ }^{b}{ }^{2004,}{ }^{c}$ 2003, ${ }^{d}$ Gouvernement des Philippines, 2002, www.dti.gov.ph/contentment/9/60/64/67.jsp. 
TD/TC/WP(2007)2/FINAL

ANNEXE J. QUELQUES INDICATEURS DE L'OFFRE DE TRAVAIL

\begin{tabular}{|c|c|c|c|c|}
\hline & Chine & République tchèque & Inde & Philippines \\
\hline $\begin{array}{l}\text { Dépenses publiques d'éducation, 2002-04 } \\
(\% \text { du PIB })^{f}\end{array}$ & $3.4^{\mathrm{e}}$ & 4.6 & 3.3 & 3.2 \\
\hline 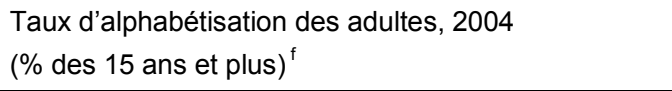 & 90.9 & $99^{\mathrm{j}}$ & 61.0 & 92.6 \\
\hline 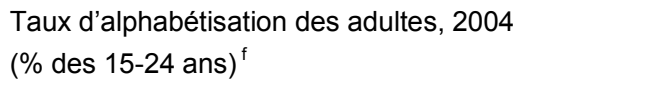 & 98.9 & .. & 76.4 & 95.1 \\
\hline Universités (nombre) $^{\mathrm{e}}$ & $1731^{i}$ & $\begin{array}{c}26 \text { universités et } \\
36 \text { établissements } \\
\text { d'enseignement supérieur }_{\text {privés }^{\mathrm{a}}}\end{array}$ & $\begin{array}{c}225 \text { universités } \\
6800 \text { collèges affiliés } \\
1128 \text { établissements } \\
\text { d'enseignement supérieur }\end{array}$ & .. \\
\hline Étudiants inscrits à l'université (millions) ${ }^{\mathrm{e}}$ & $13.3^{i}$ & 0.26 & $9.3^{k}$ & $2.76^{c}$ \\
\hline $\begin{array}{l}\text { Étudiants de l'enseignement supérieur poursuivant } \\
\text { des études dans le domaine des sciences, de } \\
\text { l'ingénierie, des industries manufacturières ou de la } \\
\text { construction (\% des étudiants de l'enseignement } \\
\text { supérieur })^{\dagger}, 1999-2004\end{array}$ & .. & 30 & 22 & 25 \\
\hline Pénétration de l'Internet (\% de la population $)^{\mathrm{h}}$ & 9.4 & 49.9 & 3.6 & 9.1 \\
\hline $\begin{array}{l}\text { Total des envois de fonds reçus, } 2002 \text { (mds d'USD) }^{9} \\
\text { (Classement mondial, total envois de fonds reçus) }\end{array}$ & $\begin{array}{r}14383 \\
(2)\end{array}$ & $\begin{array}{r}1343 \\
(26)\end{array}$ & $\begin{array}{r}14842 \\
(1)\end{array}$ & $\begin{array}{r}7,660 \\
(4)\end{array}$ \\
\hline $\begin{array}{l}\text { Indice de perception de la corruption, } 2006 \\
\text { (classement sur } 163 \text { pays) }\end{array}$ & 70 & 46 & 70 & 121 \\
\hline
\end{tabular}

${ }^{\mathrm{a}} 2005,{ }^{\mathrm{b}} 2004,{ }^{\mathrm{c}} 2003,{ }^{\mathrm{d}} 2002,{ }^{\mathrm{e}} \mathrm{EIU}(2006),{ }^{\mathrm{f}} \mathrm{PNUD}(2006)$.

g OCDE (2005), le "total des envois de fonds" est égal à la somme des "rémunérations des salariés", des "envois de fonds des travailleurs" et des "autres transferts courants dans d'autres secteurs".

${ }^{\mathrm{h}}$ Internet World Statistics, ces chiffres sont les plus récents disponibles au 29 novembre 2006, www.internetworldstats.com.

${ }^{\mathrm{i}}$ Universités et établissements d'enseignement supérieur en $2004 .{ }^{\mathrm{j}}$ CIA Factbook, estimation pour $2003 .{ }^{\mathrm{k}} \mathrm{D}$ 'après le site web www.nasscom.com, 9.3 millions d'étudiants étaient inscrits dans des collèges et établissements d'enseignement supérieur en mars 2005. 
TD/TC/WP(2007)2/FINAL

ANNEXE K. PRINCIPAUX PRESTATAIRES DE SERVICES DE SOUTIEN AUX ENTREPRISES ET DE STI EN 2005

\begin{tabular}{|c|c|c|c|c|c|c|c|}
\hline Rang & $\begin{array}{l}\text { Chine }^{55} \\
(\mathrm{Al}, 2006 \mathrm{a})\end{array}$ & $\begin{array}{c}\text { Chiffre } \\
\text { d'affaires }^{56} \\
\text { (millions } \\
\text { d'USD) }\end{array}$ & $\begin{array}{l}\text { République tchèque } \\
(\text { IDC, 2006) }\end{array}$ & $\begin{array}{c}\text { Chiffre } \\
\text { d'affaires }^{57} \\
\text { (millions } \\
\text { d'USD) }\end{array}$ & $\begin{array}{l}\text { Inde }^{58} \\
\text { (Nasscom, 2006) }\end{array}$ & $\begin{array}{c}\text { Chiffre } \\
\text { d'affaires } \\
\text { (millions } \\
\text { d'USD) }\end{array}$ & $\begin{array}{l}\text { Philippines }^{59} \\
\text { (Optel, 2005) }\end{array}$ \\
\hline 1 & Neusoft & 54 & IBM & 104 & TCS & 1,644 & Accenture \\
\hline 2 & Dalian Hi-Think Computer Tech & 37 & Hewlett-Packard & 96 & Infosys Technologies & 1,502 & AIG BPSI \\
\hline 3 & SinoCom & 32 & ČEZData & 70 & Wipro Technologies & 1,198 & American Data Exchange \\
\hline 4 & Chuwa Software & 22 & LogicaCMG & 50 & Satyam Computer Services & 745 & Caltex Shared Service Center \\
\hline 5 & HiSoft & 16 & Accenture & 40 & HCL Technologies & 588 & Crescent Services \\
\hline 6 & CS\&S & 16 & SAP & 40 & Patni Computer Systems & 342 & Fluor Daniel \\
\hline 7 & Venus Software & 15 & Siemens Business Services & 39 & I-flex Solutions & 245 & Maersk Administrative Center \\
\hline 8 & Worksoft & 12 & T-Systems & 31 & Mahindra British Telecom & 202 & Navitaire \\
\hline 9 & Beyondsoft & 11 & PVT & 28 & Polaris Software Lab & 154 & Procter \& Gamble \\
\hline 10 & iSoftStone & 8 & Unicorn & 27 & Perot Systems TSI & 145 & SPI Transact \\
\hline
\end{tabular}

\footnotetext{
${ }^{55}$ Cette liste ne tient pas compte des sociétés étrangères. D'après Analysys International (2006b), au cours du second trimestre 2006, le marché chinois des STI était dominé par IBM (5.8\%), HP (5.3\%), Digital China (2.5\%), Neusoft (2.2\%), CS\&S (1.9\%), Accenture (1.4\%), Bearing Point (1.1\%), Unisys (0.8\%), SE (0.7\%) et AsiaInfo (0.6\%).

${ }^{56}$ Conformément au classement d'IDC, ce chiffre inclut les sociétés chinoises et étrangères qui fournissent des "services de mise au point de logiciels" à des sociétés étrangères, que ce soit directement ou au travers de leurs filiales en Chine.

${ }^{57}$ Ce tableau ne tient pas compte du chiffre d'affaires généré par les centres offshore tableau.

${ }^{58}$ Pour l'année qui s'est achevée le 31 mars 2005. IBM n'est pas comprise dans cette liste à la suite de la demande en ce sens formulée auprès de Nasscom.

${ }^{59}$ Chiffres pour 2004. Les données sur le chiffre d'affaires ne sont pas disponibles et les centres de contact ne sont pas inclus dans la liste. Les dix plus grands centres de contact philippins par le nombre de sièges étaient par ordre croissant Sykes Asia, E-Telecare, PeopleSupport, Client Logic, Advanced Contact Solutions, Ambergris Solutions, Convergys, Cyber City Teleservices, ICT Group Philippines et C3.
} 
TD/TC/WP(2007)2/FINAL

ANNEXE L. EFFECTIFS DE QUELQUES GRANDS PRESTATAIRES DE STI

\section{Sociétés étrangères}

\begin{tabular}{lrrrrrr} 
& Total (EMN seules) & Accenture & ACS & Atos & Bearing Point & Cap Gemini \\
\hline Effectifs totaux à la fin de l'AC 2005 & 743,593 & 125,000 & 51,000 & 48,000 & 16,990 & 61,244 \\
Effectifs en Inde durant l'AC 2005 & 81,828 & 19,500 & 2,000 & 1,200 & 60,000 \\
En \% des effectifs totaux & $11 \%$ & $16 \%$ & $4 \%$ & $3 \%$ & $4 \%$ & 2,600 \\
\hline
\end{tabular}

\section{Sociétés étrangères, suite}

\begin{tabular}{|c|c|c|c|c|c|c|}
\hline & EDS & Keane & IBM Services & Sapient & Unisys & Xansa \\
\hline Effectifs totaux à la fin de l'AC 2005 & 116,000 & 10,000 & 190,500 & 3,259 & 36,000 & 5,600 \\
\hline Effectifs en Inde durant l'AC 2005 & 4,500 & 2,400 & 38,100 & 1,878 & 1,000 & 2,800 \\
\hline En \% des effectifs totaux & $4 \%$ & $24 \%$ & $20 \%$ & $58 \%$ & $3 \%$ & $50 \%$ \\
\hline
\end{tabular}

\begin{tabular}{|c|c|c|c|c|c|c|}
\hline & Cognizant & Infosys & Patni & Satyam & TCS & Wipro \\
\hline Effectifs totaux à la fin de l'AC 2005 & 23,200 & 45,206 & 11,930 & 23,214 & 53,177 & 49,300 \\
\hline Effectifs en Inde durant l'AC 2005 & 16,939 & 36,240 & 9,553 & 17,317 & 38,445 & 41,511 \\
\hline En $\%$ des effectifs totaux & $73 \%$ & $80 \%$ & $80 \%$ & $75 \%$ & $72 \%$ & $84 \%$ \\
\hline
\end{tabular}

Source : NASSCOM (2006). 